\title{
Development of Resonating Tubular Oscillating Linear Alternator and Engine; System Design and Modeling
}

\author{
Gregory Heiskell
}

Follow this and additional works at: https://researchrepository.wvu.edu/etd

\section{Recommended Citation}

Heiskell, Gregory, "Development of Resonating Tubular Oscillating Linear Alternator and Engine; System Design and Modeling" (2018). Graduate Theses, Dissertations, and Problem Reports. 7186.

https://researchrepository.wvu.edu/etd/7186

This Thesis is protected by copyright and/or related rights. It has been brought to you by the The Research Repository @ WVU with permission from the rights-holder(s). You are free to use this Thesis in any way that is permitted by the copyright and related rights legislation that applies to your use. For other uses you must obtain permission from the rights-holder(s) directly, unless additional rights are indicated by a Creative Commons license in the record and/ or on the work itself. This Thesis has been accepted for inclusion in WVU Graduate Theses, Dissertations, and Problem Reports collection by an authorized administrator of The Research Repository @ WVU. For more information, please contact researchrepository@mail.wvu.edu. 


\title{
Development of Resonating Tubular Oscillating Linear Alternator and Engine; System Design and Modeling
}

\section{Gregory Heiskell}

\author{
Thesis submitted \\ to The Statler College of Engineering and Mineral Resources \\ at West Virginia University \\ In partial fulfillment of the requirements for the degree of \\ Master of Science in \\ Electrical Engineering \\ Parviz Famouri, Ph.D., Chair \\ Nigel N. Clark., Ph.D. \\ Muhammad A Choudhry, Ph.D. \\ Lane Department of Computer Science and Electrical Engineering \\ Morgantown, West Virginia \\ 2018
}

Keywords: Linear, Alternator, Tubular, Oscillating, Permanent Magnet, Resonant, Harmonics Copyright 2018 Gregory Heiskell 


\section{Abstract \\ Development of Resonating Tubular Oscillating Linear Alternator and Engine; System Design and Modeling Gregory Heiskell}

A resonating tubular oscillating linear alternator and engine (OLEA) provides an alternative for electric power generation to conventional rotary alternator and engine systems. An OLEA allows direct conversion of linear reciprocating motion provided by a free piston internal combustion engine to electricity. The elimination of the engine crankshaft and bearing allows a design that is more compact and more efficient with fewer moving parts. Additionally, mechanical resonance is utilized to further enhance the performance, power density and efficiency of the system. Presented in this thesis is a study of a resonating tubular OLEA system. Electrical performance has been recorded for two different stator configurations, an air core stator and an iron core stator. Electrical performance comparisons are made to finite element modeling (FEMM/LUA scripting) results using Fourier expansion and a simplified equivalent model with good results. A higher power design of OLEA and its two stator configurations was also modeled and its performance has been predicted. In addition, some of the mechanical considerations for the free piston OLEA is included. It was found that mechanical offset of the translator and operation at large stroke lengths cause distortion of the alternator output voltage. 


\section{Acknowledgements}

Foremost, I would like to thank Dr. Parviz Famouri for bringing me in on this project to work and also ARPA-E for funding of this project. Thanks to all the coworkers and professors on this project who have made my graduate school experience at WVU wonderful and fun. 


\section{Table of Contents}

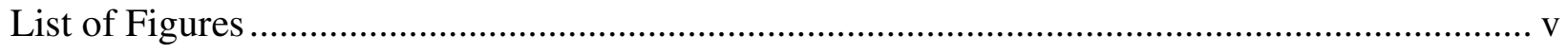

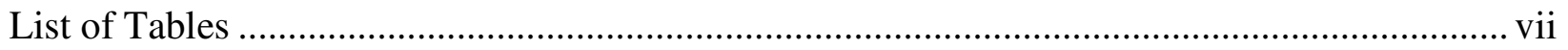

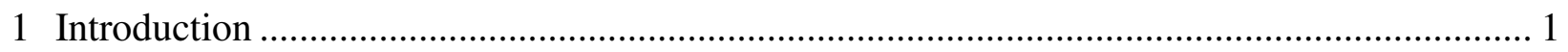

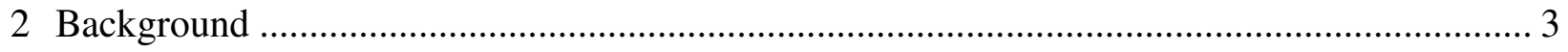

3 Mechanical and other Considerations ......................................................................... 4

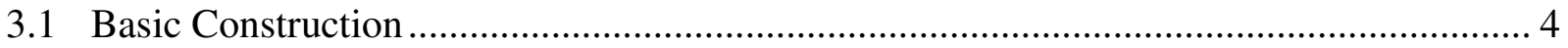

3.2 Vibration (Rigid versus Rubber Mounted) ……………….............................................. 7

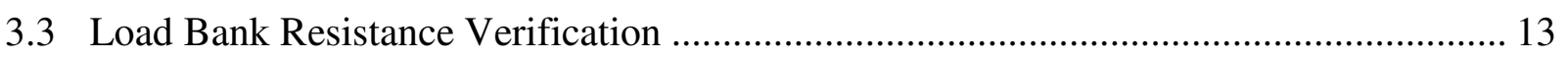

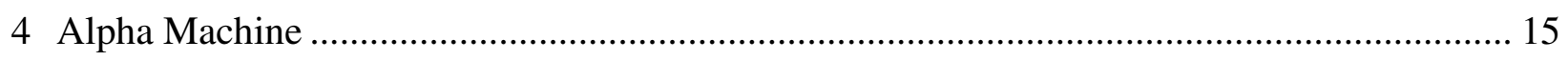

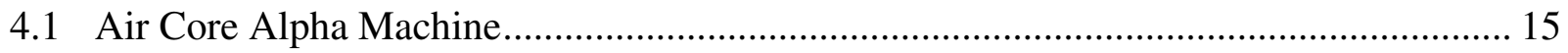

4.1.1 Air Core Alpha Test Data ................................................................................... 15

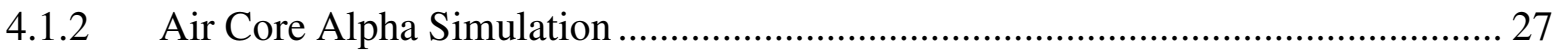

4.1.3 Air Core Alpha Simulation Results Summary ………………………………….... 35

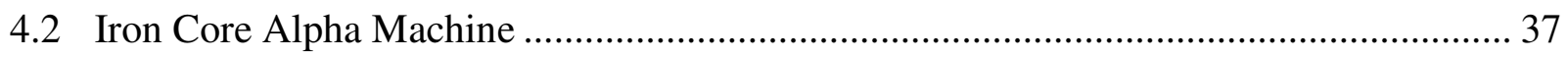

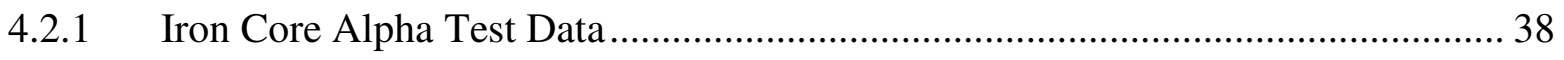

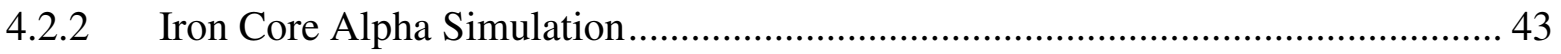

4.2.3 Iron Core Alpha Summary ............................................................................... 48

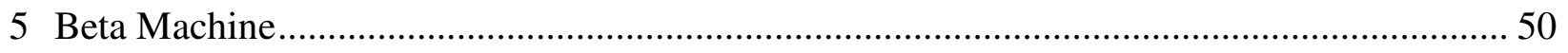

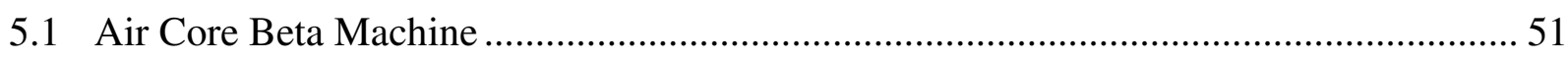

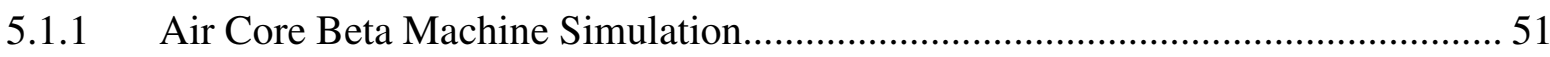

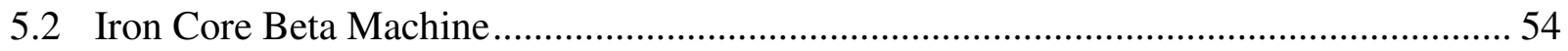

5.2.1 Iron Core Beta Machine Simulation ............................................................... 54

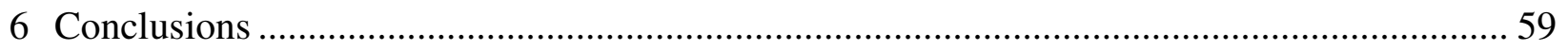

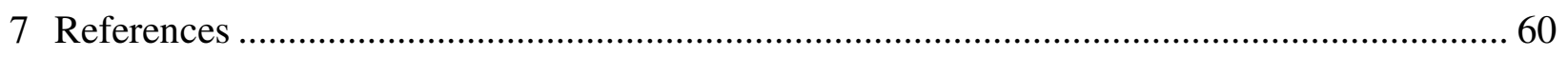

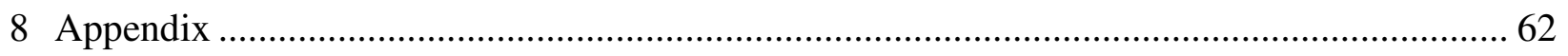

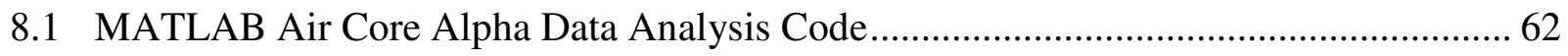

8.2 LUA Script for FEMM (Alpha Air Core $\pm 15 \mathrm{~mm}$ movement) ……................................. 65

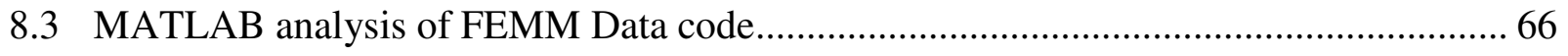

8.4 MATLAB Code for Iron Core Beta Analysis ............................................................. 71

8.5 MATLAB Code for Vibration Analysis .................................................................... 77 


\section{List of Figures}

Figure 1: Cutaway View Linear Engine and Alternator [7] …................................................. 4

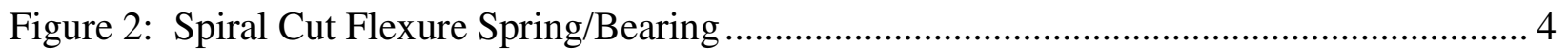

Figure 3: Alpha Machine Translator Drum and Non-Magnetic Ring Spacers before application of Magnet Ring Segments.................................................................................................... 5

Figure 4: Lathe turning of Translator Drum Endcaps............................................................ 5

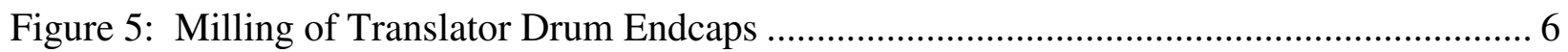

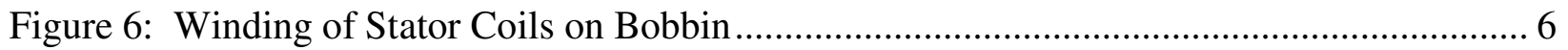

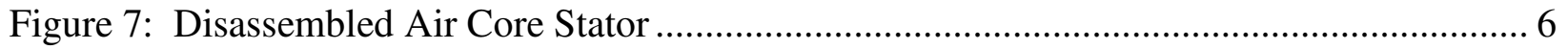

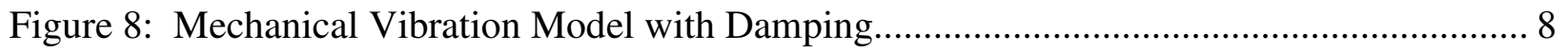

Figure 9: Equivalent Electrical Model ............................................................................... 9

Figure 10: Andre Horizontal-In-Shear Vibration Isolator .......................................................... 10

Figure 11: Beta Machine w/18 Sandvik Springs Vibration Mounted Frequency Response ....... 11

Figure 12: Beta Machine Vibration mounted, Position (m) vs Time (s) Plot............................... 12

Figure 13: Beta Machine w/18 Sandvik Springs Rigid Mounted Frequency Response............... 12

Figure 14: ANSYS bode plot Vibration mounted Beta Machine (credit: Dr. Musho) ................. 13

Figure 15: Engine and Alternator setup inside an Engine Test Bay ......................................... 16

Figure 16: Linear Engine Alternator Load Test Setup............................................................. 17

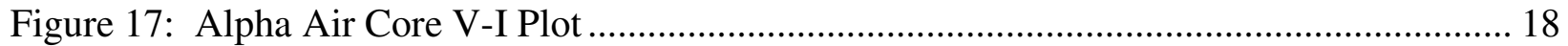

Figure 18: Air Core Alpha Alternator Load Power and Losses................................................ 19

Figure 19: Alpha Air Core Test Data Instantaneous Waveforms with 0.094 $\Omega$ Load................... 20

Figure 20: Test Based Generated EMF at 0.094ohm Load ..................................................... 21

Figure 21: Test Based Alternator Power Demand at 0.0948 Load ............................................ 22

Figure 22: Position (as measured) and Velocity .................................................................... 23

Figure 23: Air Core Alpha Machine Force Delivered to the Alternator at 0.094 $\Omega$ Load............ 24

Figure 24: Air Core Alpha Force per Amp verses Position........................................................ 24

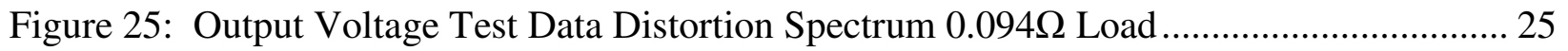

Figure 26: Output Current Test Data Distortion Spectrum 0.094 $\Omega$ Load ................................... 26

Figure 27: Air Core Alpha Test Based Generated EMF Distortion Spectrum ............................. 26

Figure 28: FEMM Axisymmetric Model Air Core Alpha Machine with Mesh ............................ 27

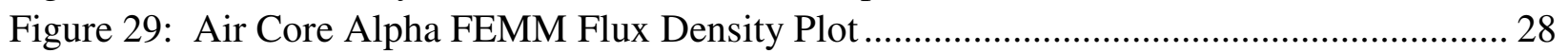

Figure 30: Alpha Air Core FEMM $\varepsilon_{\text {GEN }}(26 \mathrm{~mm}$ Disp., No offset, $73.75 \mathrm{~Hz}) \ldots \ldots \ldots \ldots \ldots \ldots \ldots \ldots \ldots \ldots . . .29$

Figure 31: Alpha Air Core FEMM $\varepsilon_{\mathrm{GEN}}$ FFT $(26 \mathrm{~mm}$ Disp., No offset, $73.75 \mathrm{~Hz})$...................... 30

Figure 32: Alpha Air Core FEMM $\varepsilon_{\text {GEN }}(26 \mathrm{~mm}$ Disp., $1 \mathrm{~mm}$ offset) ........................................ 31

Figure 33: Alpha Air Core FEMM $\varepsilon_{\text {GEN }}$ FFT (26mm Disp., 1mm offset) ................................. 31

Figure 34: Alpha Air Core FEMM $\varepsilon_{\mathrm{GEN}}$ (26mm Disp., 2mm offset) ........................................ 31

Figure 35: Alpha Air Core FEMM $\varepsilon_{\text {GEN }}$ FFT (26mm Disp., 2mm offset) .................................. 31

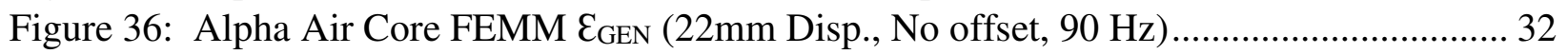

Figure 37: Alpha Air Core FEMM $\varepsilon_{\text {GEN }}$ FFT (22mm Disp., No offset) ……….......................... 32

Figure 38: Air Core Alpha Flux Linkage vs Translator Position.................................................. 33

Figure 39: Air Core Alpha Airgap Normal Flux Density ............................................................ 34 
Figure 40: Rate of Change of Flux Linkage vs Displacement............................................. 34

Figure 41: Test Data (left) vs Simulation Results (right) Alpha Air Core................................ 37

Figure 42: Disassembled Iron core Alpha Stator with back iron ......................................... 37

Figure 43: Iron Core Alpha (Titanium Flexures) Load Data ................................................. 39

Figure 44: Iron Core Alpha Open Circuit Test Voltage $(83.25 \mathrm{~Hz})$...................................... 40

Figure 45: Iron Core Alpha Open Circuit Test Data FFT $(83.25 \mathrm{~Hz})$...................................... 41

Figure 46: Iron Core Beta FEMM Model - Iron Pole Detail .................................................. 43

Figure 47: Iron Core Alpha Flux linkage vs Displacement ..................................................... 44

Figure 48: Alpha Iron Core FEMM $\varepsilon_{\mathrm{GEN}}(22 \mathrm{~mm}$ Disp., No offset, $90 \mathrm{~Hz})$............................. 45

Figure 49: Alpha Iron Core FEMM $\varepsilon_{\text {GEN }}$ FFT (22mm Disp., No offset, 90 Hz) ..................... 45

Figure 50: Alpha Iron Core FEMM $\varepsilon_{\mathrm{GEN}}(22 \mathrm{~mm}$ Disp., $2 \mathrm{~mm}$ offset, $83.25 \mathrm{~Hz}$ ) ................... 45

Figure 51: Alpha Iron Core FEMM $\varepsilon_{\mathrm{GEN}}$ FFT (22mm Disp., 2mm offset, $83.25 \mathrm{~Hz}$ ) .............. 45

Figure 52: Alpha Iron Core FEMM $\varepsilon_{\mathrm{GEN}}(22 \mathrm{~mm}$ Disp., $1 \mathrm{~mm}$ offset, $83.25 \mathrm{~Hz})$................... 46

Figure 53: Iron Core Alpha FEMM $\varepsilon_{\mathrm{GEN}}$ FFT (83.25Hz, $1 \mathrm{~mm}$ Offset) ................................ 46

Figure 54: Iron Core Alpha FEMM $\varepsilon_{\mathrm{GEN}}(83.25 \mathrm{~Hz}, 0 \mathrm{~mm}$ Offset) ....................................... 46

Figure 55: Iron Core Alpha FEMM $\varepsilon_{\mathrm{GEN}}(83.25 \mathrm{~Hz}, 0 \mathrm{~mm}$ Offset $)$....................................... 46

Figure 56: Iron Core Alpha FEMM $\varepsilon_{\mathrm{GEN}}(14 \mathrm{~mm}$ Displacement, 83.25Hz, 0mm Offset).......... 47

Figure 57: Iron Core Alpha FEMM $\varepsilon_{\mathrm{GEN}}$ FFT (14mm Displacement, 83.25Hz, 0mm Offset)... 47

Figure 58: Iron Core Alpha Machine Airgap Normal Flux Density...................................... 48

Figure 59: Beta Linear Alternator without Engine CAD model ............................................. 50

Figure 60: Air Core Beta Machine Airgap Normal Flux Density .............................................. 51

Figure 61: Air Core Beta Flux Linkage vs Displacement...................................................... 52

Figure 62: Air Core Beta FEMM $\mathcal{E}_{\mathrm{GEN}}$ 90Hz, 33mm Displacement ..................................... 52

Figure 63: Air Core Beta FEMM $\varepsilon_{\mathrm{GEN}}$ FFT 90Hz, 33mm Displacement............................... 52

Figure 64: Iron Core Beta Flux Linkage vs Displacement .................................................. 55

Figure 65: Iron Core Beta FEMM $\varepsilon_{\mathrm{GEN}} 90 \mathrm{~Hz}, 33 \mathrm{~mm}$ Displacement .................................... 55

Figure 66: Iron Core Beta FEMM $\varepsilon_{\text {GEN }}$ FFT 90Hz, 33mm Displacement ............................... 55

Figure 67: Iron Core Beta FEMM $\varepsilon_{\mathrm{GEN}} 90 \mathrm{~Hz}, 29 \mathrm{~mm}$ Displacement ...................................... 56

Figure 68: Iron Core Beta FEMM $\varepsilon_{\mathrm{GEN}}$ FFT 90Hz, 29mm Displacement ............................. 56

Figure 69: Iron Core Beta 33mm Resistive Loading ........................................................ 56

Figure 70: Iron Core Beta 29mm Resistive Loading ...................................................... 56

Figure 71: Iron Core Beta 33mm Resistive Loading w/ 143 $\mathrm{F}$ F Series Capacitor ...................... 57

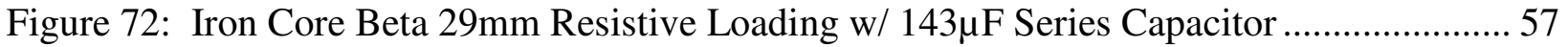




\section{List of Tables}

Table 1: Mechanical/Electrical Mobility Equivalents ................................................... 8

Table 2: Load Bank AC Resistance Test ................................................................................. 14

Table 3: Load Bank DC Resistance Test ............................................................................. 14

Table 4: Alpha Air Core Load Data...................................................................................... 18

Table 5: Calculated Air Core Alpha $\mathcal{E}_{\mathrm{GEN}}$ and Winding Losses during load ............................ 18

Table 6: Air Core Alpha MATLAB derived Measurements at 0.094ohm Load ....................... 21

Table 7: Air Core Alpha Simulation Tabulated Summary ....................................................... 36

Table 8: Iron Core Alpha (Titanium Flexures) Load Data ...................................................... 38

Table 9: Calculated Iron Core Alpha (Titanium Flexures) $\varepsilon_{\mathrm{GEN}}$ and Winding Losses during load

Table 10: Iron Core Alpha Test Result Summary .............................................................. 42

Table 11: Iron Core Alpha Simulation Tabulated Summary ................................................ 49

Table 12: Air Core Beta Simulation Tabulated Summary .................................................. 53

Table 13: Iron Core Beta Simulation Tabulated Summary ................................................. 58 


\section{Introduction}

A linear alternator allows direct conversion of linear motion to electrical energy. An oscillating linear electric alternator allows direct conversion of short stroke oscillatory motion to alternating current electrical energy. The power source of the oscillating linear alternator can be anything with a reciprocating linear motion. They can be powered by Stirling engines, which have been proposed for space power stations [1]. They have also been proposed to capture wave motion energy by harnessing the rising and falling motion of ocean waves to generate electricity [2]. The Oscillating Linear Engine and Alternator (OLEA) is powered by an internal combustion engine where the piston is referred to as a free piston since the piston is not constrained by a crank.

Compared to traditional rotary machines, a linear alternator and engine requires no conversion from linear motion to rotary motion, offering benefits over a traditional slider crank rotary system [3]. The elimination of the crank and its crank bearings reduces frictional losses. With fewer moving parts, complexity is also reduced and higher reliability is achievable [4]. Overall, a linear alternator and engine provides an alternative to a rotary system that is smaller, simpler, more efficient, and more reliable.

OLEAs are suitable for applications of wave energy, hybrid electric vehicles, remote power generation, backup power, and Stirling engines. The application of OLEAs for remote power generation results in a more efficient, compact, and reliable alternative to rotary generators where no utility power is available [4]. The robustness and efficiency also makes the OLEA a reliable backup or standby power source. They are described as being the ideal system for use in hybrid electric vehicles (HEV) due to being efficient, compact, and reliable [3]. The German Aerospace Center (DLR) is developing a free piston OLEA that acts as a range extender that can

provide power to discharged batteries for HEVs. They also proposed that it can be used as an aircraft auxiliary power unit (APU) and in decentralized combined heat and power plants (CHP) $[5]$.

The Advanced Research Projects Agency-Energy (ARPA-E) GENSETS program provided West Virginia University (WVU) funding for development and commercialization of a $1 \mathrm{~kW}$ linear alternator and 2 stroke engine OLEA with a goal of high fuel to electrical conversion efficiency. 
The ARPA-E mission is to advance high potential, high impact energy technologies that are too early for private sector funding. ARPA-E projects have the potential to radically improve U.S. economic prosperity, national security, and environmental wellbeing. ARPA-E provides America's energy researchers with funding, technical assistance, and market readiness [6].

Much of the early design work for the linear engine and alternator system at WVU was already completed for the first prototype (alpha machine) by the team when I came on board. The preliminary alternator design (alpha design) was already completed with major credit going to Jayaram Subramaniam and Dr. Famouri and the inverter and position detection for starting of the linear engine by Feheshteh Mahmudzadeh Ghomi [7]. The complete construction, assembly, testing, and evaluation of the results of the alpha machine were necessary to establish a baseline of performance to allow construction of additional machines with well predicted performance.

This thesis covers the assembly and testing of the linear alternator with an evaluation of the test results and comparisons to finite element simulations that provide a means of predicting electrical performance of a resonant tubular linear alternator. Chapter 3 outlines the mechanical construction of the linear alternator and includes an evaluation of vibration mounting on the system. Chapter 4 contains actual test data of the alpha air core and iron core machines and a finite element simulation analysis is made and compared. Chapter 5 is the finite element analysis of the beta machine and predicts its performance even though at the time of writing has not been ran as an alternator yet.

The overall goal of the project is to create a $1 \mathrm{~kW}$ oscillating linear alternator engine that is simple, has a long life, low cost, and a high fuel to electric efficiency. 


\section{Background}

Linear electric machines have been extensively researched lately. Boldea and Nasar were among the first to develop general equations for single phase and three phase tubular linear alternators. Before that, papers that existed only focused on suitability of the design for practical applications [1] [8]. Since then numerous papers have been written, mostly concentrating on the permanent magnet linear machines. Permanent magnet machines offer a high power density while also reducing the effects of stator reactance due to their low permeability [1]. The shape of the linear electric machine has also been studied with one study comparing the tubular design to a flat type design [9].

A linear electric machine can be described as a rotary machine that has been cut in half and flattened [10] therefore many characteristics are common among both. Permanent magnets offer advantages in rotary machines such as high power density and the elimination of slip rings in synchronous machines and also have the same advantages in linear machines. The WVU oscillating linear alternator design uses rare earth permanent magnets as the rotor magnetization source. Permanent magnets provide a high power density and low weight. The magnetization orientation of the permanent magnets have also been studied. For rotary machines, axial magnets were found that for a given power rating, axial field machines have a lower volume compared to radial field machines thereby giving a higher power density [11]. Others have come to the same conclusions that axial magnetic fields outperform radial fields [12] [13]. The same has been studied concerning tubular linear machines and finding that output voltage, flux density, power, and efficiency is higher with axial magnetic fields [14].

Numerous studies have been done on the free piston engine with its history and applications being thoroughly documented in a paper by Mikalsen [15]. It has been developed for commercialization by Toyota and they currently hold several patents relating to free piston

engine systems [16]. General motors proposed an opposed piston system with a centrally located combustion chamber and bounce chambers on opposing ends [16]. Without a crank to constrain the piston, piston motion and compression ratios are variable. Feng, et al. have analyzed the combustion processes inside a free piston linear engine and compared them against a traditional rotary engine [17]. 


\section{$3 \quad$ Mechanical and other Considerations}

\subsection{Basic Construction}

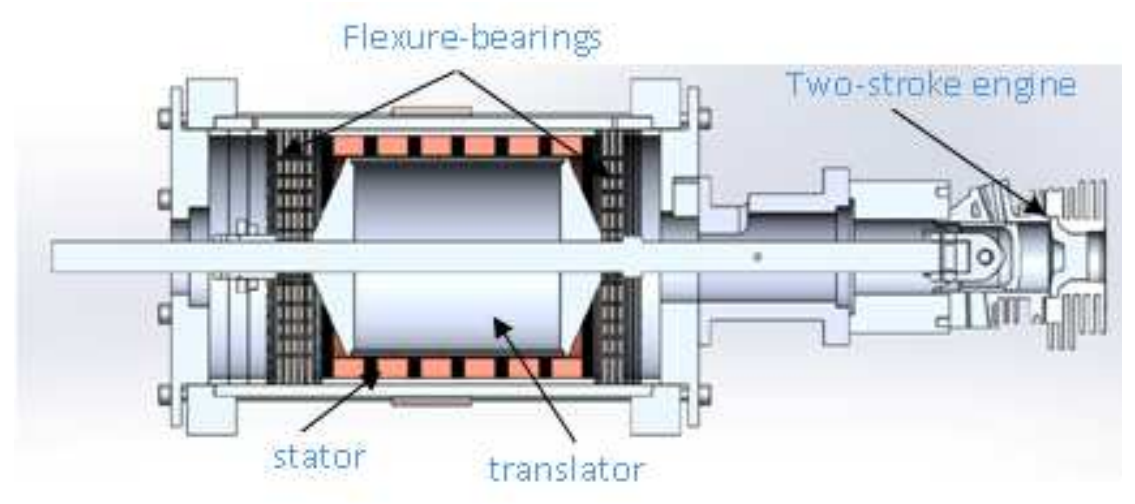

Figure 1: Cutaway View Linear Engine and Alternator [7]

The linear engine and alternator system that is undergoing research at WVU is a resonant oscillating mass spring system. The construction of the alternator consists of a drum of axially programmed magnetic rings (referred hereinafter as the translator) sitting between spiral cut planar flexure springs with the magnetic drum inside of a stator of copper coils. The planar flexure springs allow movement of the translator in the axial direction while also acting as bearings due to a high stiffness in the radial direction. The frequency of oscillation of a rigid mounted machine is determined by the moving mass and the stiffness of the springs by the equation $\omega=\sqrt{\mathrm{k} / \mathrm{m}}$ where $\mathrm{k}$ is the total stiffness of the springs and $\mathrm{m}$ is the moving mass. The flexure springs themselves have approximately $1 / 3$ of their own mass contributing to the moving mass and therefore a maximum achievable frequency is the natural frequency of the flexure. Increasing the quantity of flexures increases the frequency of oscillation asymptotically to the natural frequency. It is desirable to operate at a high frequency. The voltage that is induced in the coils of the alternator is proportional to the velocity of the translator. Either an increased displacement amplitude or increased frequency of oscillation will increase the velocity of the translator and increase the induced voltage. The output power of the alternator is proportional to the square of the voltage while stator resistance losses are proportional to the square

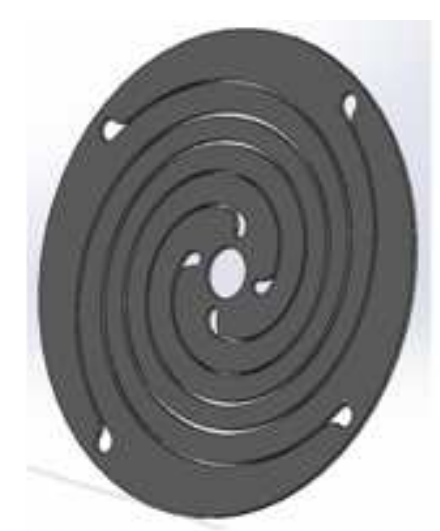

Figure 2: Spiral Cut Flexure Spring/Bearing of the output current. Displacement amplitude is determined by the stroke of the engine. So to achieve the highest efficiency and power, it is desirable to operate at the highest frequency possible. 
Permanent magnets attach to a lightweight aluminum drum with aluminum endcaps connecting to a $15 \mathrm{~mm}$ outside diameter translator shaft which connects all moving components of the system. The aluminum endcaps were milled out creating spokes to reduce mass to increase frequency. The magnetic rings that affix to the translator drum also needed to be low mass. Rare-earth neodymium magnet rings of $100 \mathrm{~mm}$ diameter, $20 \mathrm{~mm}$ in length, and only $2 \mathrm{~mm}$ thick were selected for the design. Because of the fragility of neodymium magnets of these dimensions, the magnet rings had to be manufactured as arc segments. Ninety degree arc segments were used and the segments were attached to the drum to form rings with a quick setting two part adhesive.

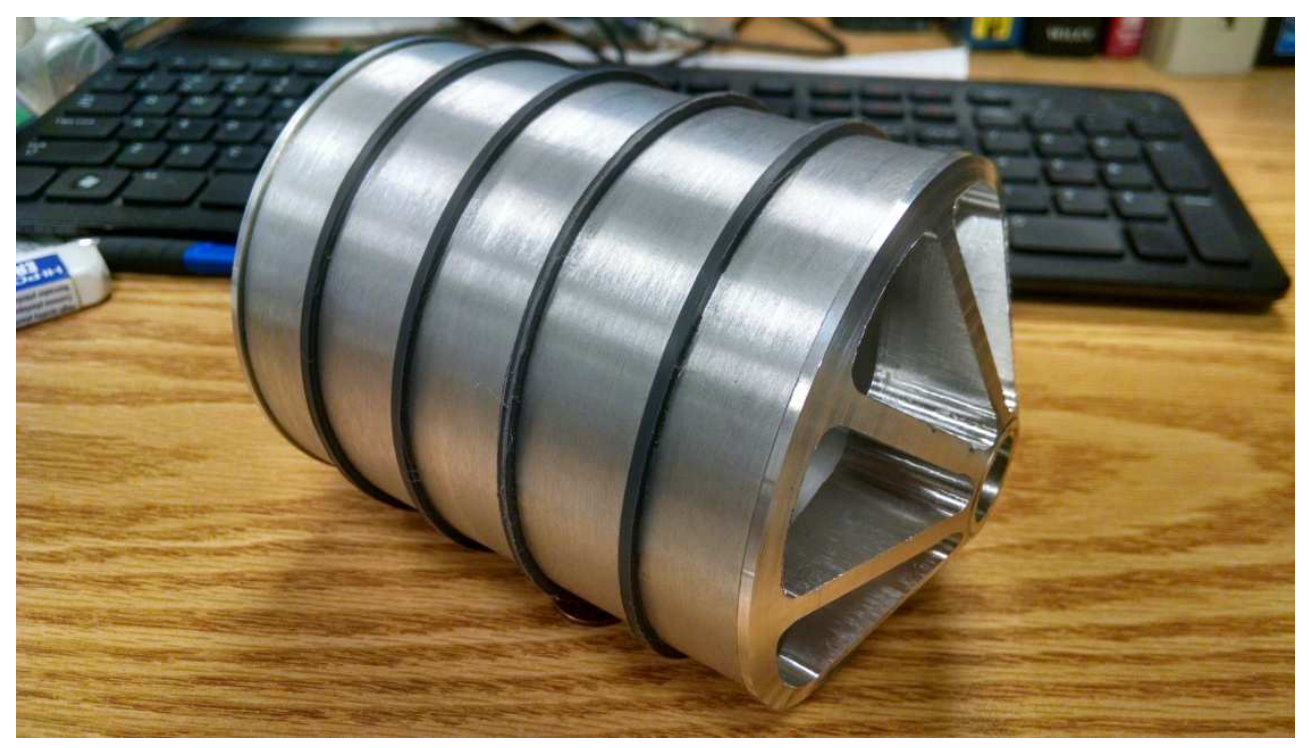

Figure 3: Alpha Machine Translator Drum and Non-Magnetic Ring Spacers before application of Magnet Ring Segments

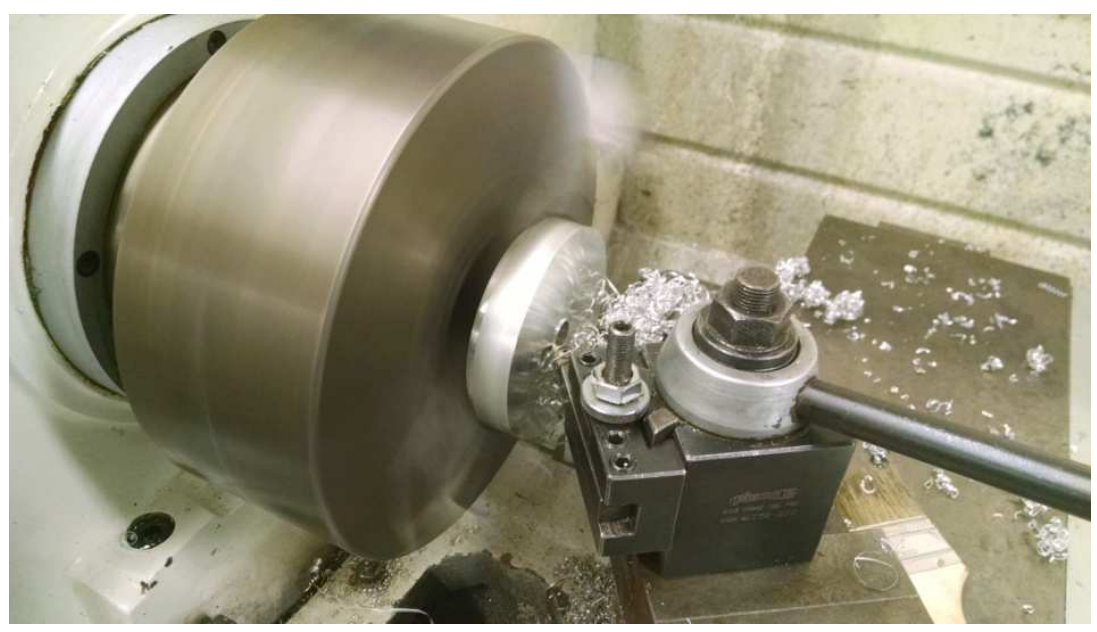

Figure 4: Lathe turning of Translator Drum Endcaps 


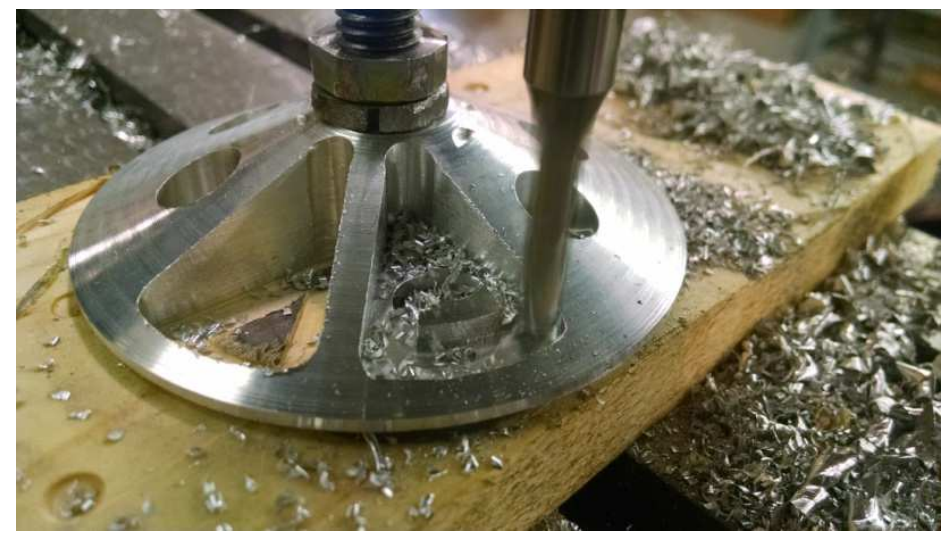

Figure 5: Milling of Translator Drum Endcaps

The translator shaft is attached and supported by the flexure springs on either side and to the engine's piston on one end. Between the piston and the shaft is a coupler that allows for radial and directional misalignment of the engine and alternator shaft.

The stator consists of copper coils which were constructed from

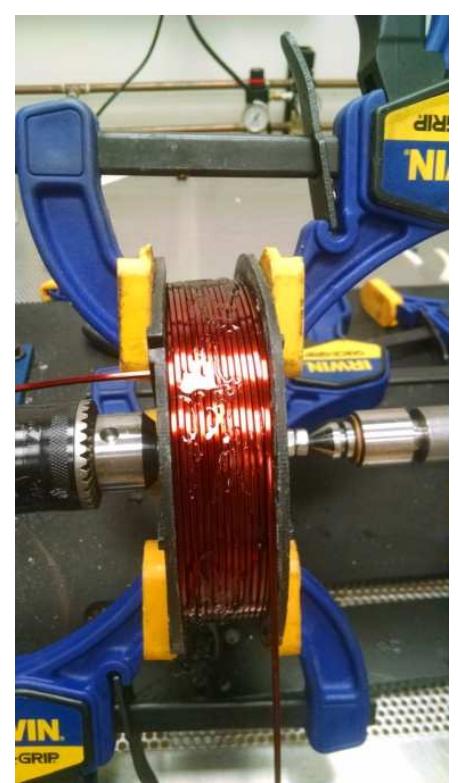

Figure 6: Winding of Stator Coils on Bobbin $13 \mathrm{AWG}$ square magnet wire wound onto a bobbin. The bobbin was squeezed with clamps to tightly pack the turns and the coils were coated with cyanoacrylate superglue to help them maintain their shape before being installed into the steel stator backiron. For the alpha alternator, 6 coils of 24 turns each were used for the stator. The electrical leads were brought out through a slit in the backiron shell and the coils were connected in series in an alternating fashion to create an alternating sequence of north and south magnetic poles. The coils were then bonded as one piece by pouring a two part epoxy casting resin over the inside of the coils while paying special attention to the spacing of the coils for the proper pole pitch.

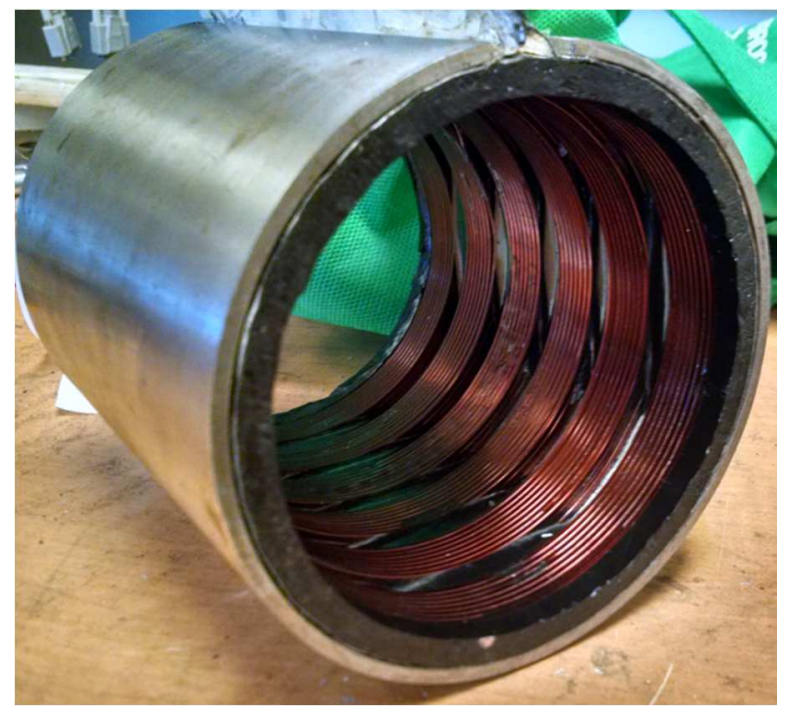

Figure 7: Disassembled Air Core Stator 
The iron core stator was produced in much the same way. Additional care was made to prevent shorting the windings to the steel. The individual coils were wrapped in class $\mathrm{H}$ glass tape (Scotch 69) and steel laminations were added to the spacing between the coils. After casting, the entire stator was dipped in resin and baked in an oven to reduce eddy losses in the laminations.

\subsection{Vibration (Rigid versus Rubber Mounted)}

The reciprocating motion of the linear alternator and engine produces considerable vibration. It was discovered while running the WVU linear alternator as a motor, the displacement amplitude would decrease when the alternator was placed upon the floor as opposed to suspending from above with straps. Rigidly mounting the alternator was attempted, first to the concrete floor, and later to a heavy steel beam. Both resulted in a lower displacement than when the machine was suspended. Attempts to rigidly mount the alternator resulted in vibration energy being transmitted into the building structure. Vibration was noticed in the surrounding walls and even resulted in items being shaken from the walls and desks. It was discovered that vibration isolation of the machine results in lower power losses due to the reduction of reciprocating forces being transmitted into the structure which the machine is mounted or held.

Two ideal cases can be considered, one where a perfectly rigid structure is available for mounting and a perfectly frictionless plane to set the machine on. Neither of these exist in nature and the frequency of relative motion between the translator and the frame is different in these two cases. Vibration mounts that allows some movement of the frame can considerably alter the oscillating motion of the machine.

To study the effects of vibration mounting, the machine and its mounts can be modelled as a mechanical system. The force generated by the engine combustion or engine motoring is acting between the mass of the machine frame and the mass of the translator. The main flexure springs are between the frame and the translator and they have an associated damping component. The entire frame and translator is sitting on the vibration isolator springs also with a damping component. The mechanical system can be drawn as in Figure 8 below. 


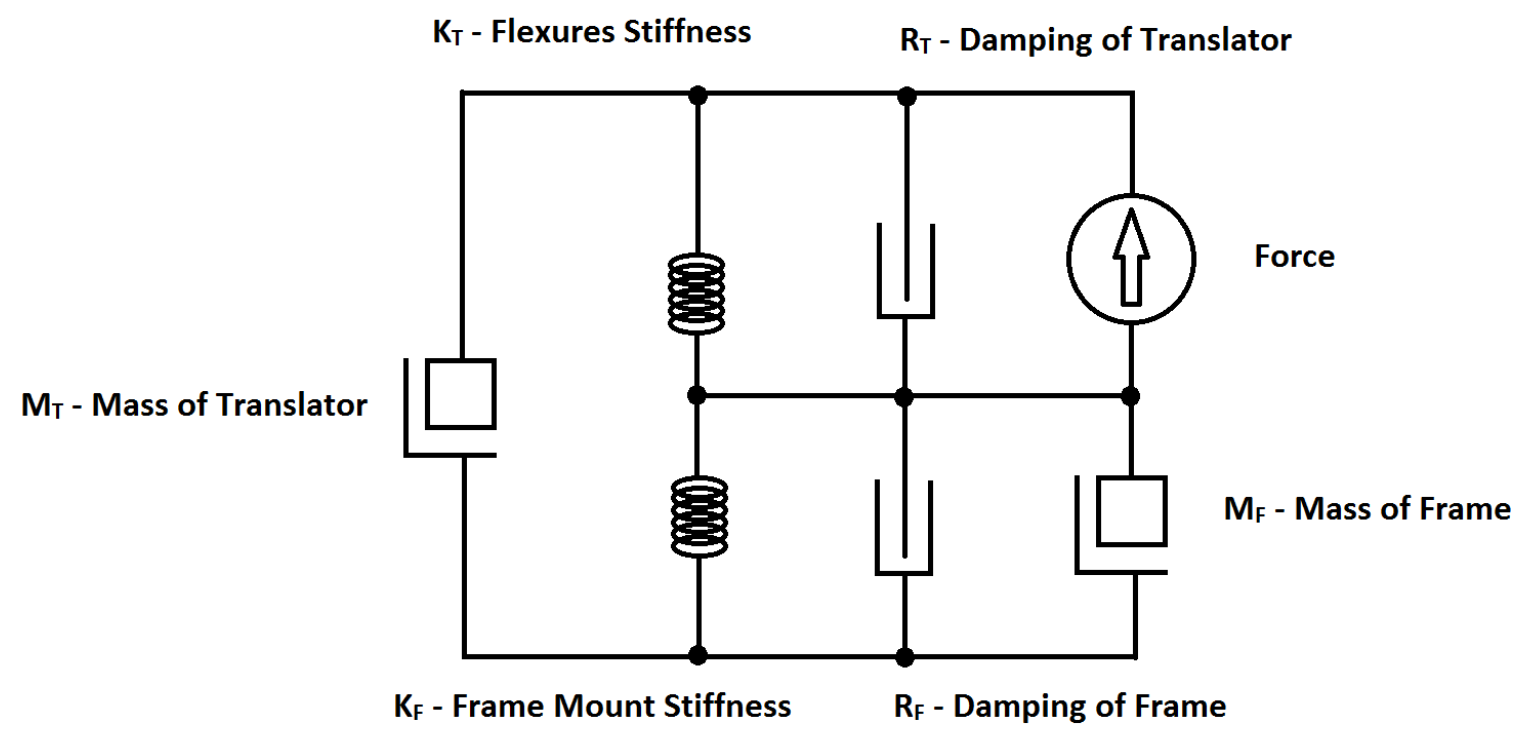

Figure 8: Mechanical Vibration Model with Damping

The mechanical system was converted to an equivalent electrical system using the mobility analogy [18]. The mobility analogy preserves the topology of the mechanical system and converts forces to currents, velocity to voltage, masses to capacitances, springs to inductors, and dampers to resistors. The electrical and mechanical equivalents are given in Table 1 below. Care must be taken to use the MKS (meters, kilograms, and seconds) SI unit system for correct conversion to amperes, volts, farads, and henries.

\begin{tabular}{|l|l|}
\hline $\begin{array}{l}\text { Electrical } \\
\text { Equivalent }\end{array}$ & $\begin{array}{l}\text { Mechanical } \\
\text { Equivalent }\end{array}$ \\
\hline Resistance (R) & $\begin{array}{l}\text { Lubricity (1/B) } \\
\text { (inverse friction } \\
\text { damping) }\end{array}$ \\
\hline Capacitance (C) & Mass (M) \\
\hline Inductance (L) & $\begin{array}{l}\text { Compliance (1/K) } \\
\text { (inverse stiffness) }\end{array}$ \\
\hline Voltage (V) & Velocity (v) \\
\hline Current (I) & Force (f) \\
\hline
\end{tabular}

Table 1: Mechanical/Electrical Mobility Equivalents 


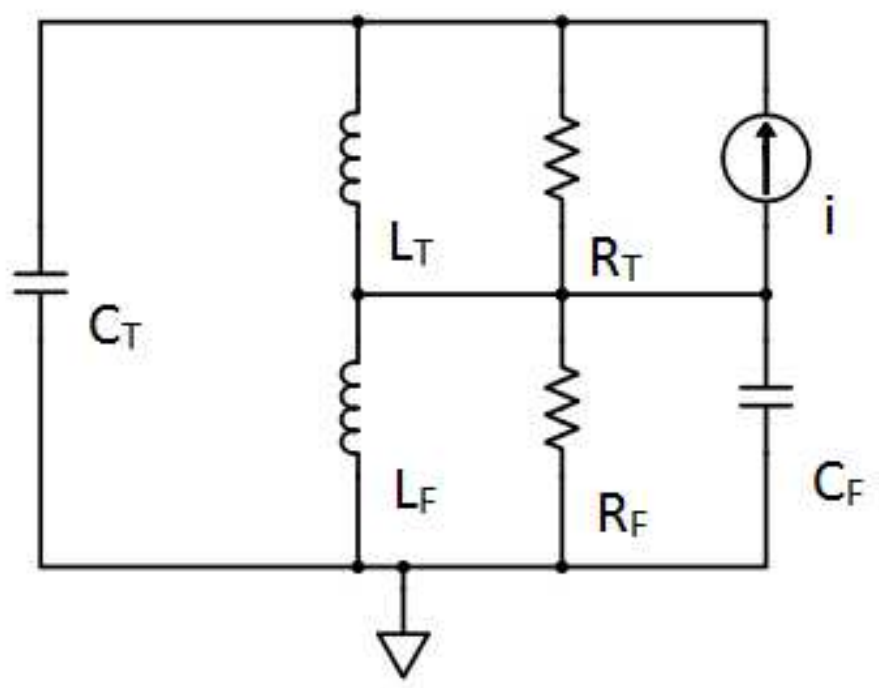

Figure 9: Equivalent Electrical Model

The equivalent electrical model shown in Figure 9 above can be represented as a state space model. The following variables are used and the state space model becomes:

- $\mathrm{u}=\mathrm{i}$

- $\mathrm{x}_{1}=\mathrm{i}_{\mathrm{LT}}$

- $\mathrm{x}_{2}=\mathrm{i}_{\mathrm{LF}}$

- $\mathrm{x}_{3}=\mathrm{V}_{\mathrm{CT}}$

- $\mathrm{x}_{4}=\mathrm{V}_{\mathrm{CF}}$

- $\mathrm{y}=\mathrm{V}_{\mathrm{CT}}-\mathrm{V}_{\mathrm{CF}}$ current source current through $\mathrm{L}_{\mathrm{T}}$ current through $\mathrm{L}_{\mathrm{F}}$ voltage across $\mathrm{C}_{T}$ voltage across $\mathrm{C}_{\mathrm{F}}$ voltage across current source

$$
\left[\begin{array}{c}
\dot{x} 1 \\
\dot{x} 2 \\
\dot{x} 3 \\
\dot{x} 4
\end{array}\right]=\left[\begin{array}{cccc}
0 & 0 & \frac{1}{L_{T}} & \frac{-1}{L_{T}} \\
0 & 0 & 0 & \frac{1}{L_{F}} \\
\frac{-1}{C_{T}} & 0 & \frac{-1}{C_{T} R_{T}} & \frac{1}{C_{T} R_{T}} \\
\frac{1}{C_{F}} & \frac{-1}{C_{F}} & \frac{1}{C_{F} R_{T}} & \frac{-1}{C_{F}}\left(\frac{1}{R_{F}}+\frac{1}{R_{T}}\right)
\end{array}\right]\left[\begin{array}{l}
x 1 \\
x 2 \\
x 3 \\
x 4
\end{array}\right]+\left[\begin{array}{c}
0 \\
0 \\
\frac{1}{C_{T}} \\
\frac{-1}{C_{F}}
\end{array}\right] u
$$




$$
y=\left[\begin{array}{llll}
0 & 0 & 1 & -1
\end{array}\right]\left[\begin{array}{l}
x 1 \\
x 2 \\
x 3 \\
x 4
\end{array}\right]+[0]
$$

The state space model can be loaded directly into MATLAB as a "sys" system using the "ss" command. Then a bode plot and impulse response can be plotted. The system of differential equations can also be solved numerically to plot the time domain solution. The time domain solution of velocity can then be integrated to give the time domain position solution.

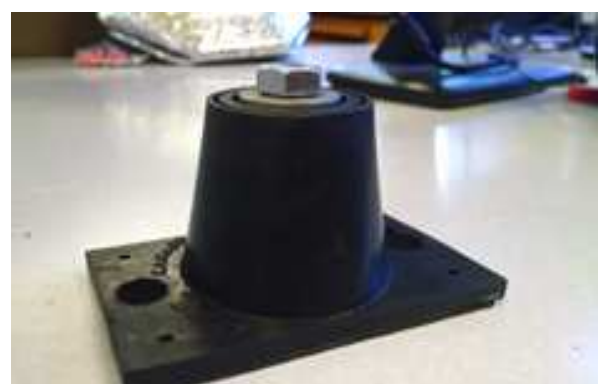

Figure 10: Andre Horizontal-InShear Vibration Isolator

Because of the large moving mass of the beta machine causing considerable vibration and losses during motoring testing, analysis was first performed on it. No analysis has been performed on the alpha machine and may be considered for future work. The following parameters are used for the analysis of the Beta machine state space model in MATLAB:

- $\mathrm{L}_{\mathrm{T}}=1 /(19903 * 18) \mathrm{H}$

- $\mathrm{R}_{\mathrm{T}}=1 \Omega$

- $\mathrm{L}_{\mathrm{F}}=1 /(0.7 \mathrm{e} 6) \mathrm{H}$

- $\mathrm{R}_{\mathrm{F}}=.1 \Omega$

- $\mathrm{C}_{\mathrm{F}}=34.5 \mathrm{~F}$

- $\mathrm{C}_{\mathrm{T}}=3.2 \mathrm{~F}$
$1 /$ Stiffness of flexures

1/Damping of Translator

1/Stiffness of Frame mounts

1/Damping of Frame

Mass $34.5 \mathrm{~kg}$ Frame

Mass $3.2 \mathrm{~kg}$ Translator (4mm thick magnets)

The stiffness of the frame mounts was determined from the data sheet for the Andre horizontalin-shear vibration isolators that stated 500lbs (0.5inches) which is $175000 \mathrm{~N} / \mathrm{m}$ and 4 mounts are used (one on each corner.) A total of $700000 \mathrm{~N} / \mathrm{m}$ of stiffness.

The following bode plot was generating using these parameters. As can be seen in Figure 11 the resonant frequency is $56.1 \mathrm{~Hz}$. This closely matched the resonant frequency of the Beta Machine tested with 18 Sandvik steel springs when tested with the heavy $4 \mathrm{~mm}$ thick ring magnets. 


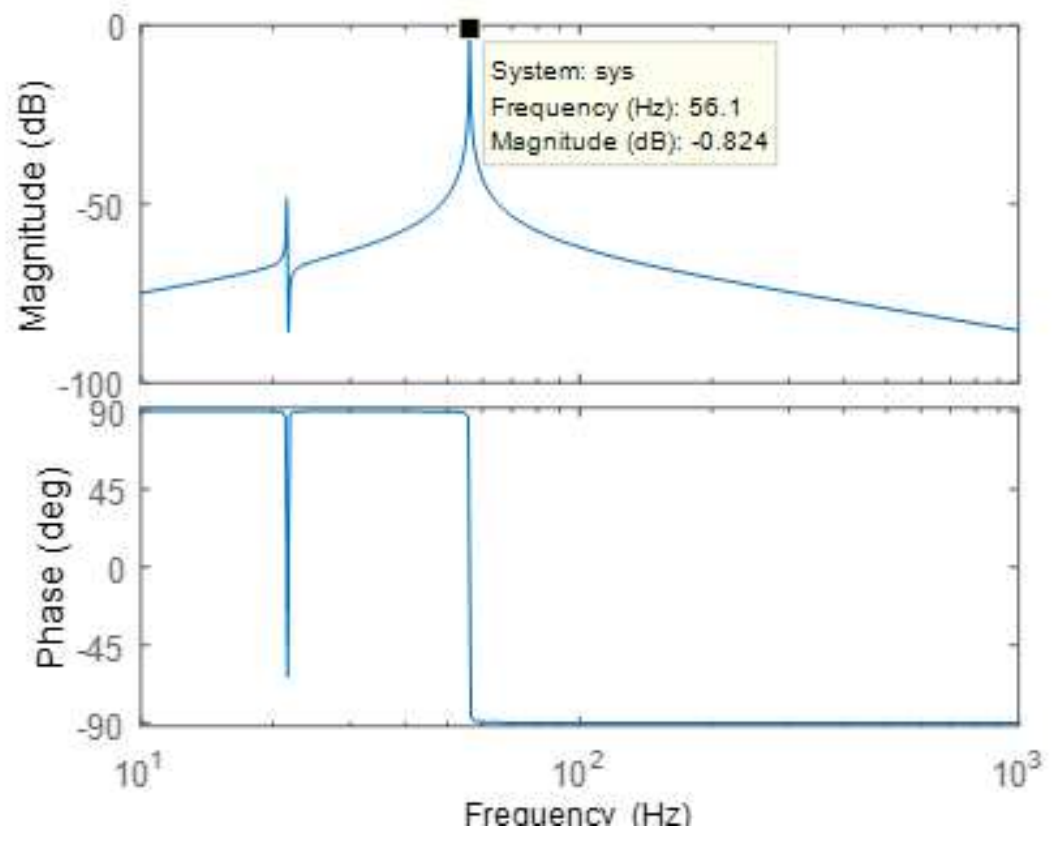

Figure 11: Beta Machine w/18 Sandvik Springs Vibration Mounted Frequency Response

An input function of a pulse square wave $(56.1 \mathrm{~Hz})$ with $25 \%$ duty cycle and amplitude of 10 amps (newtons) was used with the system of equations given in the state space model to determine the time domain output velocity. The MATLAB function "ode45" was used to solve the system of equations for velocity. The velocity was integrated using the "cumtrapz" command to calculate time domain position. Steady state amplitude was reached after about 7 seconds and is shown below in Figure 12. Because the only energy losses in the system are the damping components, their values have a large effect on the calculated steady state amplitude. The values chosen were adjusted until the amplitude was within an acceptable range. MATLAB code used can be found in Appendix 8.5. 


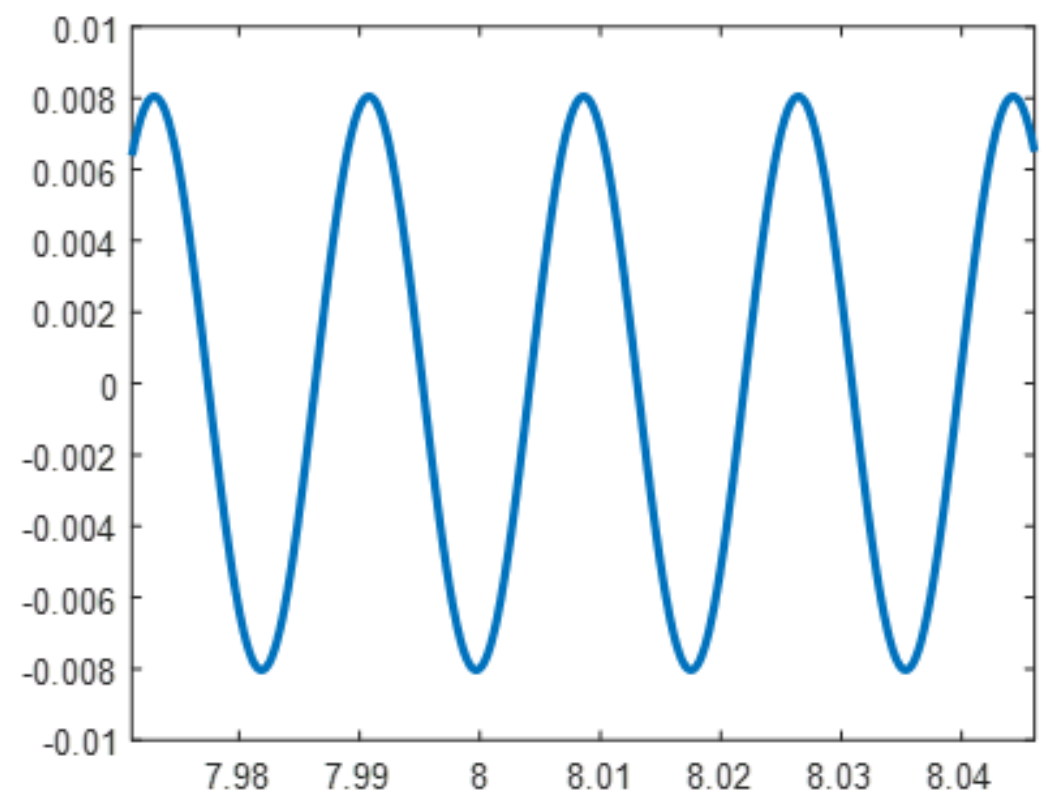

Figure 12: Beta Machine Vibration mounted, Position (m) vs Time (s) Plot

To model the machine as if it were rigidly mounted the same equations are used and the stiffness of the mounts is increased. The value $\mathrm{L}_{\mathrm{F}}=1 /(1 \mathrm{e} 16) \mathrm{H}$ was used to make the value of inductance close to zero. Zero could not be used because this would cause a divide by zero error. The same bode plot was repeated and can be seen in Figure 13.

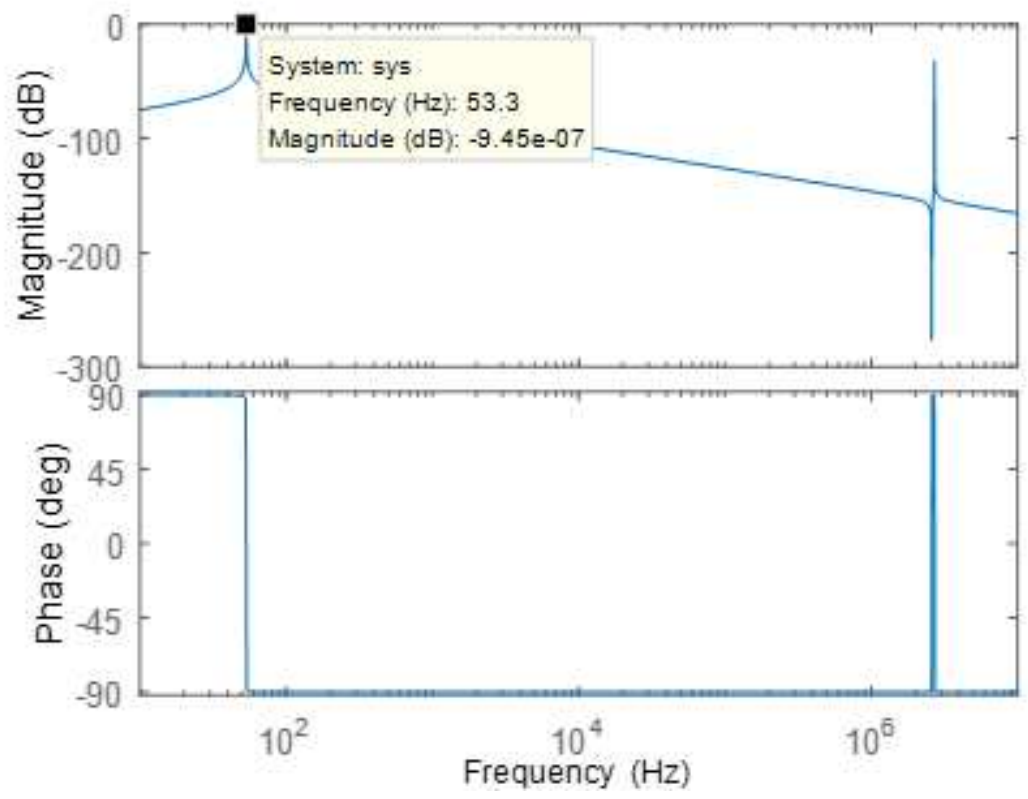

Figure 13: Beta Machine w/18 Sandvik Springs Rigid Mounted Frequency Response 
A similar analysis was performed by Dr. Terence Musho using ANSYS software. A system of equations was not developed, only a model drawn in software. He achieved a similar looking bode plot and nearly identical resonant frequencies $(56.8 \mathrm{~Hz}$ for vibration mounting, $53.2 \mathrm{~Hz}$ for rigid.) Figure 14 shows the bode plot for the vibration mounted Beta machine as determined by ANSYS software. Notice that the vertical axis of this position amplitude plot is different from the MATLAB velocity amplitude plots.
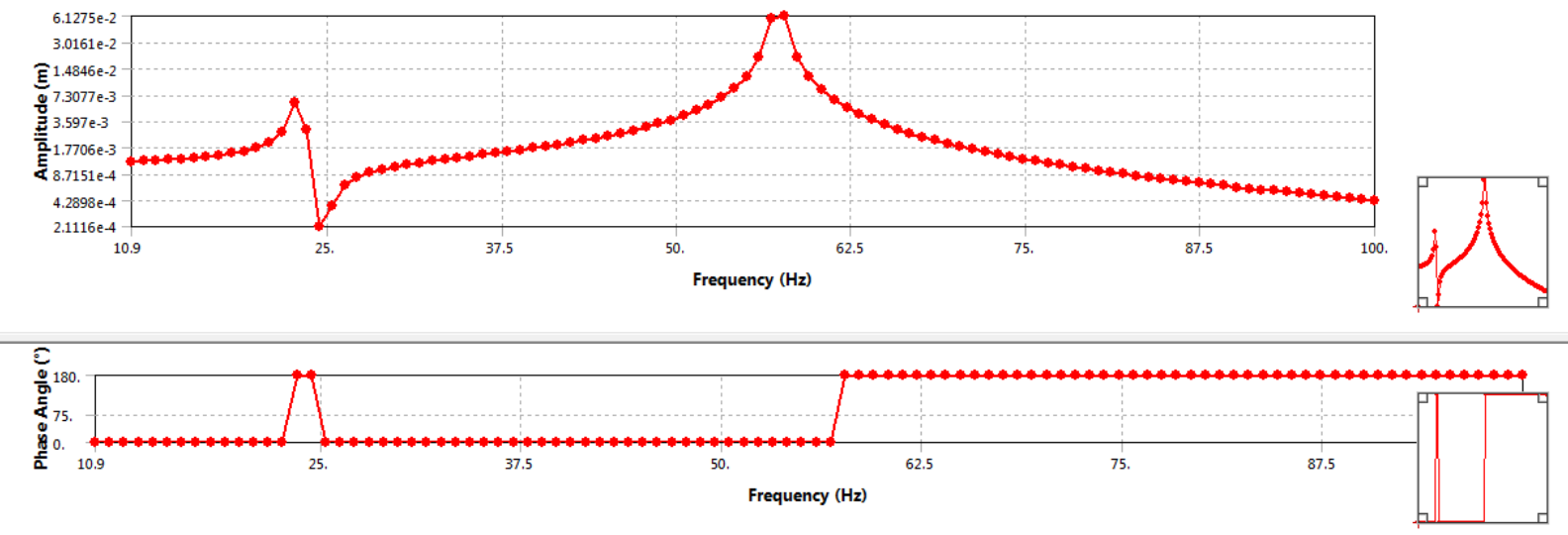

Figure 14: ANSYS bode plot Vibration mounted Beta Machine (credit: Dr. Musho)

The resonant frequency is higher when the machine is mounted on rubber mounts and the frame is allowed to move. Rigidly mounting the machine will decrease the resonant frequency and in practice causes significant mechanical losses due to transmission of the vibration forces into the mounting structure. In practice, the machine hanging on rubber straps in a near vertical orientation, provided the greatest ease of use and low losses. The rubber straps did not transmit forces to the building walls and allowed the machine to move side-to-side while in operation. Rubber straps can be seen in the test setup shown in Figure 15.

\subsection{Load Bank Resistance Verification}

High ampacity resistors from WVU's power lab were used to make a suitable load bank for the linear alternator. A bank of resistors with a nameplate rating of $1.125 \mathrm{ohms}$ was found to be made up of 12 wire wound resistors in series. Knowing that the stator resistance of the alpha machine was $0.273 \mathrm{ohms}$ and wanting to achieve maximum power from the machine, switches were added across the resistors that allowed reducing the resistance to as close to $0.273 \mathrm{ohms}$ in multiple steps. Three switches were added across every 3 series resistors to allow load increments of $0.281 \mathrm{ohms}$. Later a fourth switch was added to short across all but the last resistor to allow a load of 0.094 ohms. 
The load bank was tested with a DC bench voltage source and an AC voltage source (variac) and compared to the theoretical value. The voltage and currents were recorded for each to calculate the resistances.

AC Test:

\begin{tabular}{|l|l|l|l|l|}
\hline & Voltage & Current & $\begin{array}{l}\text { Calculated } \\
\text { resistance }(V / I)\end{array}$ & $\begin{array}{l}\text { Theoretical } \\
\text { Resistance }\end{array}$ \\
\hline $\mathrm{S} 1$ & 3.736 & 3.124 & 1.196 & 1.125 \\
\hline $\mathrm{S} 1+\mathrm{S} 2$ & 3.459 & 3.758 & 0.920 & 0.844 \\
\hline $\mathrm{S} 1+\mathrm{S} 2+\mathrm{S} 3$ & 3.06 & 4.781 & 0.640 & 0.563 \\
\hline $\mathrm{S} 1+\mathrm{S} 2+\mathrm{S} 3+\mathrm{S} 4$ & 2.3 & 6.422 & 0.358 & 0.281 \\
\hline
\end{tabular}

Table 2: Load Bank AC Resistance Test

DC Test:

\begin{tabular}{|l|l|l|l|l|}
\hline & Voltage & Current & $\begin{array}{l}\text { Calculated } \\
\text { resistance (V/I) }\end{array}$ & $\begin{array}{l}\text { Theoretical } \\
\text { Resistance }\end{array}$ \\
\hline $\mathrm{S} 1$ & 13.0 & 11.23 & 1.158 & 1.125 \\
\hline $\mathrm{S} 1+\mathrm{S} 2$ & 9.8 & 11.23 & 0.873 & 0.844 \\
\hline $\mathrm{S} 1+\mathrm{S} 2+\mathrm{S} 3$ & 6.74 & 11.3 & 0.596 & 0.563 \\
\hline $\mathrm{S} 1+\mathrm{S} 2+\mathrm{S} 3+\mathrm{S} 4$ & 3.48 & 11.39 & 0.306 & 0.281 \\
\hline $\mathrm{S} 1+\mathrm{S} 2+\mathrm{S} 3+\mathrm{S} 4+\mathrm{S} 5$ & 1.396 & 11.27 & 0.124 & 0.094 \\
\hline
\end{tabular}

Table 3: Load Bank DC Resistance Test 


\section{Alpha Machine}

This section is divided into two sections, the air core stator machine and the iron core stator machine. Each of these sections is further divided into actual test data that were recorded and analyzed, and the finite element simulation results. At the end of each section a comparison is presented between the test data and the simulation results.

The parameters of the alpha machine are given below:

- Pole Pitch

- Magnet Length

- Number of Turns

- Number of Coils

- Number of Magnets

- Coil Inside Diameter

- Ring Magnet Outside Diameter

- Magnet Thickness

- Iron Pole Thickness

- Airgap

- Magnet type
$22 \mathrm{~mm}$

$20 \mathrm{~mm}$

$8 \times 3=24$ (per coil)

6

5

$104 \mathrm{~mm}$

$100 \mathrm{~mm}$

$2 \mathrm{~mm}$

$3 \mathrm{~mm}$

$1 \mathrm{~mm}$

N35, 1/4 Arc Segments
(Iron Core Only)

(Iron Core Only)

\subsection{Air Core Alpha Machine}

\subsubsection{Air Core Alpha Test Data}

The air core alpha machine was tested at various load levels to determine its synchronous machine equivalent model. A test system was set up that allowed starting of the natural gas engine using the machine as a motor sourced by an inverter. After the engine had started, the inverter voltage source switch was opened to disconnect the inverter from the machine. Then a second switch was closed connecting a resistive load to the machine. Five different load levels were possible and measurements at the machine terminals were taken with a power analyzer recording voltage, current, and average power (watts). 


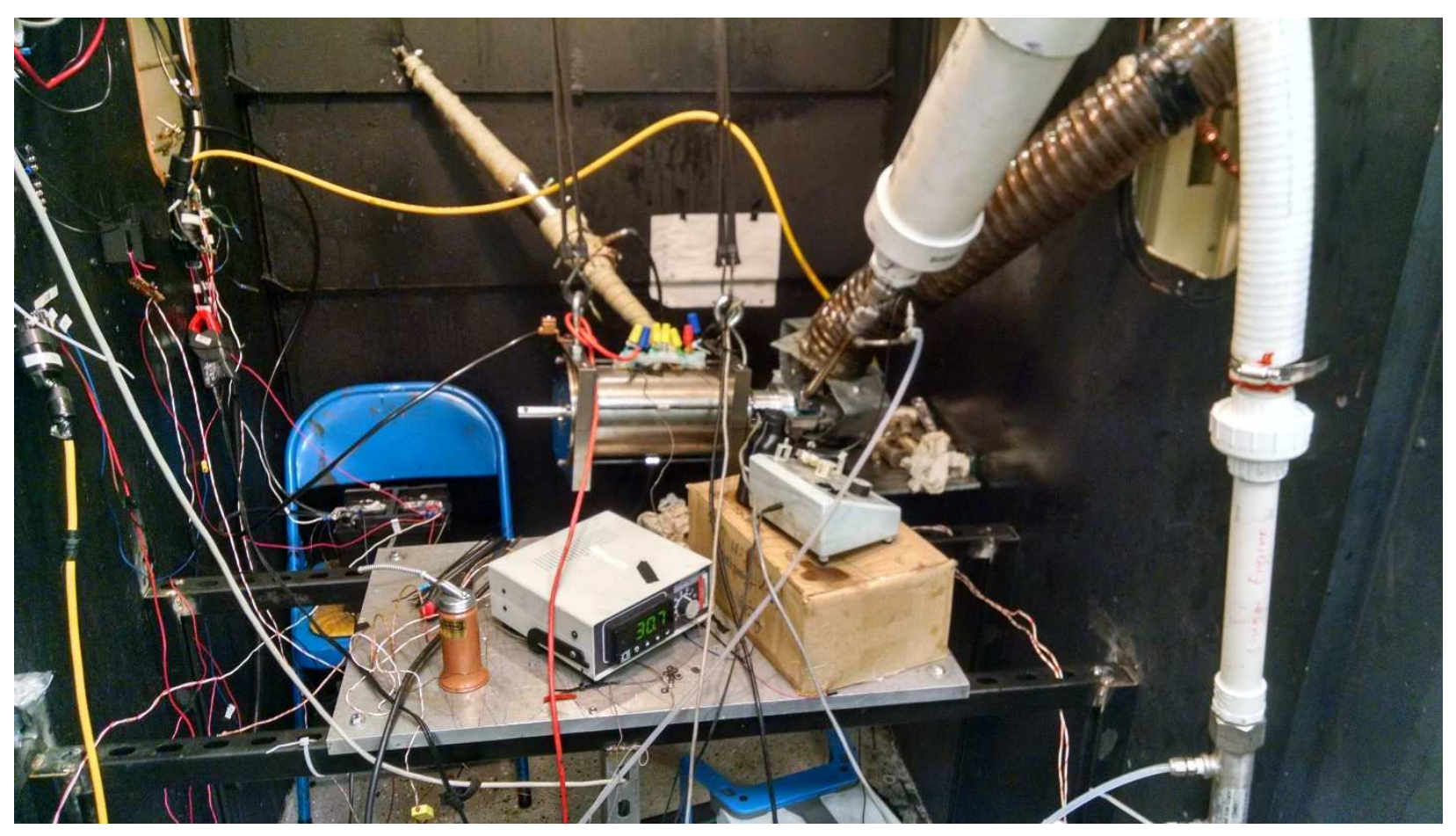

Figure 15: Engine and Alternator setup inside an Engine Test Bay

The alpha air core machine was assembled with 8 titanium flexures that was resonate at approximately $74 \mathrm{~Hz}$. With a single cylinder, two stroke engine attached, the engine alternator system was run, various load levels were tested, and data were recorded. Because of the short amount of run time between load transitions, photographs of the power analyzer were taken recording RMS voltage, RMS current, average power, and frequency. Only one data download consisting of instantaneous voltage, current, and position was completed at the last load level.

The test setup can be seen in Figure 16. The switches that isolate the load and inverter were important as the reverse diodes across each IGBT of the inverter would conduct while the alternator was generating voltage. The DC supply output capacitors would charge and the IGBTs would conduct this generated voltage when switched on. This made the voltage and current waveforms shown on the power analyzer complex and a simple resistive load was desired.

For operation the inverter switch was closed and the load bank switch S1 was opened. The DC supply was increased until a proper displacement was achieved to begin combustion of the linear engine. Then the fuel and timing was adjusted until the engine was running smoothly and was properly warmed up. The DC supply voltage was slowly decreased, adjusting the engine fuel and timing as necessary, until the DC supply could be switched off. The inverter switch was then opened followed by the closing of the load switch S1. Slightly before closing the load switch the fuel had to be increased slightly to allow for the additional load placed on the engine. Then each successive load switch could be closed and as before increasing the fuel a second or two before closing of the switch to prevent killing the engine. 


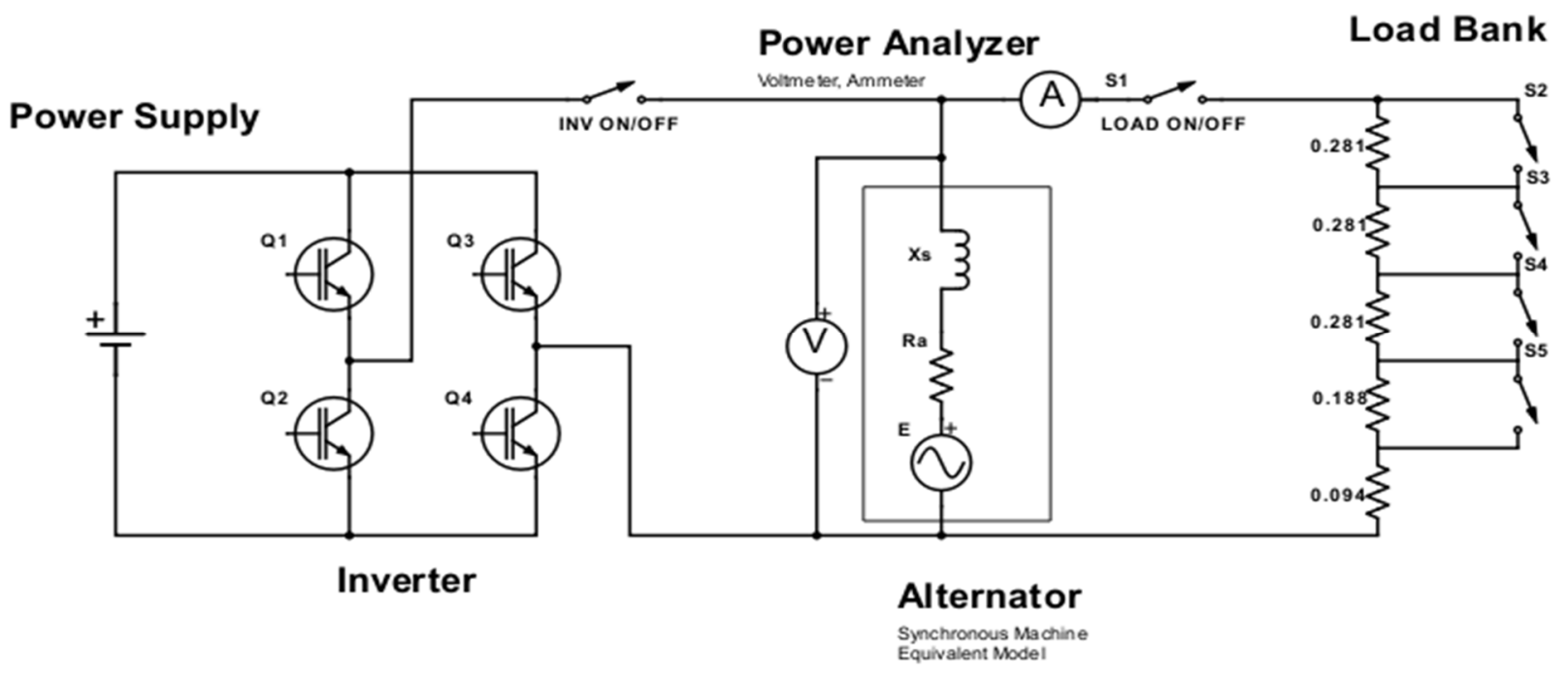

Figure 16: Linear Engine Alternator Load Test Setup

The basic parameters of the air core alpha machine are listed below. The stator resistance and inductance values were later used for more detailed analysis to follow.

- 8 titanium springs

- $2 \mathrm{~mm}$ thick N35 magnets on translator drum

- Frequency $-74 \mathrm{~Hz}^{*}$

- Stroke length $22 \mathrm{~mm}$ (for starting, up to $26-27 \mathrm{~mm}$ when running.)

- 24 turns per coil, 6 coils series connected.

- Resistance of stator windings $\mathrm{R}_{\mathrm{a}}$ (series connected) $-0.273 \Omega$

- Inductance of stator $-0.425 \mathrm{mH}$ (as measured.)

*Resonant frequency can vary $2-3 \mathrm{~Hz}$ with displacement amplitude due to the flexures springs having a slightly nonlinear force to displacement relationship.

All five load levels (S1 through S5) were able to be tested with the air core machine. An open circuit voltage of $12 \mathrm{~V}$ was recorded. Test data are recorded below in Table 4 and a V-I relationship plot is given in Figure 17.

\begin{tabular}{|r|r|r|r|r|r|}
\hline \multicolumn{1}{|l|}{ Switch } & \multicolumn{1}{l|l}{$\begin{array}{l}\text { Load } \\
\text { Resistance }\end{array}$} & \multicolumn{1}{l|}{$\begin{array}{l}\text { Voltage } \\
\text { V }\end{array}$} & $\begin{array}{l}\text { Current } \\
\mathrm{I}_{\mathrm{L}}\end{array}$ & Power (Watts) & $\begin{array}{l}\text { Frequency } \\
(\mathrm{Hz})\end{array}$ \\
\hline $\mathrm{S} 1$ & 1.125 & 9.24 & 5.696 & 49.5 & 74.195 \\
\hline $\mathrm{S} 1+\mathrm{S} 2$ & 0.84375 & 8.985 & 6.973 & 58.6 & 76.27 \\
\hline $\mathrm{S} 1+\mathrm{S} 2+\mathrm{S} 3$ & 0.5625 & 8.164 & 8.625 & 65.1 & 74.598 \\
\hline $\mathrm{S} 1+\mathrm{S} 2+\mathrm{S} 3+\mathrm{S} 4$ & 0.28125 & 6.52 & 12.569 & 74.9 & 74.18 \\
\hline
\end{tabular}




\begin{tabular}{|r|r|r|r|r|r|}
\hline S1+S2+S3+S4+S5 & 0.09375 & 3.416 & 19.8 & 63.2 & 73.707 \\
\hline
\end{tabular}

Table 4: Alpha Air Core Load Data

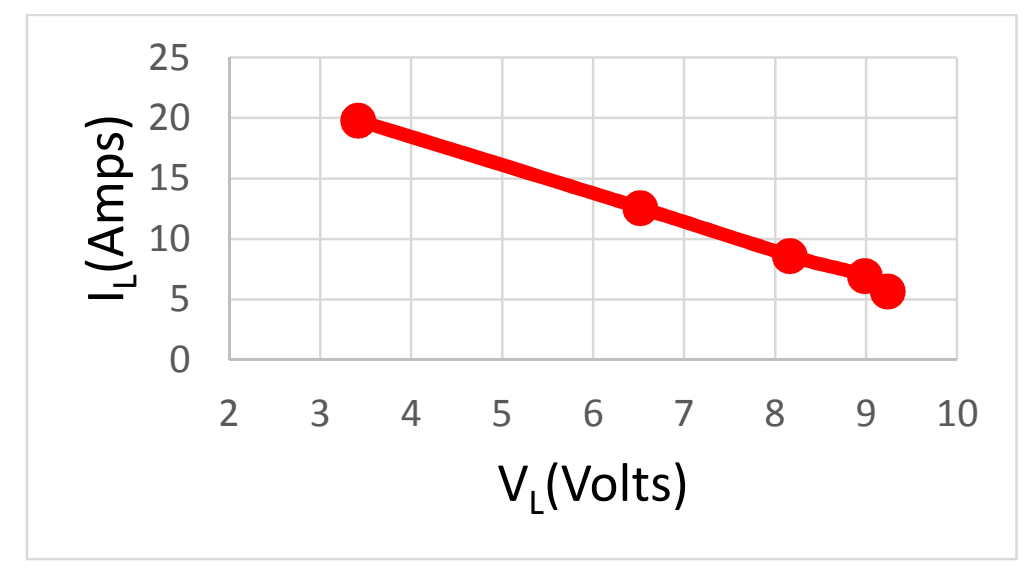

Figure 17: Alpha Air Core V-I Plot

Using the recorded frequency and the previous measured stator resistance and inductance, the source impedance was calculated.

$$
Z_{S}=R_{a}+j 2 \pi f * L_{S} \quad R_{a}=0.273 \Omega, L_{S}=0.000425 H
$$

Then the generated emf $\mathcal{E}_{\mathrm{GEN}}$ magnitude was calculated for each load level by adding the source drop to the measured voltage.

$$
\varepsilon_{G E N}=\left|V_{L}+I_{L} * Z_{S}\right|
$$

Machine winding resistance $I^{2} R$ losses were also calculated using the load current and measured stator resistance.

$$
P_{\text {Loss }}=I_{L}^{2} * R_{a}
$$

\begin{tabular}{|l|r|r|}
\hline Switch & $\varepsilon_{\text {GEN }}$ (Calculated) & $\begin{array}{l}\text { PLOSS } \\
\text { (Calculated) }\end{array}$ \\
\hline S1 & 10.8538288 & 8.857326 \\
\hline S1+S2 & 10.98084045 & 13.27401 \\
\hline S1+S2+S3 & 10.65800231 & 20.30864 \\
\hline S1+S2+S3+S4 & 10.2580264 & 43.12847 \\
\hline S1+S2+S3+S4+S5 & 9.643776461 & 107.0269 \\
\hline
\end{tabular}

Table 5: Calculated Air Core Alpha $\varepsilon_{G E N}$ and Winding Losses during load 
The calculated $\varepsilon_{\mathrm{GEN}}$ values displayed in Table 5 were all close to the measured open circuit voltage of $12 \mathrm{~V}$. A slight variation is to be expected due to possible displacement amplitude differences between each measurement.

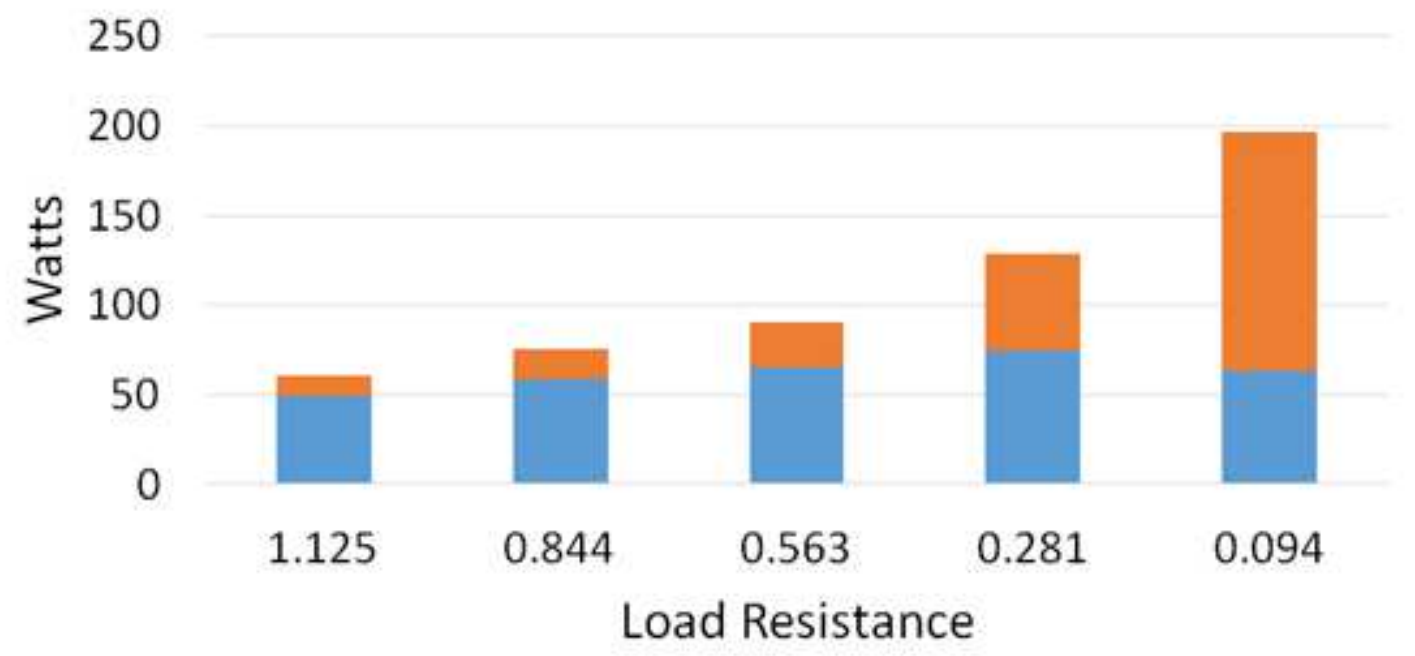

\section{Load Power I I2R Winding Loss}

Figure 18: Air Core Alpha Alternator Load Power and Losses

Figure 18 above shows power that the linear alternator is producing to the load and the winding losses at each load level. As can be expected, the winding losses become an increasing percentage of total power as the load resistance decreases. At the lowest recorded load the efficiency of the alternator is $82 \%$ and drops to $32 \%$ at the highest load. The maximum power that the air core alpha machine can produce will happen at 50\% efficiency when the inductive impedance of the stator is cancelled by an equal capacitive impedance load. I.e. $\mathrm{R}_{\mathrm{L}}=0.273 \Omega$ and $\mathrm{X}_{\mathrm{C}} \approx \mathrm{j} 0.20 \Omega$. The maximum power is therefore:

$$
P_{M A X}=\frac{\varepsilon_{G E N}{ }^{2}}{4 * R_{a}}=\frac{11^{2}}{4 * 0.273}=111 \mathrm{Watts}
$$

At maximum power found above, the engine would have to produce 111 watts of power for the load and another 111 watts of power for the stator winding losses.

The last load level (all five load switches closed) was captured and recorded with a Yokagawa PZ4000 power analyzer. Approximately 3 cycles $(40 \mathrm{~ms})$ of instantaneous voltage, current, and position data were recorded at a sampling rate of $1.25 \mathrm{MHz}$. The data were recorded in comma separated value (CSV) format and imported into MATLAB. As can be seen in Figure 19 below, the voltage and current are not purely sinusoidal. The calculations that were performed above assumed a purely sinusoidal voltage and current but remain valid when the stator reactance is 
neglected. The air core stator reactance of $0.20 \Omega$ (at $74 \mathrm{~Hz}$ ) does not significantly alter the previously calculated $\varepsilon_{\mathrm{GEN}}$ and $\mathrm{P}_{\mathrm{MAX}}$ values. Also, because the load is purely resistive, the distortion does not affect the load power factor and it remains at unity. The code used to analyze the instantaneous data below is valid for distorted wave shapes and a similar $\varepsilon_{\mathrm{GEN}}$ was found as listed in Table 6 below.

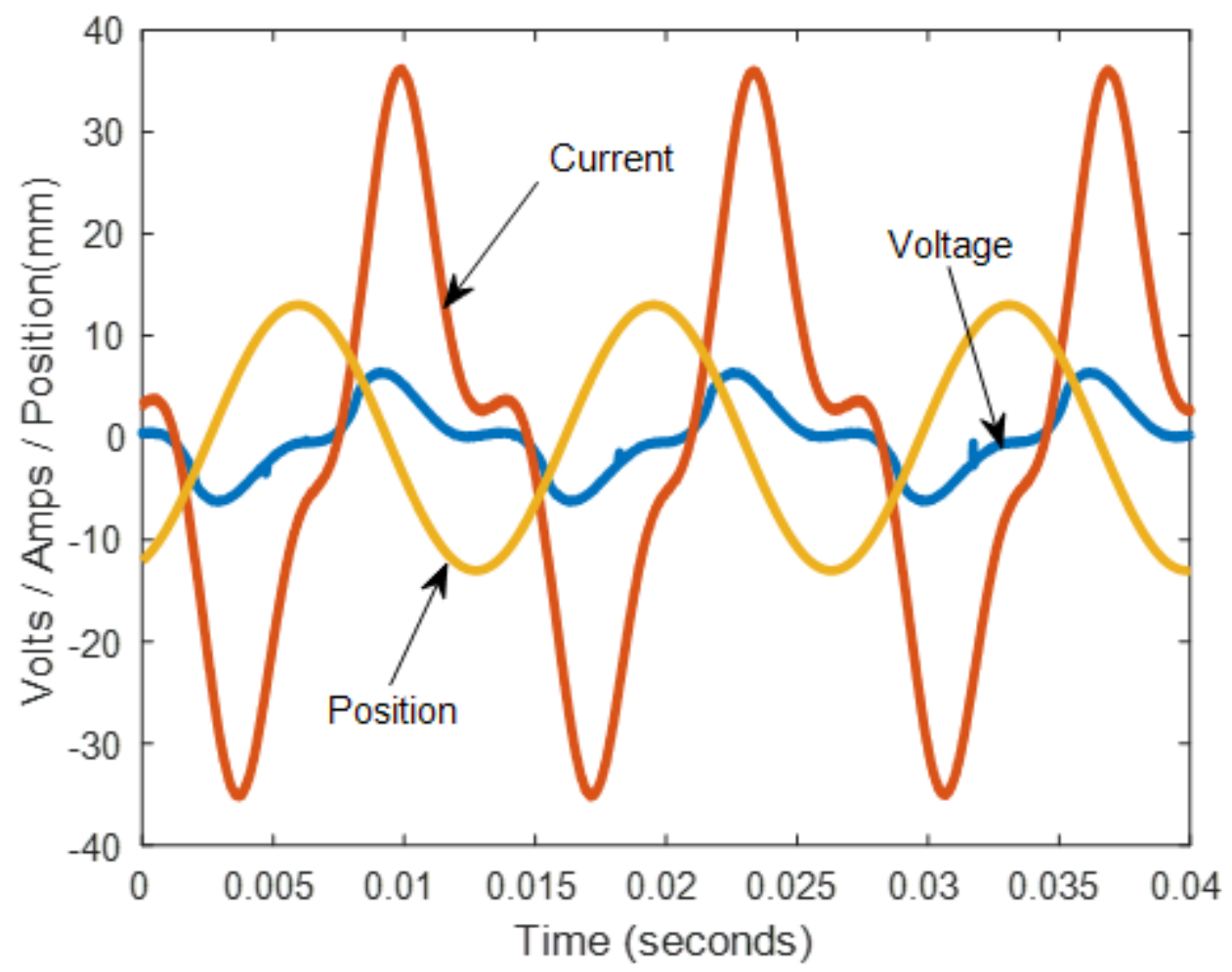

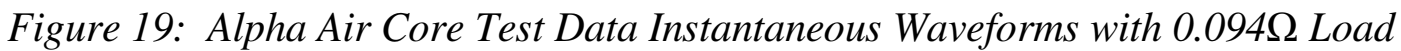

The energy stored in the mass spring system is larger than the energy that is extracted in one stroke by the alternator. The mass spring system is dominant over the alternator and the oscillations remain sinusoidal with alternator loading. As the position data demonstrates, the movement is nearly a perfect sinusoid and the MATLAB "fit" function was used to fit a sinusoid function. With a clean sinusoid, the gradient function could be used to calculate the instantaneous velocity that is used in subsequent calculations. Also the current waveform was filtered with the "smooth" function utilizing a Savitzky-Golay moving average filter to improve the calculation of its derivative. The voltage waveform was not smoothed, however there is some EMI noise that is apparent on the waveform just before the crest of the position. This is the noise from the spark plug ignition and can be seen just before engine "top dead center" in Figure 19.

\begin{tabular}{|l|l|}
\hline $\mathrm{V}_{\mathrm{rms}}$ & 3.4284 \\
\hline
\end{tabular}




\begin{tabular}{|l|l|}
\hline$I_{\text {rms }}$ & 19.7924 \\
\hline Average Power $(\mathrm{W})$ & 63.3371 \\
\hline Displacement $(\mathrm{pk}-\mathrm{pk})(\mathrm{mm})$ & 26.07 \\
\hline Frequency & 73.71 \\
\hline Winding Losses & 106.95 \\
\hline Voltage THD & $44.83 \%$ \\
\hline Current THD & $36.31 \%$ \\
\hline$\varepsilon_{\text {GEN }}(\mathrm{RMS})$ & 10.7641 \\
\hline Velocity $(\mathrm{pk})(\mathrm{m} / \mathrm{s})$ & 6.04 \\
\hline Acceleration $(\mathrm{pk})\left(\mathrm{m} / \mathrm{s}^{2}\right)$ & 2795 \\
\hline
\end{tabular}

Table 6: Air Core Alpha MATLAB derived Measurements at 0.094ohm Load

Table 6 above lists some basic calculations that were performed on the instantaneous waveforms of Figure 19. These values are in agreement with those recorded in Table 4.

Considering the synchronous machine equivalent model as shown in Figure 16, the instantaneous generated $\varepsilon_{\mathrm{GEN}}$ was calculated using the measured inductance, resistance, and terminal voltage of the machine using the following equation. A positive current flowing out of the generator was used as the convention.

$$
\varepsilon_{G E N}=V_{T E R M}+L_{S} \frac{d i}{d t}+R_{a} i \text { where } L_{S}=0.000425 H, R_{a}=0.273 \Omega
$$

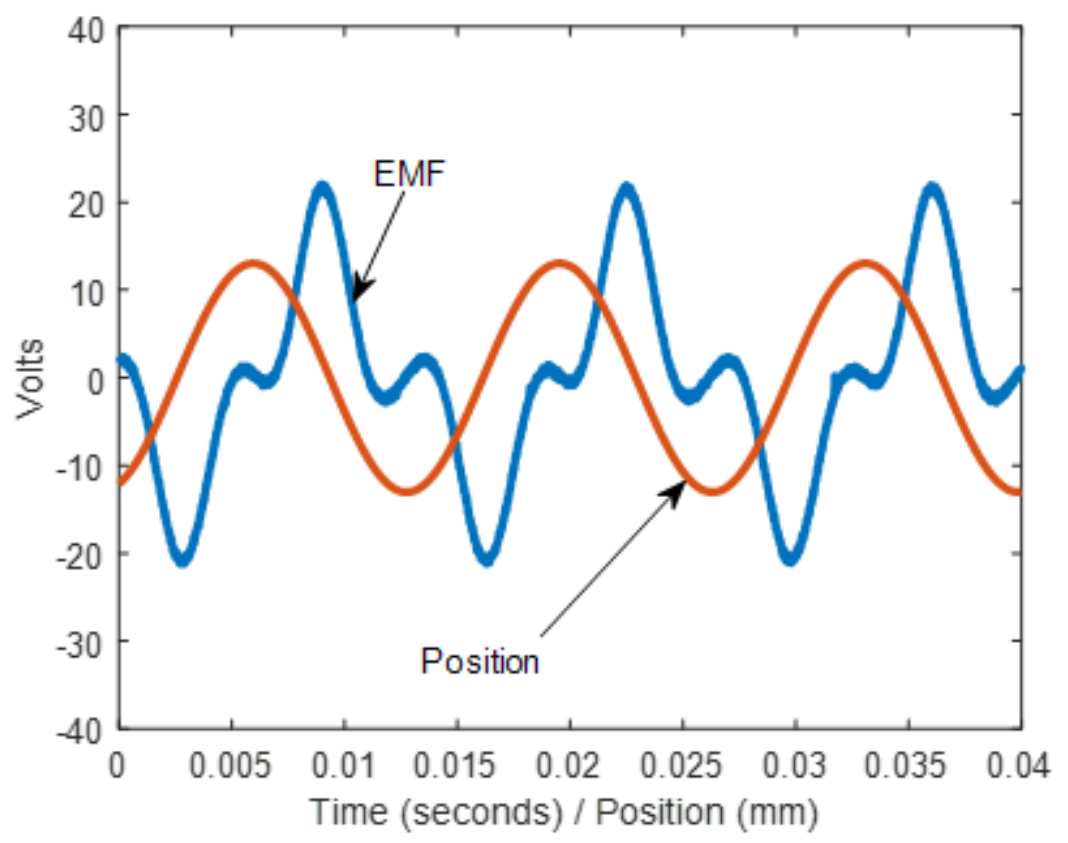

Figure 20: Test Based Generated EMF at 0.094ohm Load 
The power needed by the alternator was plotted using the product of instantaneous $\varepsilon_{\mathrm{GEN}}$ and current. The average power of the waveform in Figure 21 is 170.29 watts and is equivalent to the sum of the winding losses and load power listed in Table 6 . Note that the frequency of the power is twice that of the voltage and current because power is sourced during movement in both directions. It is believed that the slight difference in power for each direction seen in Figure 21 could be caused by engine combustion. During the combustion firing stroke, more power is sourced to the alternator whereas on the compression stroke energy stored in the flexure springs is providing the power to the alternator as well as to compression of the gasses in the engine cylinder. The velocity calculated from the position data is shown in Figure 22 and no difference in velocity was seen during the combustion stroke to fully explain the difference in power. Regardless, the difference in peak power for each stroke is small and may simply be caused by a small error or offset in the voltage or current measurements.

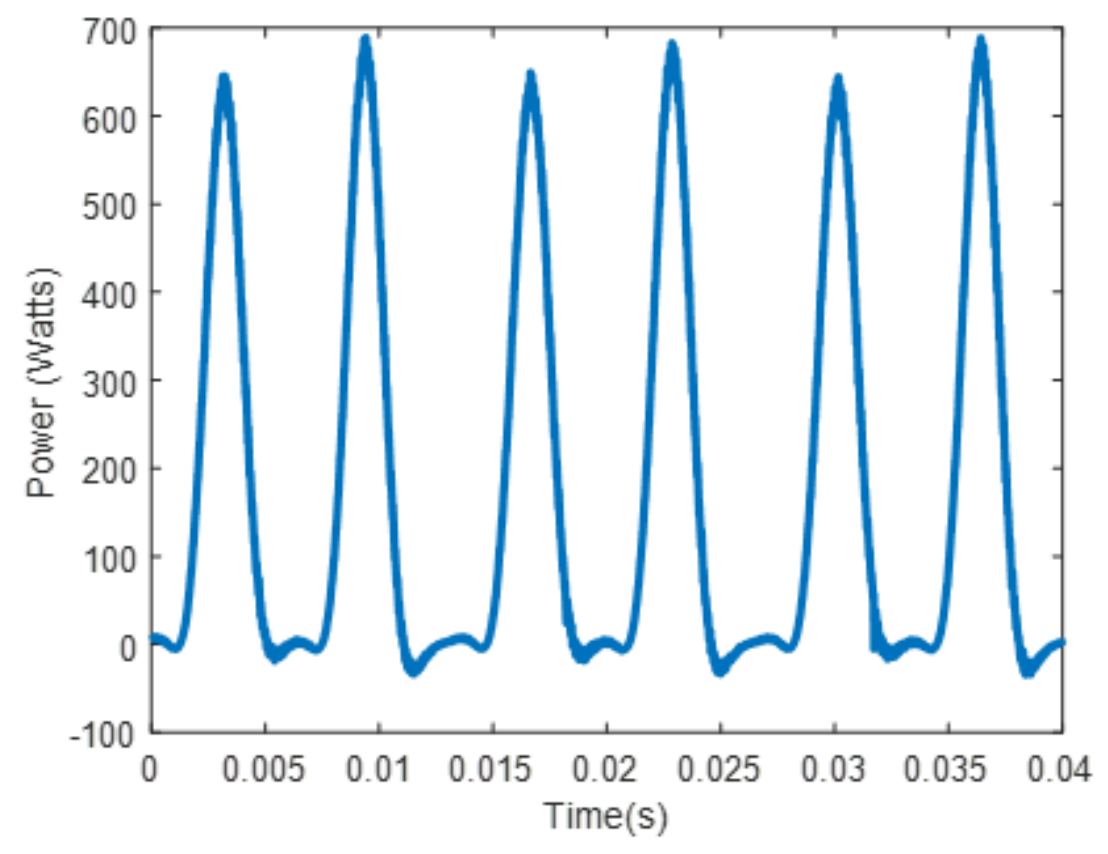

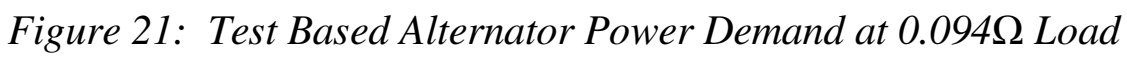




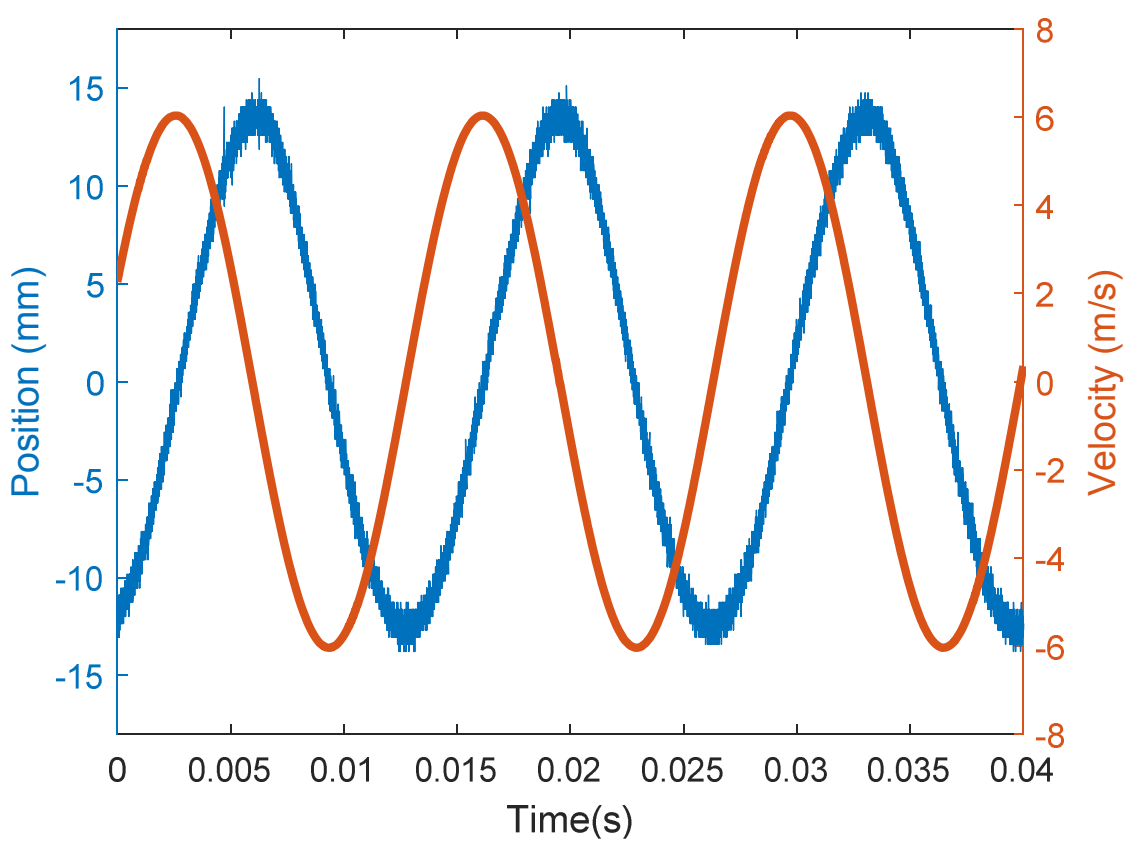

Figure 22: Position (as measured) and Velocity

Using the instantaneous power and velocity waveforms, the instantaneous force can be calculated. This is the force that the permanent magnets on the translator experience from magnetic forces which are attached to the drum and translator rod. This force, along with the flexure spring forces and mass acceleration forces, are transmitted down the translator rod to the engine's piston. The equation for instantaneous force is simply Force $=$ Power $/$ velocity and is shown below in Figure 23. Because velocity is zero at top and bottom dead centers, a discontinuity appears in the waveform and should be ignored. The peak alternator force occurs at the times when velocity is the highest. 


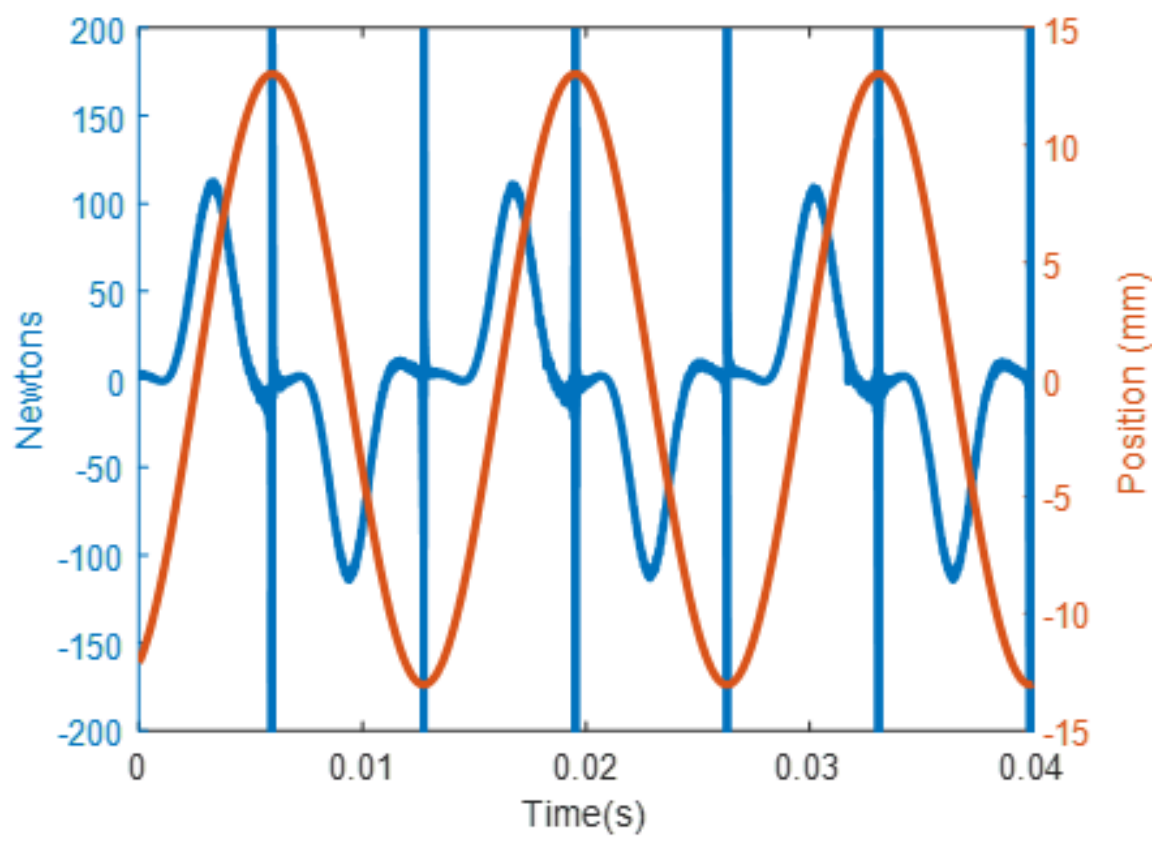

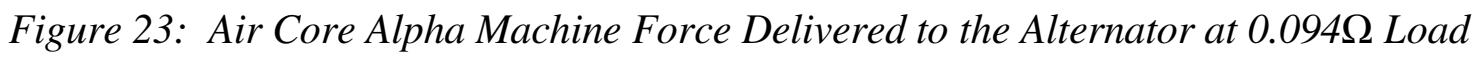

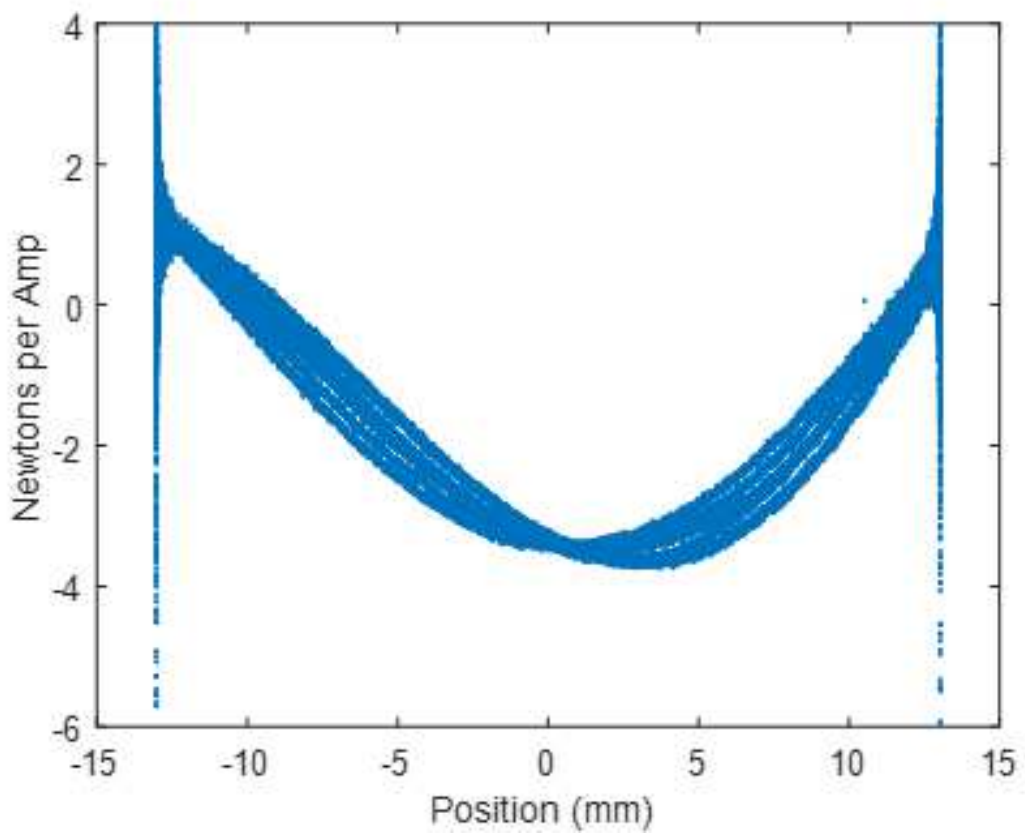

Figure 24: Air Core Alpha Force per Amp verses Position 
Force (Newtons) per Ampere was also plotted verses position and can be seen in Figure 24. As can be expected, the force is the highest near the neutral (zero) position because the rate of change of flux linkages is at a maximum at the neutral position.

As can be seen in Figure 19, there is considerable voltage and current distortion. An FFT algorithm was written in MATLAB to measure the frequency components up the $15^{\text {th }}$ harmonic. A Hann function filter was applied to the waveform and it was zero padded to increase the frequency resolution [19] [20]. The voltage and current spectrums are shown below in Figure 25 and Figure 26. The FFT spectrum of the generated emf was also calculated and is shown in Figure 27. There are even order harmonics present in all waveforms. These second order harmonics can be attributed to the neutral position not being perfectly aligned to the center of the coil windings.

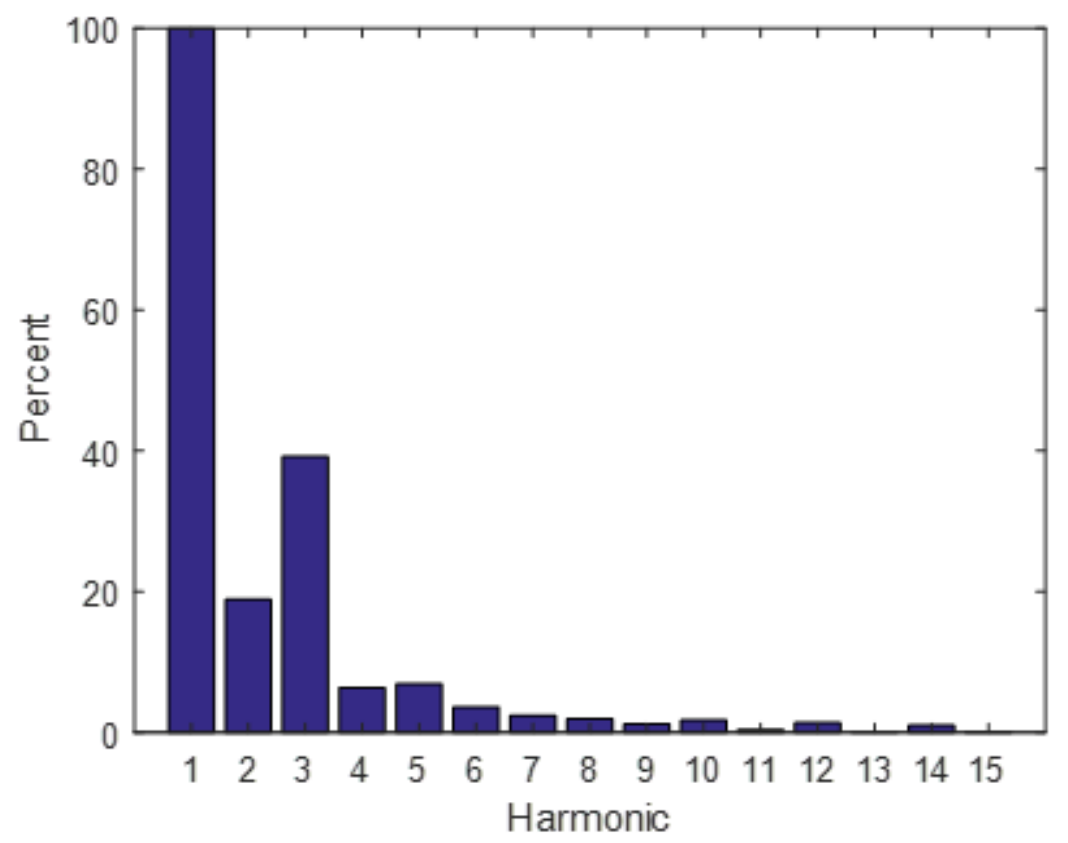

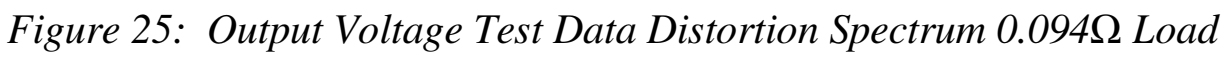




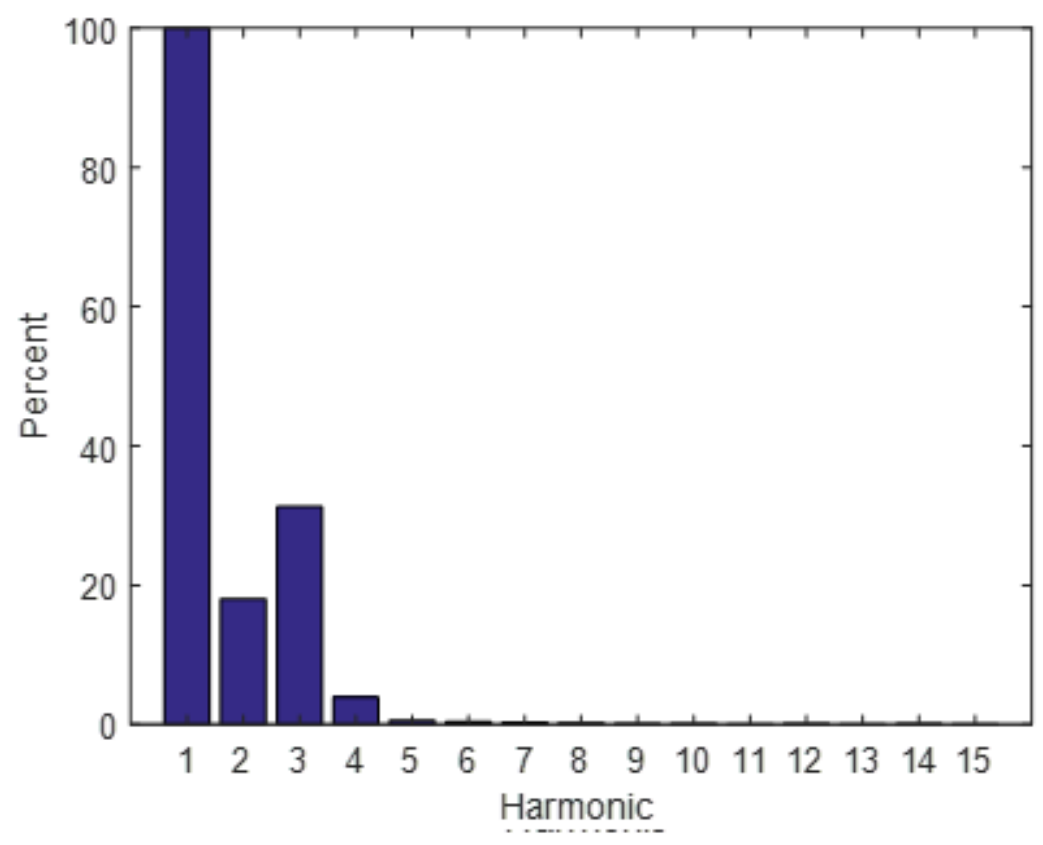

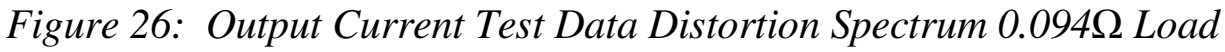

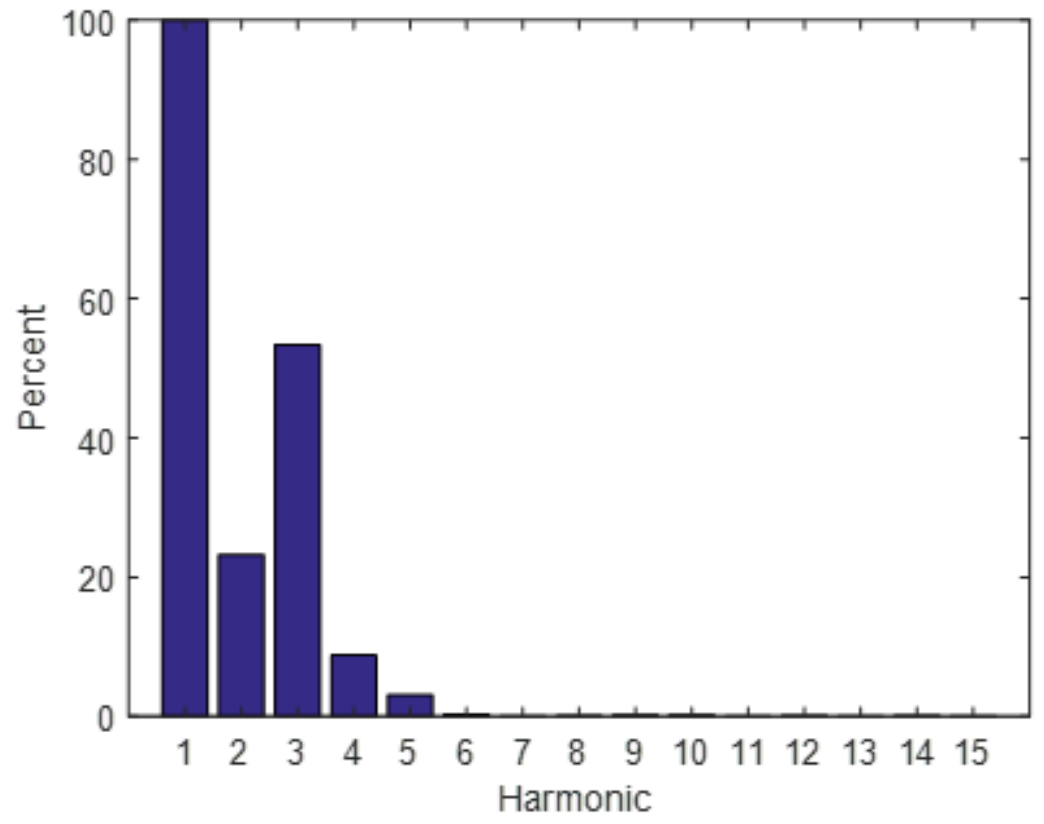

Figure 27: Air Core Alpha Test Based Generated EMF Distortion Spectrum 


\subsubsection{Air Core Alpha Simulation}

The air core alpha machine was modeled in Finite Element Methods Magnetics (FEMM). FEMM is a finite element software for magnetics. In addition to being a magnetostatics solver, FEMM is a finite element electrostatic and heat flow solver. FEMM is a software distributed under the Aladdin Free Public License and is available for personal, academic, or commercial

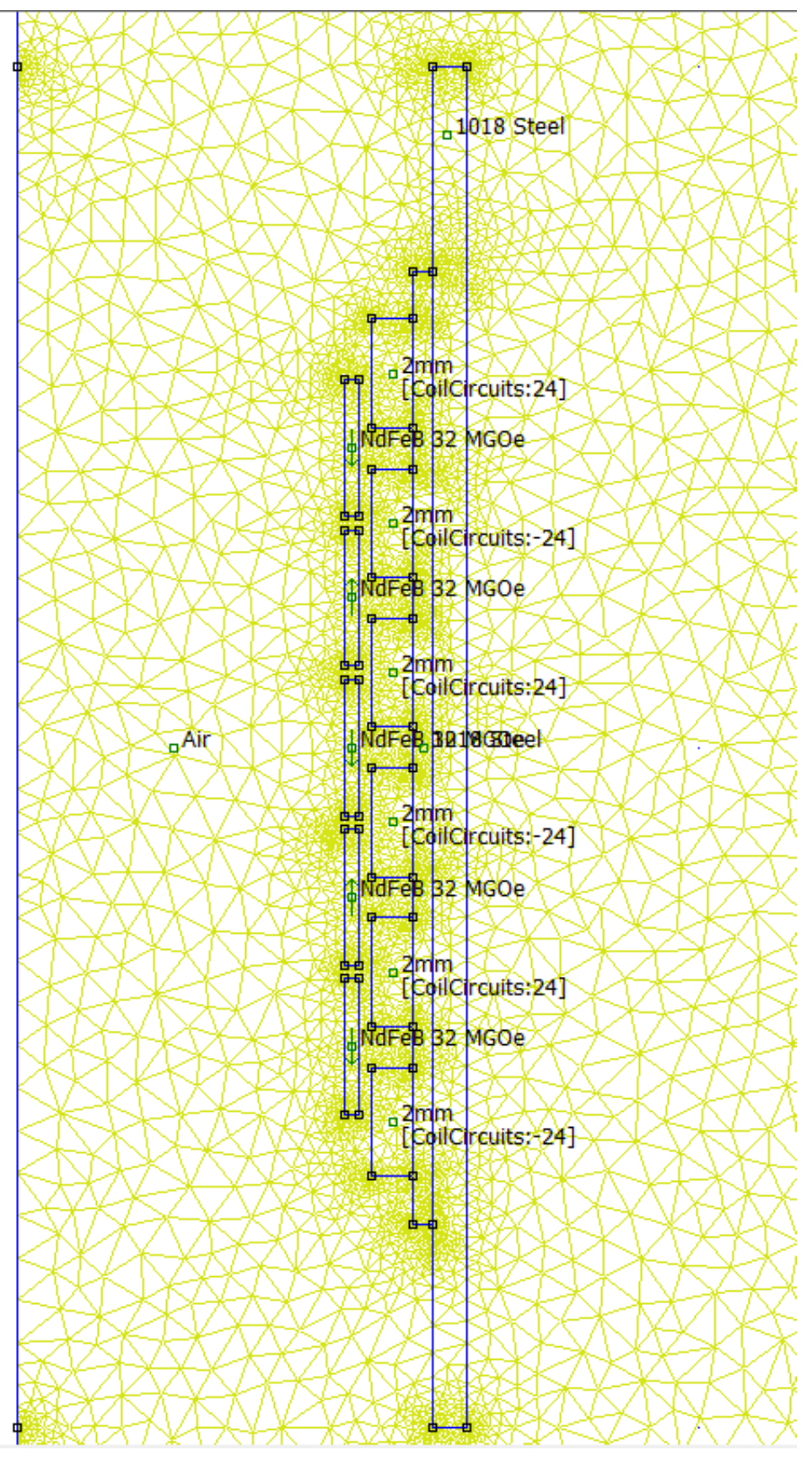

Figure 28: FEMM Axisymmetric Model Air Core Alpha Machine with Mesh use.

FEMM is relatively straightforward to use. There are two types of problems that can be solved with FEMM, two dimensional and axisymmetric. The tubular linear alternator is well suited for modeling as an axisymmetric model. The model is drawn as a cross-section of the machine that is revolved around a vertical axis.

Figure 28 shows the air core alpha axisymmetric model drawn in FEMM. The model consists of nodes, segments, block labels, and groups. Nodes are placed at each corner of a part and segments connect the nodes to create areas of a material or coil. Block labels are assigned to each area to assign the material type. Many default material types are available in the material library including copper, aluminum, various steels, permanent magnets, etc. Circuits can be defined for areas consisting of copper wires. The number of turns within a copper area must be defined. To define a coil that is reverse connected, a negative sign before the number of turns is used.

When the problem definition is chosen as axisymmetric, the $r=0$ axis is the axis that the parts will be revolved around. The model is 
drawn to scale and a boundary is defined around the part. Then a mesh can be auto-generated within the boundary. After the mesh is generated the solver can be ran. The solver can display a flux density plot as shown Figure 29. Other properties can also be found such as self-inductance and resistance of the coils. Of particular interests is the normal flux through a line segment. A line can be drawn, which represents a ring area in axisymmetric analysis, and the normal magnetic flux that passes through can be determined.

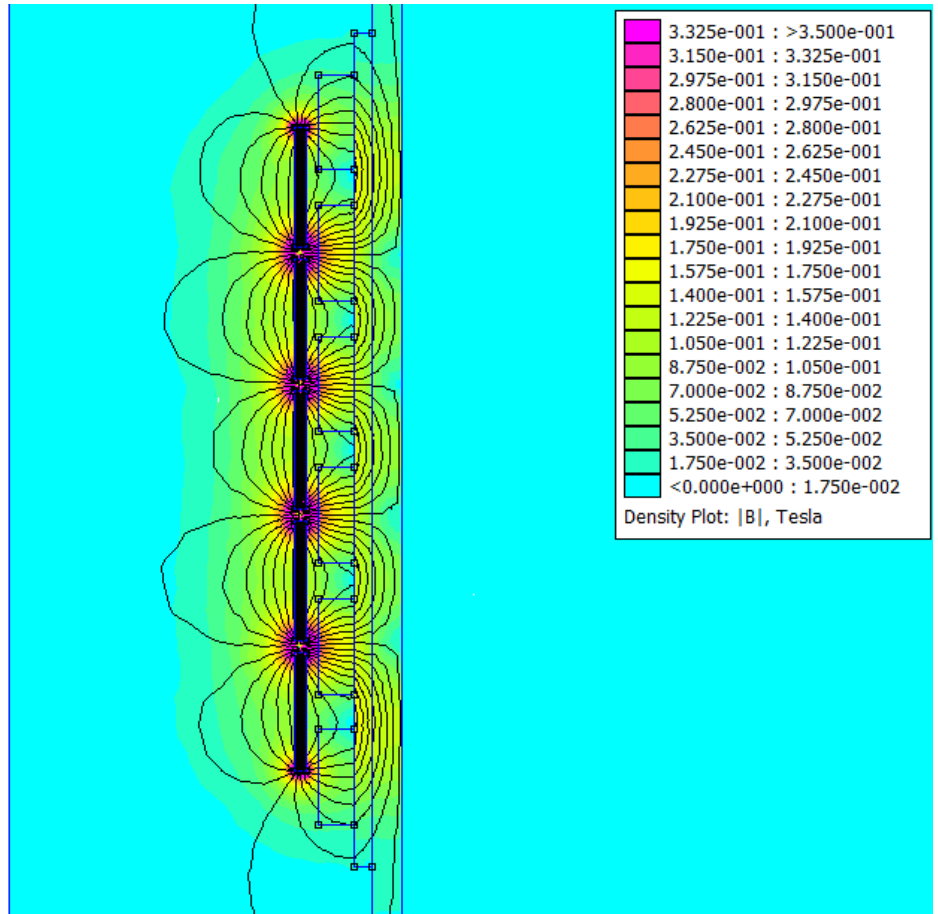

Figure 29: Air Core Alpha FEMM Flux Density Plot
A LUA script was written in FEMM which automates the measurement of normal flux through the area enclosed by each loop of wire. The coils were not excited for this measurement. A loop was written that moves the N32 permanent magnets (assigned as group 1 in the FEMM model) $15 \mathrm{~mm}$ from center to $+15 \mathrm{~mm}$ from center in $0.5 \mathrm{~mm}$ increments and the normal magnetic flux for each turn of copper wire was measured. The script creates a separate csv file for each position and each coil. Within each file is a matrix of normal flux values for each turn of copper wire, an 8x3 array for the alpha machine. The LUA script that was used can be found in Appendix 8.2. The LUA script also captures the flux density plot in BMP file format for each position. If desired, an animated GIF file can be made from these BMP files showing the changing magnetic flux.

A MATLAB script was written that loads the resulting data files and generates a single three dimensional matrix array $61 \times 8 \times 3$. Then a frequency was chosen $(73.75 \mathrm{~Hz}$ in this case to match the test data in Section 4.1.1.) The time was calculated for each data position point assuming a pure sinusoidal movement. A displacement amplitude of $26 \mathrm{~mm}$ was chosen, again to match the test data. The normal flux data from position -13 through 13 was used and the other values were ignored. The normal flux for every turn of each coil was summed together for the total flux linkage, then the "diff" function was used to differentiate this flux linkage with respect to time. The rate of change of flux linkage is equal to the voltage induced in the coil. This was done for each of the six individual coils and then the voltages of each were alternately added and subtracted to show the total series connected - no load generated voltage. The MATLAB script used can be found below in Appendix 8.3. Figure 30 shows the simulation calculated induced voltage for the series connected air core alpha machine operating at $26 \mathrm{~mm}$ of displacement and Figure 31 shows the harmonic spectrum for the same voltage. 
The wave shape somewhat matches the test data EMF as seen in Figure 20. The same extra two humps can be seen and this is caused by the displacement exceeding the pole pitch of $22 \mathrm{~mm}$. Notice that the simulated induced voltage is symmetrical and does not contain even harmonic components. The test results showed a 2 nd harmonic component of nearly $20 \%$ and an unevenness of the two smaller extra humps.

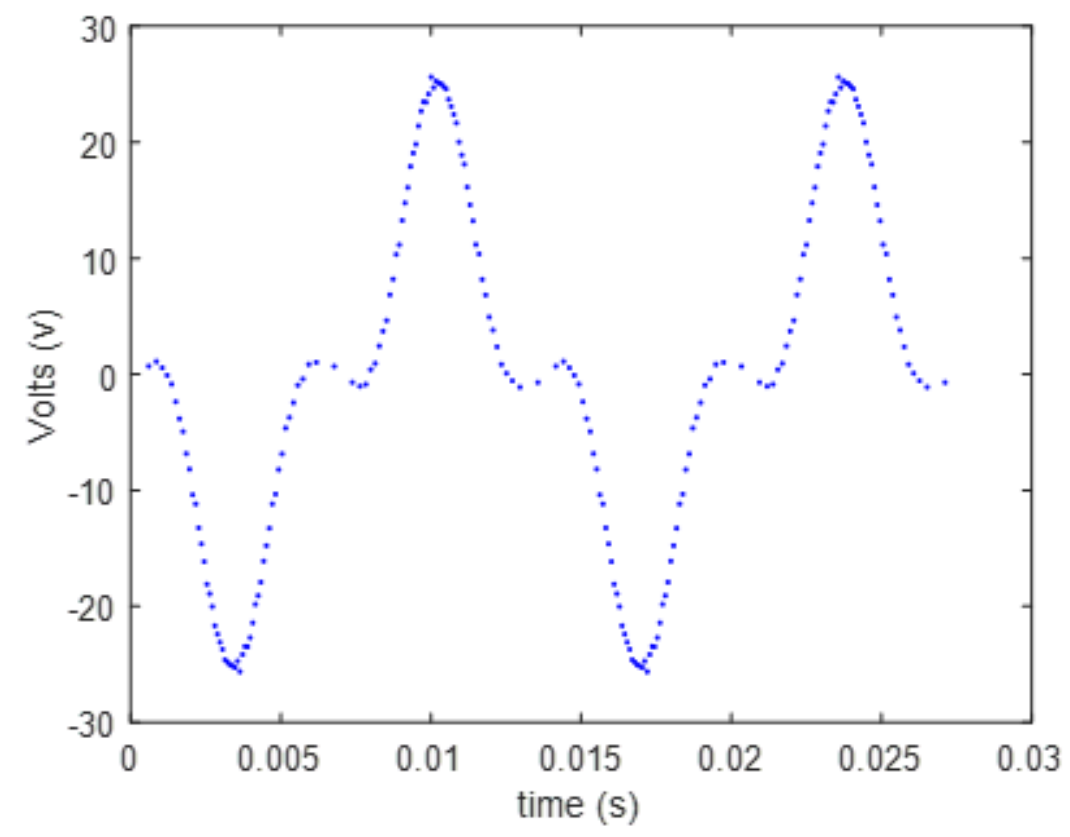

Figure 30: Alpha Air Core FEMM $\varepsilon_{G E N}(26 m m$ Disp., No offset, $73.75 \mathrm{~Hz}$ ) 


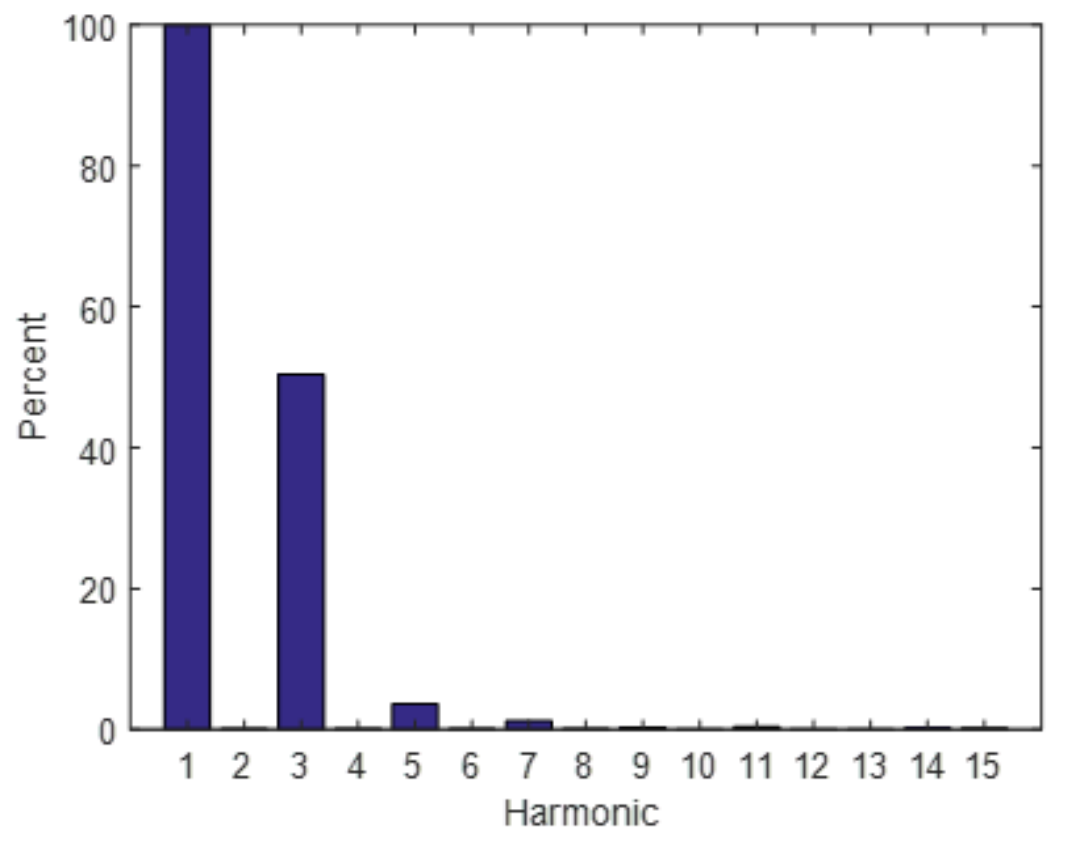

Figure 31: Alpha Air Core FEMM $\varepsilon_{G E N}$ FFT (26mm Disp., No offset, $73.75 \mathrm{~Hz}$ )

Additional simulations were performed to investigate what happens when an offset is introduced to the neutral position of the translator. A $1 \mathrm{~mm}$ offset was made and the previous simulation repeated. A $1 \mathrm{~mm}$ or $2 \mathrm{~mm}$ offset can easily happen due to assembly error as alignment is performed by trying to center the translator magnet poles to the center of the coils by sight. Figure 32 is the new induced voltage with a $1 \mathrm{~mm}$ offset and Figure 33 shows the harmonic distortion. The wave shape is very similar to that seen in Figure 20 that is based on test data. The TDH is slightly higher with an offset and even harmonics now appear with a second order harmonic of $14.6 \%$ 


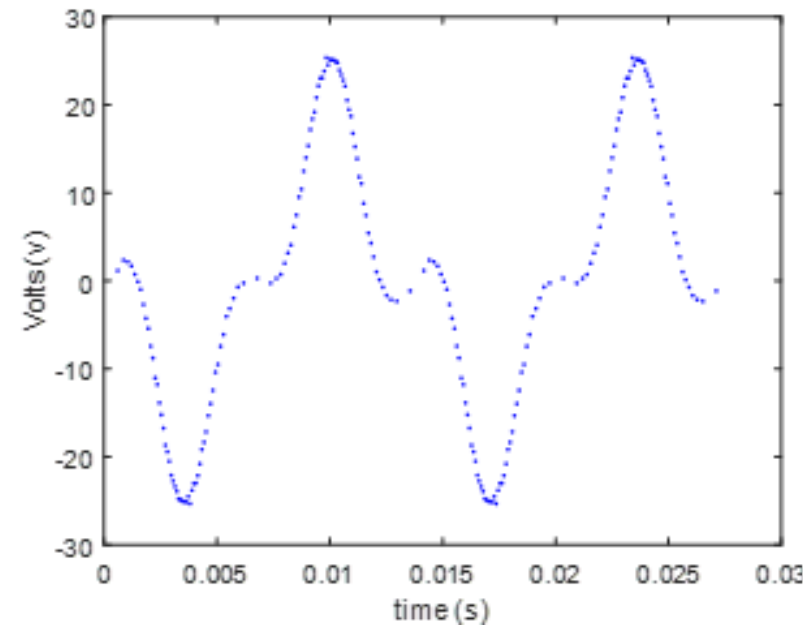

Figure 32: Alpha Air Core FEMM $\varepsilon_{G E N}$ (26mm Disp., $1 \mathrm{~mm}$ offset)

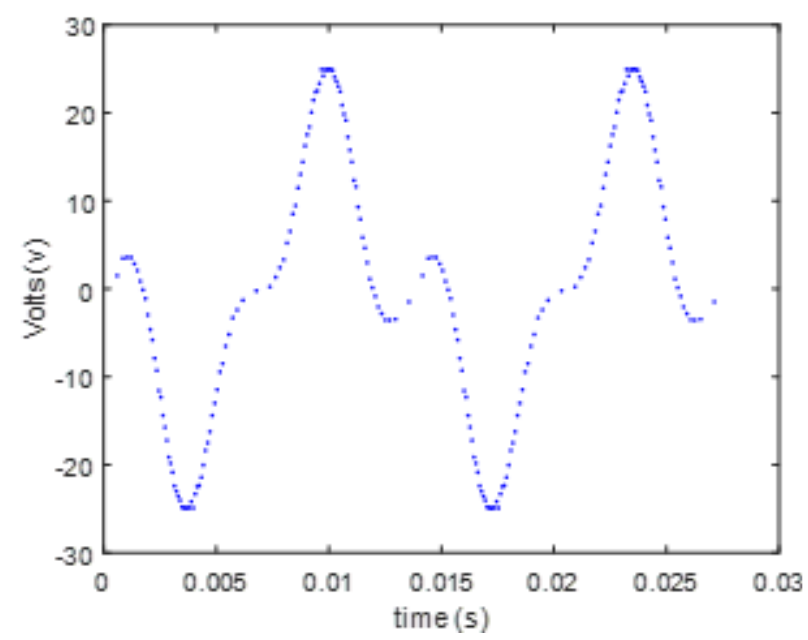

Figure 34: Alpha Air Core FEMM $\varepsilon_{G E N}$ (26mm Disp., 2mm offset)

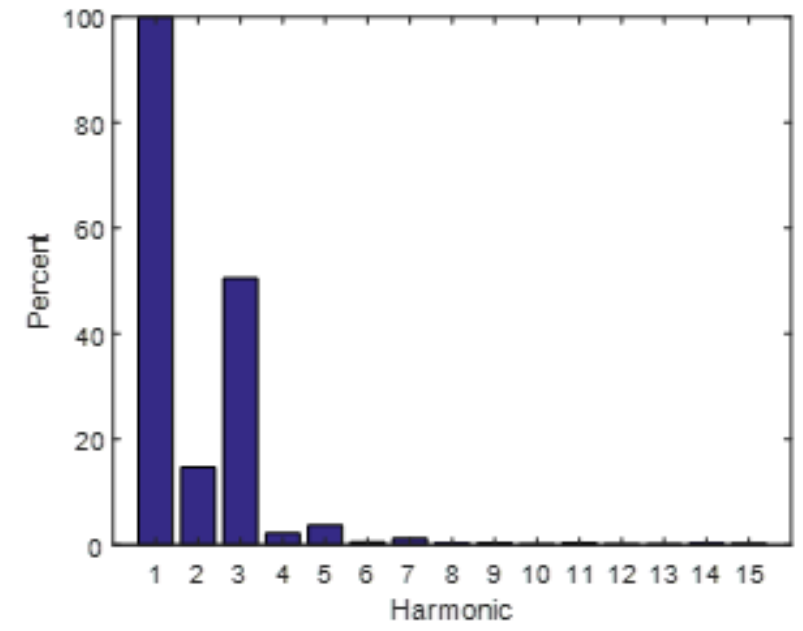

Figure 33: Alpha Air Core FEMM $\varepsilon_{G E N} F F T$ (26mm Disp., Imm offset)

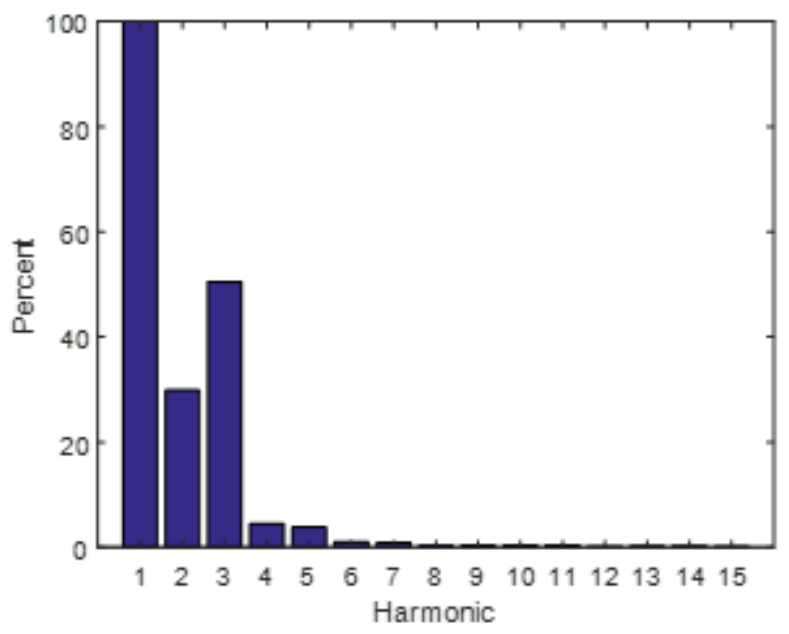

Figure 35: Alpha Air Core FEMM $\varepsilon_{G E N}$ FFT (26mm Disp., 2mm offset)

The same simulation was repeated with a $2 \mathrm{~mm}$ offset as well and similar results were found with an even slightly higher harmonic content and THD of 59\%.

Lastly the ideal case was simulated with a displacement of $22 \mathrm{~mm}$ perfectly centered and running at $90 \mathrm{~Hz}$ frequency. The peak voltage was nearly the same as the before. The reduced displacement and higher frequency was nearly a perfect tradeoff. Only a $3 \%$ increase in peak translator velocity was calculated for this case. A reduction in the third harmonic component 
$(33.3 \%)$ can be seen as compared to the $26 \mathrm{~mm}$ case. The $5^{\text {th }}$ and $7^{\text {th }}$ harmonics are $1.1 \%$ and $0.5 \%$ respectively. The voltage THD is $33.4 \%$

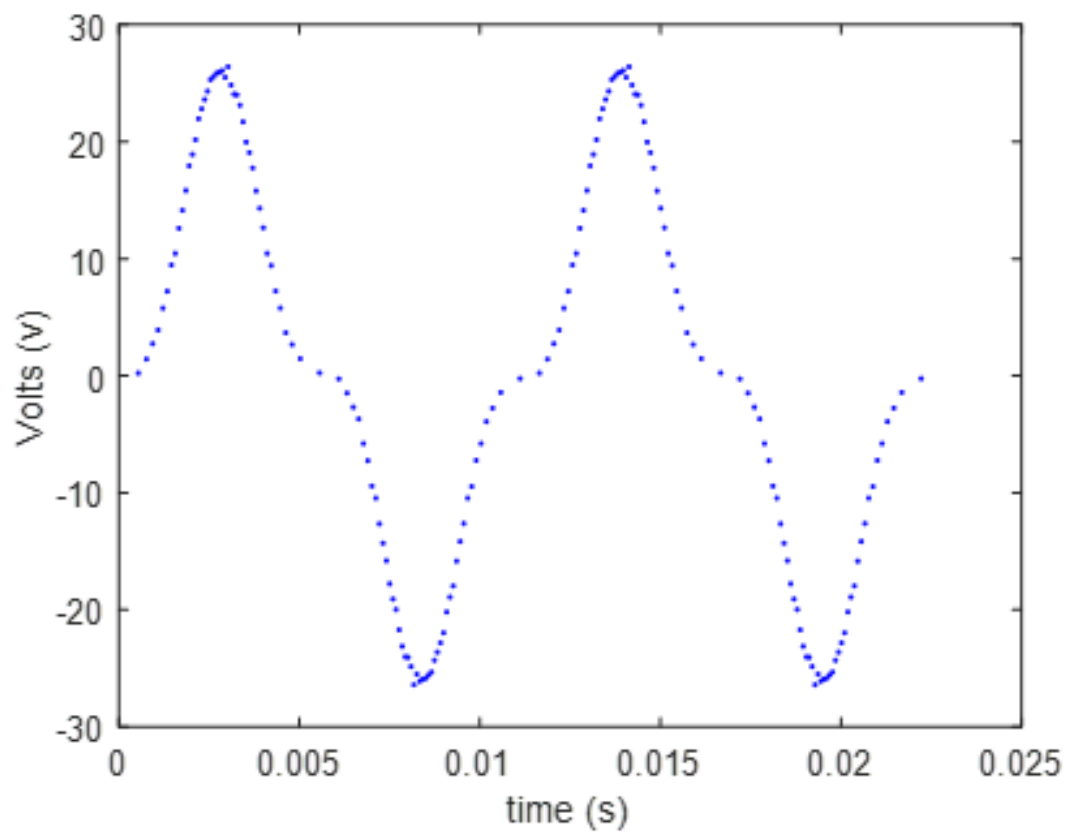

Figure 36: Alpha Air Core FEMM $\varepsilon_{G E N}(22 m m$ Disp., No offset, $90 \mathrm{~Hz})$

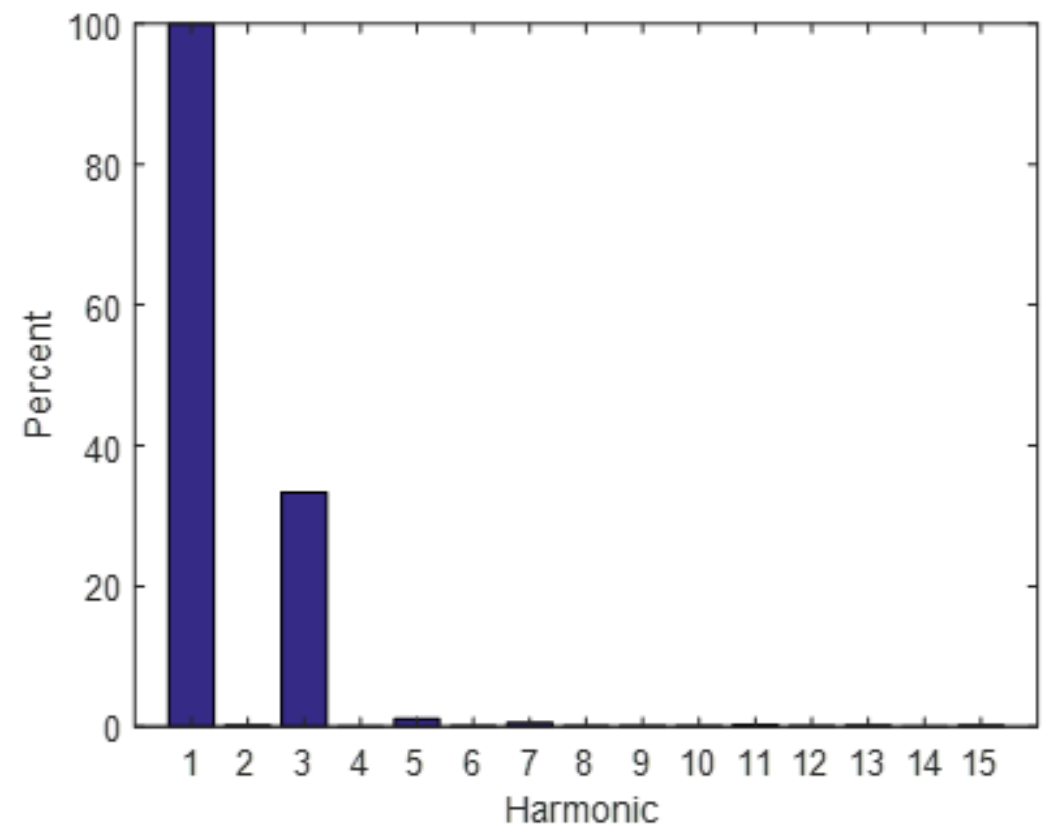

Figure 37: Alpha Air Core FEMM $\varepsilon_{G E N}$ FFT (22mm Disp., No offset)

The FEMM model was slightly modified by adding 1 amp of current to the series connected coils and the translator was set to the zero (centered) position. The flux linkage was viewed directly 
with the result circuit properties button. The flux linkage was found to be 0.000417342 Webers. The N35 magnets in the model were changed to air in the model and the flux linkage again measured for a verification check. The flux linkage was found to be 0.000407177 Webers. There is a slight difference which could be attributed to two causes. The first is that the relative permeability of $\mathrm{N} 35$ magnetic material is $\mu_{\mathrm{r}} \approx 1.05$ and this would increase the magnetic flux. The second is there may be a slight error introduced in the calculation due to the discretization of the finite element model. Nevertheless, the difference is small and the value of 0.000417342 Webers/Amp nearly matches perfectly the measured inductance of the air core stator of $4.25 \mathrm{mH}$.

Next a FEMM LUA script was used to measure the flux linkage of the series connected windings from $-15 \mathrm{~mm}$ to $15 \mathrm{~mm}$ every $0.5 \mathrm{~mm}$. The command "mo_getcircuitproperties("CoilCircuits")" was used and a file was generated that contained the flux linkage at every position. This flux linkage vs translator position was plotted below in Figure 38. As can be expected, the flux linkage is maximum and minimum at the $-11 \mathrm{~mm}$ and $11 \mathrm{~mm}$ points. The flux linkage $(\lambda)$ varies nearly sinusoidal with position. If desired, the first derivative of this curve with respect to position can also be used to calculate induced EMF by using the below equation.

$$
\varepsilon_{G E N}=\frac{d \lambda}{d t}=\frac{d \lambda}{d x} \cdot \frac{d x}{d t}
$$

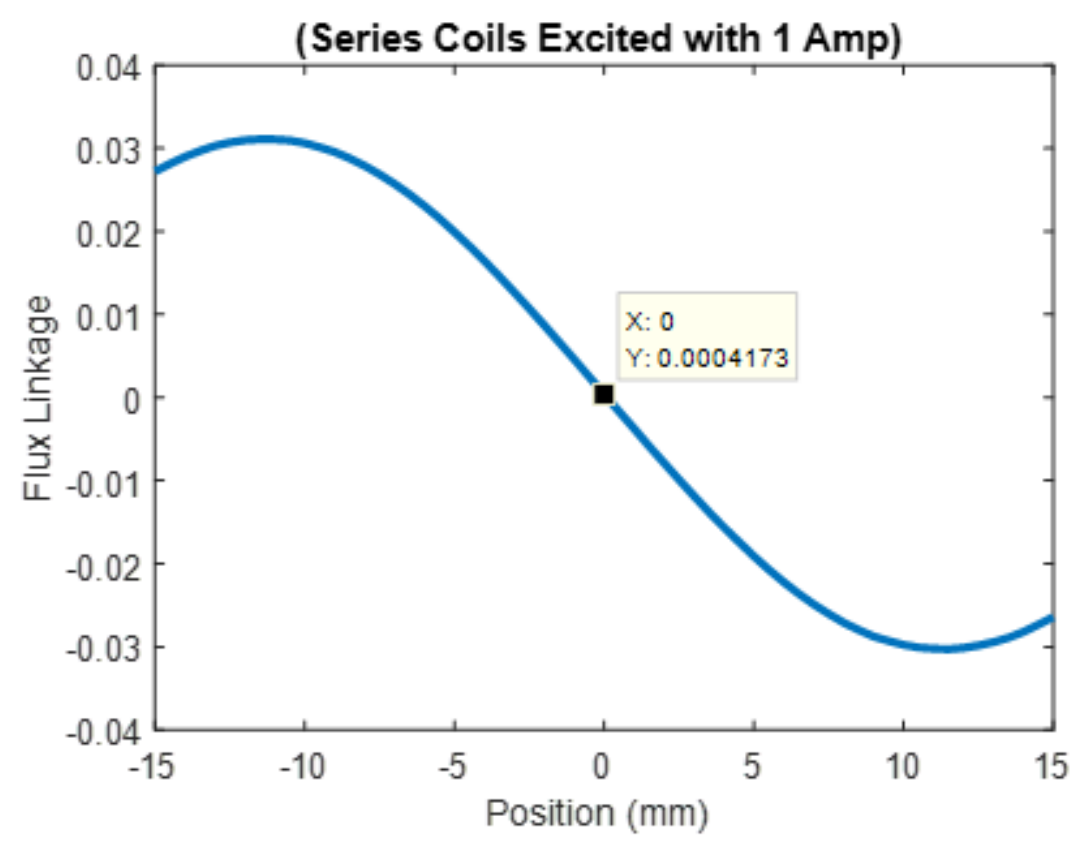

Figure 38: Air Core Alpha Flux Linkage vs Translator Position

The airgap normal flux density was plotted with FEMM using the line plot command at a distance of $0.5 \mathrm{~mm}$ above the translator drum magnets. Measured samples were also taken every 
$1 \mathrm{~mm}$ for a distance of half the drum using a HIRST GM08 gauss meter. Figure 39 below shows the plot and the measured samples. As can be seen, the measured peak flux density is slightly lower and may account for the discrepancy in the measured versus simulated performance.

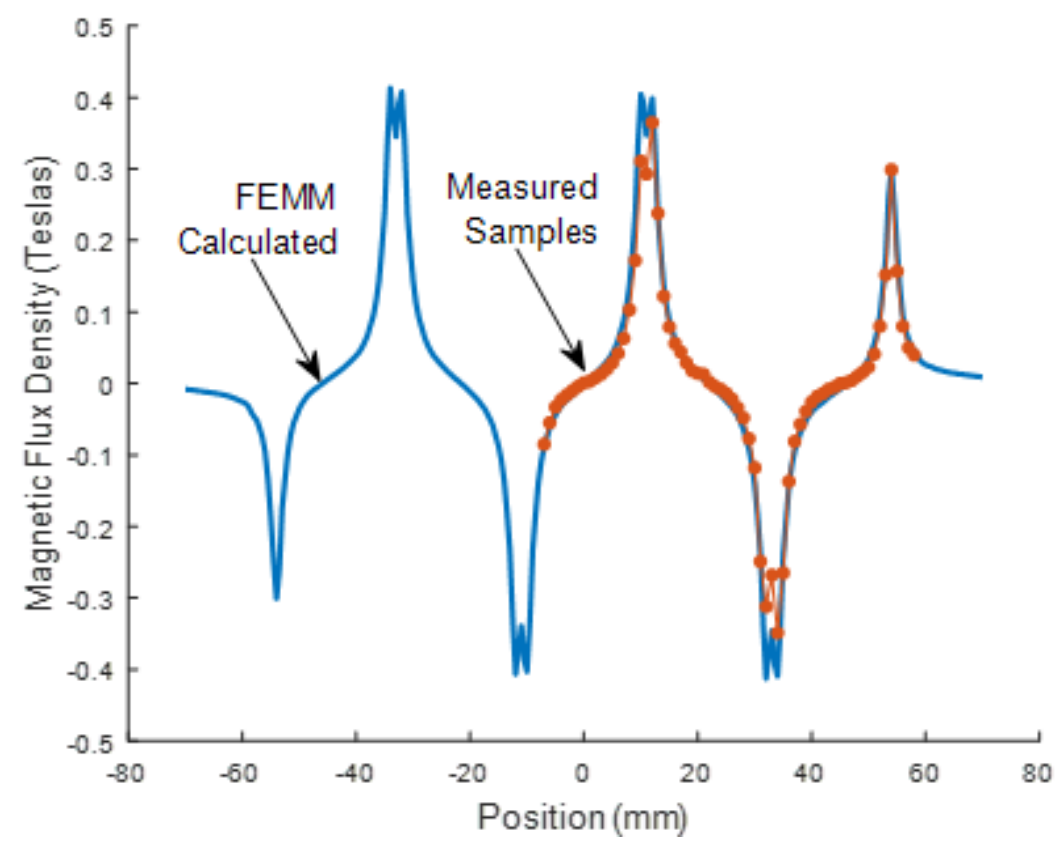

Figure 39: Air Core Alpha Airgap Normal Flux Density

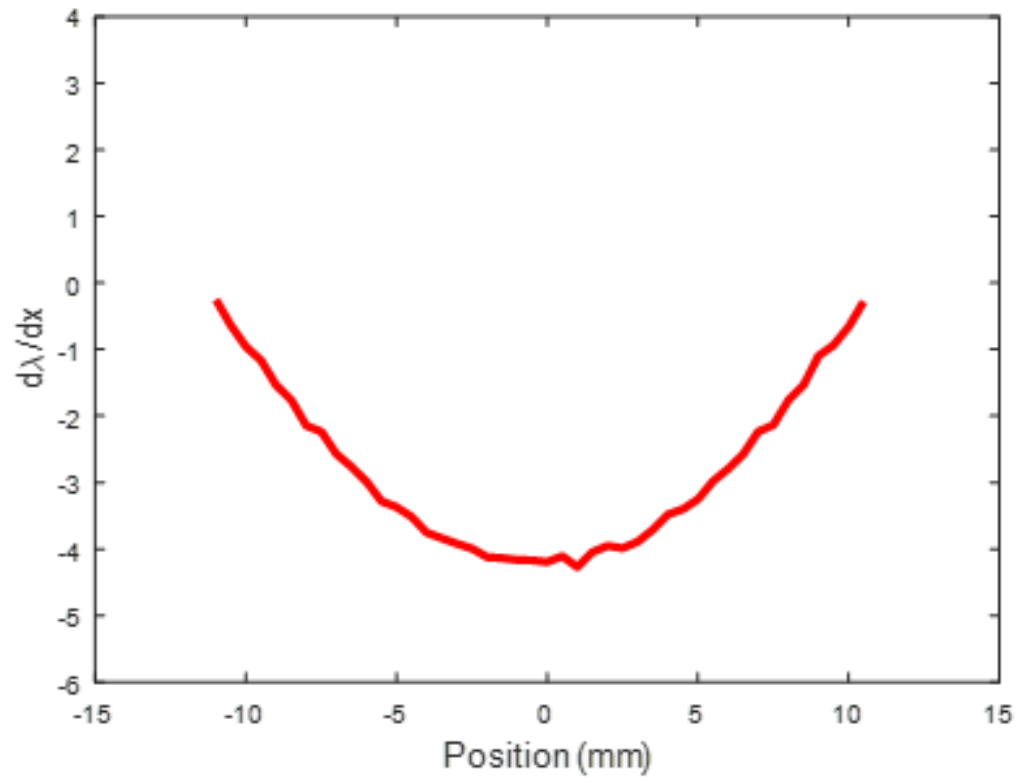

Figure 40: Rate of Change of Flux Linkage vs Displacement 
The rate of change of flux linkage over displacement is shown in Figure 40. The relationship between force and rate of change of flux linkage can be described by the below equation.

$$
f_{e}=i * \frac{\partial \lambda(i, x)}{\partial x}-\frac{\partial W_{f}(i, x)}{\partial x}[21]
$$

The air core stator does not undergo a change in field energy $\left(\mathrm{W}_{\mathrm{f}}\right)$ over displacement and that term becomes zero. The rate of change of flux linkage over displacement is therefore equivalent to force per ampere for the air core stator and can be compared to the measured force versus displacement plot (Figure 24). The simulation resulted in a slightly larger force than that found by measurement.

\subsubsection{Air Core Alpha Simulation Results Summary}

The air core alpha machine FEMM model and MATLAB analysis can nearly perfectly recreate the wave shape from the test data however the voltage actually produced is about $12 \%$ lower than what is simulated $(22 \mathrm{~V}$ peak vs $25 \mathrm{~V}$ peak). The magnets on the translator drums being made of arc segments instead of complete rings may be one factor. The other is the magnetic material may not be as strong as the magnet in the model library which. It is shown that an offset in the translator's position relative to the coil centers can greatly increase the harmonic distortion of the produced voltage. Tabulated results are shown in Table 7 below.

\begin{tabular}{|l|l|l|l|l|}
\hline & FEMM & Measured & & \\
\hline $\begin{array}{l}\text { Stator } \\
\text { Resistance }(\Omega)\end{array}$ & 0.267895 & 0.273 & & \\
\hline $\begin{array}{l}\text { Stator } \\
\text { Inductance }(\mathrm{mH})\end{array}$ & 0.417342 & 0.425 & & \\
\hline & & & & \\
\hline & Case 1 & Case 2 & Case 3 & Case 4 \\
\hline Displacement & 26 & 26 & 26 & 22 \\
\hline Offset (mm) & 0 & 1 & 2 & 0 \\
\hline Frequency & 73.75 & 73.75 & 73.75 & 90 \\
\hline THD \% & 50.51 & 52.69 & 58.99 & 33.37 \\
\hline VRMS & 13.1166 & 13.1049 & 13.0689 & 14.5280 \\
\hline Vpk & 25.62 & 25.35 & 24.97 & 26.40 \\
\hline $1^{\text {st }}$ Amplitude & 16.5468 & 16.3824 & 15.9012 & 19.4762 \\
\hline $1^{\text {st }}$ Angle & 1.8301 & 1.8301 & 1.8301 & -1.3088 \\
\hline $2^{\text {nd }}$ Amplitude & 0.0144 & 2.3927 & 4.7452 & 0.0329 \\
\hline $2^{\text {nd }}$ Angle & 1.9002 & -1.1170 & -1.1156 & -1.1823 \\
\hline $3^{\text {rd }}$ Amplitude & 8.3332 & 8.2604 & 8.0325 & 6.4940 \\
\hline $3^{\text {rd }}$ Angle & -0.8192 & -0.8195 & -0.8194 & 2.4186 \\
\hline
\end{tabular}




\begin{tabular}{|l|l|l|l|l|}
\hline $4^{\text {th }}$ Amplitude & 0.0168 & 0.3483 & 0.7194 & 0.0029 \\
\hline $4^{\text {th }}$ Angle & -0.7776 & 2.9105 & 2.8786 & 1.1433 \\
\hline $5^{\text {th }}$ Amplitude & 0.6007 & 0.6032 & 0.6085 & 0.2161 \\
\hline $5^{\text {th }}$ Angle & -3.0782 & -3.0790 & -3.0949 & 0.1133 \\
\hline $6^{\text {th }}$ Amplitude & 0.0088 & 0.0773 & 0.1612 & 0.0101 \\
\hline $6^{\text {th }}$ Angle & -0.2605 & -2.4336 & -2.5648 & 2.8573 \\
\hline $7^{\text {th }}$ Amplitude & 0.2013 & 0.1884 & 0.1389 & 0.1106 \\
\hline $7^{\text {th }}$ Angle & -2.4890 & -2.4447 & -2.3201 & 0.5635 \\
\hline $8^{\text {th }}$ Amplitude & 0.0106 & 0.0424 & 0.0509 & 0.0118 \\
\hline $8^{\text {th }}$ Angle & -2.5401 & -0.1054 & -0.3953 & -2.9101 \\
\hline $9^{\text {th }}$ Amplitude & 0.0398 & 0.0455 & 0.0563 & 0.0211 \\
\hline $9^{\text {th }}$ Angle & -1.1451 & -1.2525 & -1.8177 & 2.6946 \\
\hline $10^{\text {th }}$ Amplitude & 0.0044 & 0.0201 & 0.0540 & 0.0233 \\
\hline $10^{\text {th }}$ Angle & -1.7307 & -2.0518 & -2.0887 & -2.0421 \\
\hline $11^{\text {th }}$ Amplitude & 0.0606 & 0.0550 & 0.0637 & 0.0601 \\
\hline $11^{\text {th }}$ Angle & -1.6150 & -1.5098 & -1.7910 & 1.9878 \\
\hline $12^{\text {th }}$ Amplitude & 0.0058 & 0.0161 & 0.0232 & 0.0164 \\
\hline $12^{\text {th }}$ Angle & 0.7367 & 3.1135 & 3.0058 & 1.6886 \\
\hline $13^{\text {th }}$ Amplitude & 0.0030 & 0.0068 & 0.0361 & 0.0335 \\
\hline $13^{\text {th }}$ Angle & 0.8573 & 0.5786 & -1.4471 & -2.3918 \\
\hline $14^{\text {th }}$ Amplitude & 0.0377 & 0.0419 & 0.0477 & 0.0093 \\
\hline $14^{\text {th }}$ Angle & 1.9576 & -1.6859 & -1.8162 & 1.9107 \\
\hline $15^{\text {th }}$ Amplitude & 0.0315 & 0.0361 & 0.0136 & 0.0308 \\
\hline $15^{\text {th }}$ Angle & -0.8837 & -0.7874 & 2.3194 & -1.6213 \\
\hline
\end{tabular}

Table 7: Air Core Alpha Simulation Tabulated Summary

To determine terminal voltage and load current, superposition can be used to evaluate the machine's equivalent circuit at each harmonic frequency. Complex voltages and currents can be converted to sinusoids in the time domain and added for each harmonic component.

Figure 41 shows a side by side comparison of simulation terminal voltage and current with actual test data. For the comparison, the generated emf was reduced $12 \%$ before terminal voltages and current were calculated. A load inductance of $80 \mathrm{uH}$ was also added to the simulated load due to the appearance of a lagging current in the test data. Although not measured, the wire-wound resistors would have some inherent inductance. The comparison of voltage magnitude and shape are nearly equal. The current magnitude of the test data is somewhat lower and this may be due to some unaccounted added resistance of connecting wires and twist-on wire connectors that were used in the test setup. Overall a very close match. 


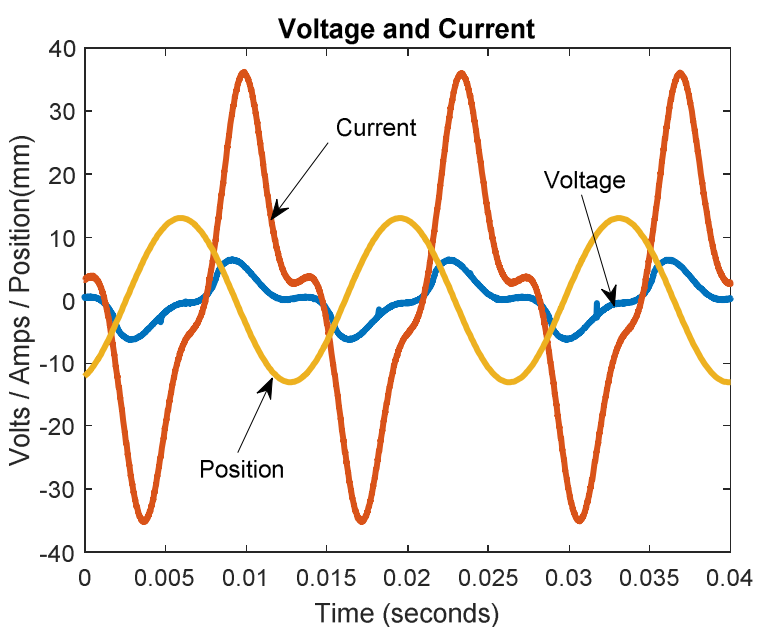

Aircore Alpha Terminal Voltage and Current $0.0940 \mathrm{hm}$ load

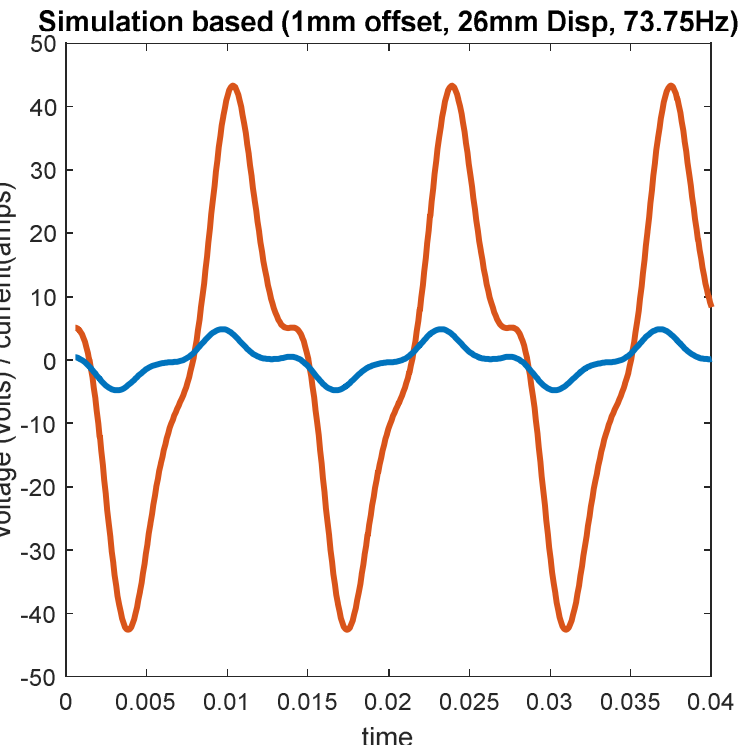

Figure 41: Test Data (left) vs Simulation Results (right) Alpha Air Core

\subsection{Iron Core Alpha Machine}

The alpha iron core machine was tested using the same test setup as seen in Figure 16 and using the same titanium flexure springs. Two load stages were able to be ran and average load power, RMS current, and RMS voltage was able to be recorded. No instantaneous waveforms were captured with the titanium flexures. Later, the flexure springs were changed to a stiffer design in hopes to increase the resonant frequency. A higher frequency increases output voltage proportionally therefore allowing an increase in output power. Instantaneous open circuit data were captured but load data were not able to be captured as the engine could not sustain operation long enough to capture data.

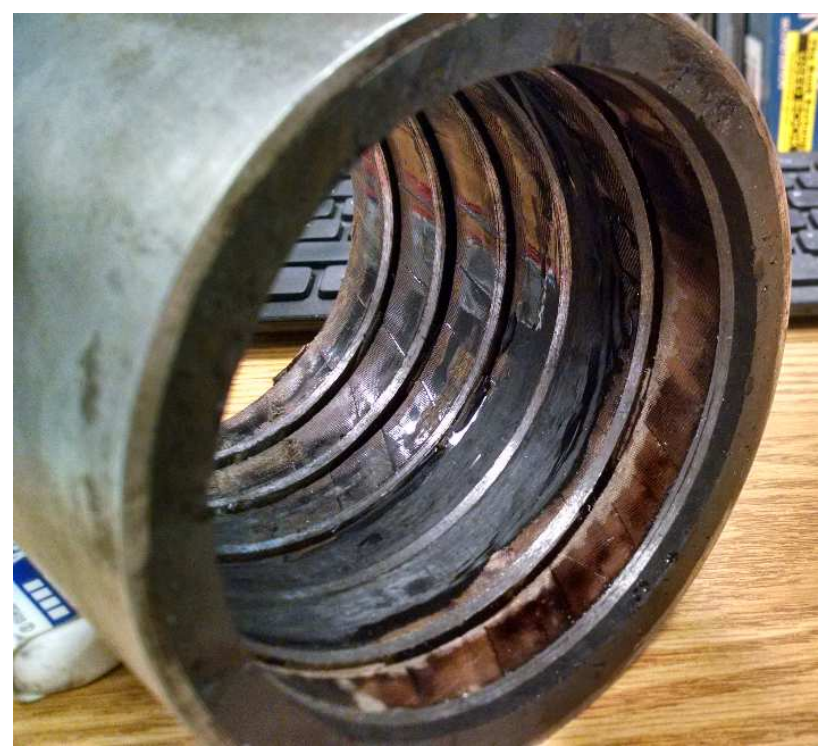

Figure 42: Disassembled Iron core Alpha Stator with back iron 


\subsubsection{Iron Core Alpha Test Data}

The basic parameters of the iron core alpha machine using the titanium flexures are listed below. The stator resistance and inductance values were later used for more detailed analysis to follow.

- 8 Titanium springs

- $2 \mathrm{~mm}$ thick N35 magnets on translator drum

- Frequency $-74 \mathrm{~Hz}$ (Although this can vary with displacement due to the flexures being slightly non-linear)

- Stroke Length $22 \mathrm{~mm}$ (for starting, up to $26-27 \mathrm{~mm}$ when running.)

- 24 turns per coil, 6 coils series connected.

- Resistance of stator windings $\mathrm{R}_{\mathrm{a}}$ (series connected) $-0.273 \Omega$

- Inductance of stator $-0.75 \mathrm{mH}$ (as measured.)

As stated above, only two load stages were able to be achieved. A maximum power of nearly 159 watts was able to be sourced to the load bank. According to the maximum power transfer theorem, the maximum power that could be sourced to the load is 294 watts.

\begin{tabular}{|r|r|r|r|r|r|}
\hline Switch & \multicolumn{1}{l|l}{$\begin{array}{l}\text { Load } \\
\text { Resistance }\end{array}$} & \multicolumn{1}{l|}{$\begin{array}{l}\text { Voltage } \\
\mathrm{V}_{\mathrm{L}}\end{array}$} & \multicolumn{1}{l|}{$\begin{array}{l}\text { Current } \\
\mathrm{I}_{\mathrm{L}}\end{array}$} & \multicolumn{1}{l|}{$\begin{array}{l}\text { Frequency } \\
(\mathrm{Hz})\end{array}$} \\
\hline $\mathrm{S} 1$ & 1.125 & 15.63 & 8.736 & 127.3 & 71.10 \\
\hline $\mathrm{S} 1+\mathrm{S} 2$ & 0.84375 & 15.31 & 11.165 & 158.9 & 75.23 \\
\hline
\end{tabular}

Table 8: Iron Core Alpha (Titanium Flexures) Load Data 


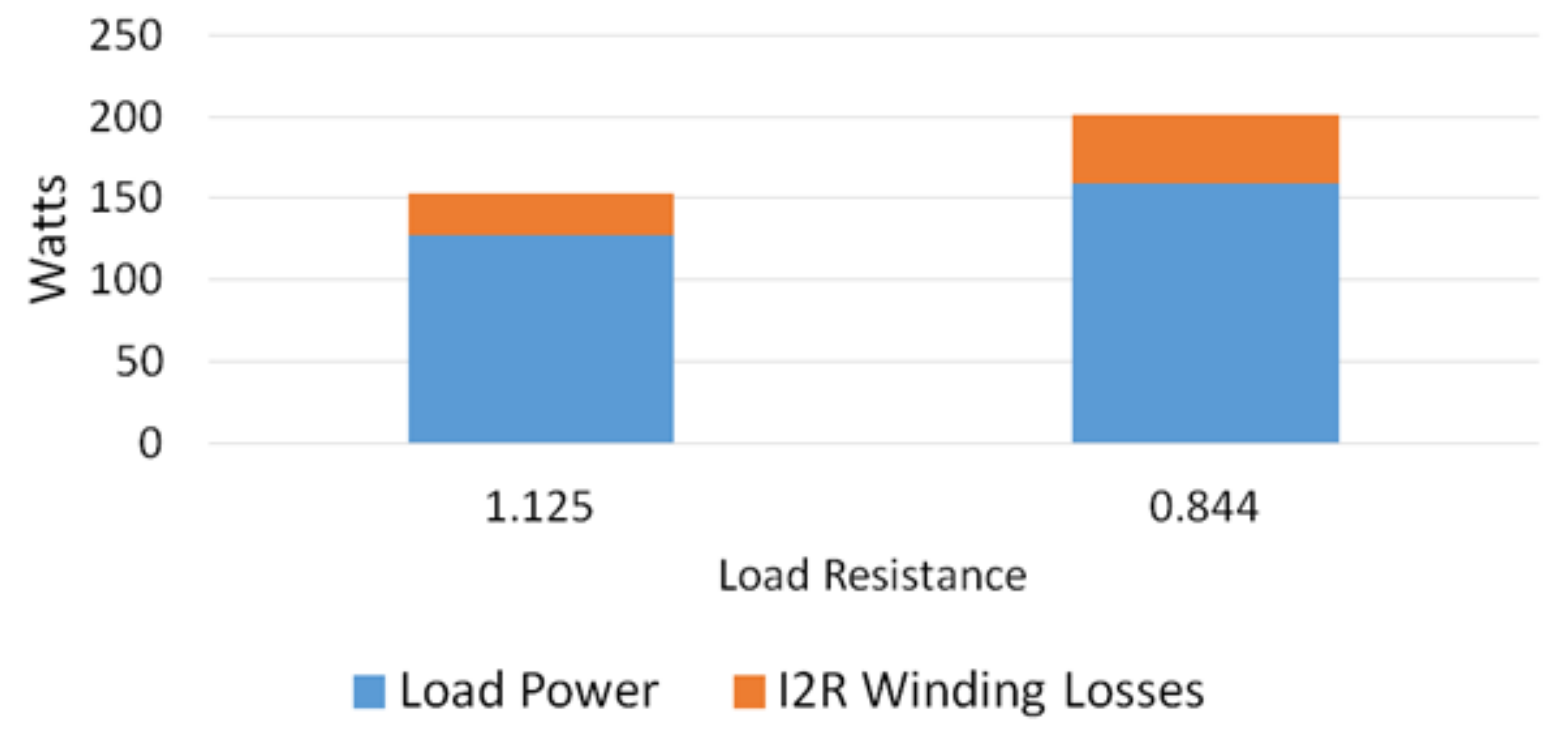

Figure 43: Iron Core Alpha (Titanium Flexures) Load Data

\begin{tabular}{|c|c|c|}
\hline Switch & $\varepsilon_{\mathrm{GEN}}($ Calculated $)$ & $\begin{array}{l}\text { P } \\
\text { (Coss } \\
\text { Calculated) }\end{array}$ \\
\hline S1 & 19.748 & 25.948 \\
\hline $\mathrm{S} 1+\mathrm{S} 2$ & 21.107 & 42.383 \\
\hline
\end{tabular}

Table 9: Calculated Iron Core Alpha (Titanium Flexures) $\varepsilon_{G E N}$ and Winding Losses during load

The iron core alpha machine with Sandvik flexures was then tested and open circuit voltage and position data were recorded. The frequency of the iron core machine was $83.25 \mathrm{~Hz}$ because the Sandvik steel flexures were stiffer than the titanium flexures. Only open circuit voltage was able to be captured with the Sandvik springs. Each time an electrical load was added to the alternator, the engine could not produce enough power to sustain combustion. Therefore load data were not able to be captured at this frequency for the iron core alpha machine.

The basic parameters of the iron core alpha machine with Sandvik flexures are listed below. The stator resistance and inductance values were later used for more detailed analysis to follow.

- 8 Sandvik Steel (4arm) springs

- $2 \mathrm{~mm}$ thick N35 magnets on translator drum

- Frequency $-83.25 \mathrm{~Hz}$ (Although this can vary with displacement due to the flexures being slightly non-linear)

- Stroke Length $22 \mathrm{~mm}$

- 24 turns per coil, 6 coils series connected.

- Resistance of stator windings $\mathrm{R}_{\mathrm{a}}$ (series connected) $-0.273 \Omega$ 
- Inductance of stator $-0.75 \mathrm{mH}$ (as measured.)

The instantaneous open circuit voltage and position is shown in Figure 44 below for the iron core machine operating at nearly $22 \mathrm{~mm}$ displacement. The voltage THD (30.37\%) is lower for the iron core machine than that of the air core machine $(44.83 \%)$. As with the air core machine, this waveform also shows a $2^{\text {nd }}$ harmonic component indicating a mechanical offset. The position waveform is again nearly pure sinusoidal. The additional cogging force (magnetic attraction force) of the iron poles did not create any recordable distortion of the sinusoidal motion of the translator.

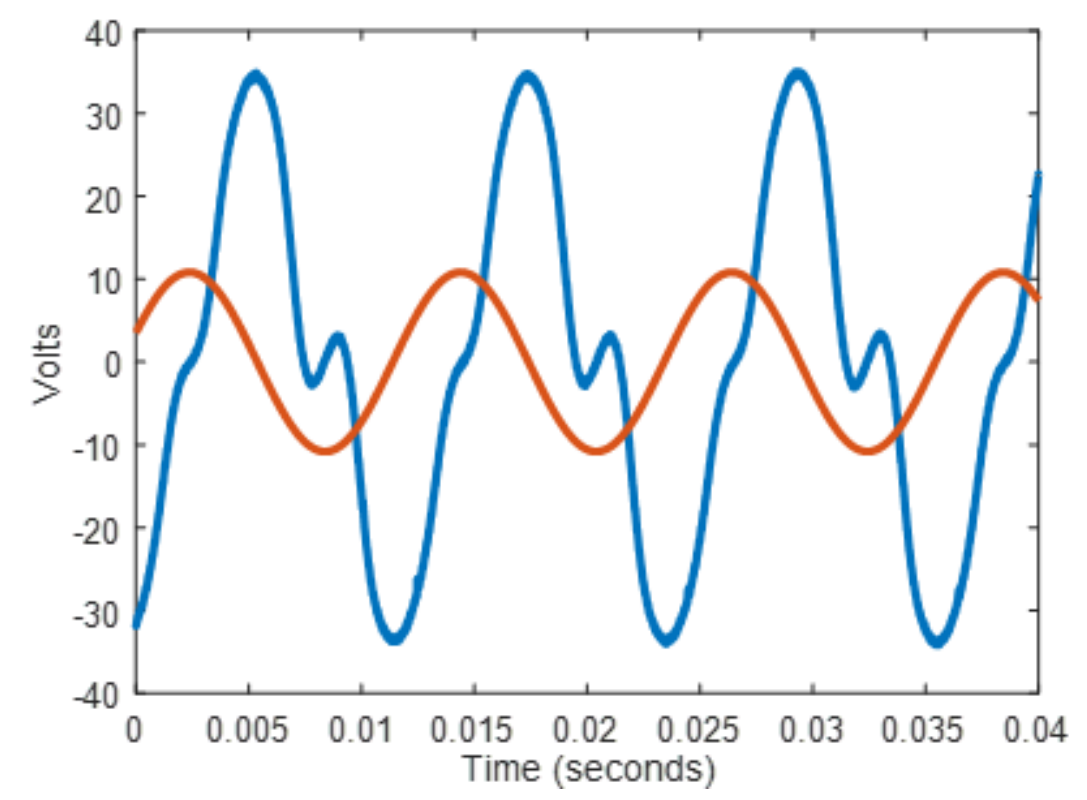

Figure 44: Iron Core Alpha Open Circuit Test Voltage (83.25Hz) 


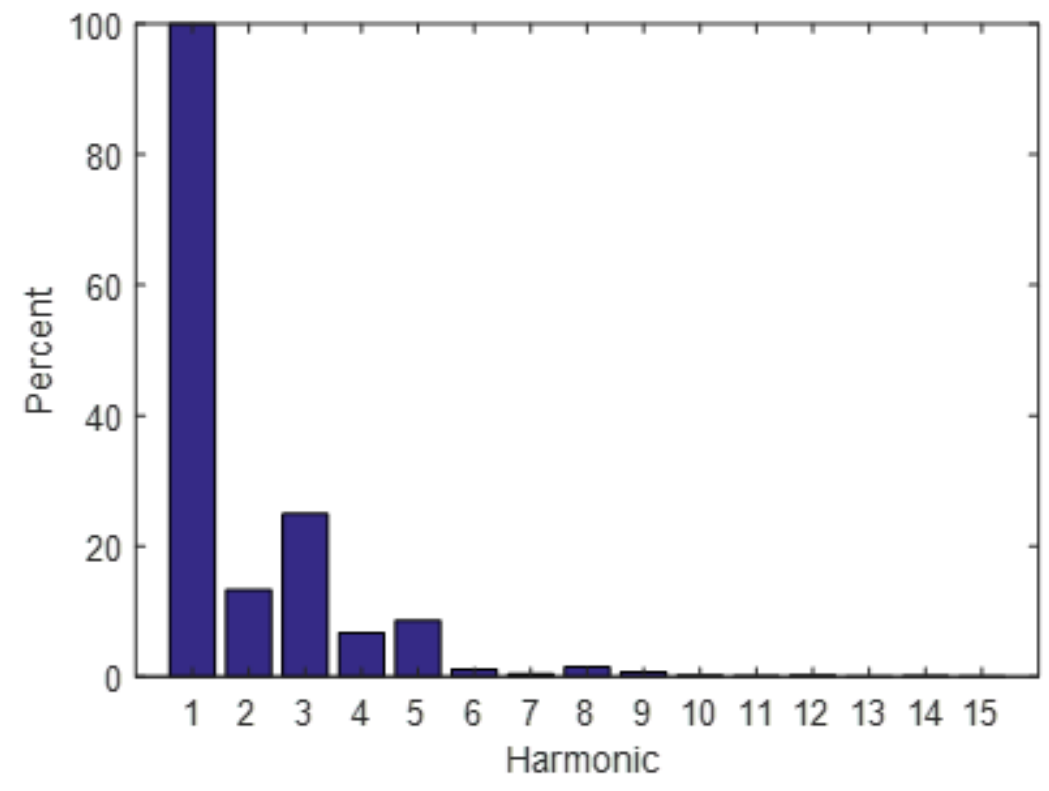

Figure 45: Iron Core Alpha Open Circuit Test Data FFT (83.25Hz)

\begin{tabular}{|l|l|}
\hline Stator & 0.267895 \\
Resistance $(\Omega)$ & 0.273 (measured) \\
\hline Stator & 0.730006 \\
Inductance $(\mathrm{mH})$ & 0.75 (measured) \\
\hline & Open Circuit \\
\hline & Test 1 \\
\hline Displacement & 21.64 \\
\hline Offset $(\mathrm{mm})$ & \\
\hline Frequency & 83.25 \\
\hline THD $\%$ & 30.37 \\
\hline VRMS & 21.56 \\
\hline Vpk & 35.03 \\
\hline $1^{\text {st }}$ Amplitude & 29.1993 \\
\hline $1^{\text {st }}$ Angle & -2.8440 \\
\hline $2^{\text {nd }}$ Amplitude & 3.8821 \\
\hline $2^{\text {nd }}$ Angle & 2.0824 \\
\hline $3^{\text {rd }}$ Amplitude & 7.2817 \\
\hline $3^{\text {rd }}$ Angle & -2.1939 \\
\hline $4^{\text {th }}$ Amplitude & 1.9639 \\
\hline $4^{\text {th }}$ Angle & -0.3089 \\
\hline $5^{\text {th }}$ Amplitude & 2.5163 \\
\hline $5^{\text {th }}$ Angle & 1.4886 \\
\hline $6^{\text {th }}$ Amplitude & 0.3284 \\
\hline
\end{tabular}




\begin{tabular}{|l|l|}
\hline $6^{\text {th }}$ Angle & 0.1098 \\
\hline $7^{\text {th }}$ Amplitude & 0.1103 \\
\hline $7^{\text {th }}$ Angle & 3.0139 \\
\hline $8^{\text {th }}$ Amplitude & 0.4265 \\
\hline $8^{\text {th }}$ Angle & -2.3800 \\
\hline $9^{\text {th }}$ Amplitude & 0.2132 \\
\hline $9^{\text {th }}$ Angle & -0.3703 \\
\hline $10^{\text {th }}$ Amplitude & 0.0574 \\
\hline $10^{\text {th }}$ Angle & -1.4397 \\
\hline $11^{\text {th }}$ Amplitude & 0.0167 \\
\hline $11^{\text {th }}$ Angle & 1.4280 \\
\hline $12^{\text {th }}$ Amplitude & 0.0530 \\
\hline $12^{\text {th }}$ Angle & 1.8705 \\
\hline $13^{\text {th }}$ Amplitude & 0.0123 \\
\hline $13^{\text {th }}$ Angle & -1.9771 \\
\hline $14^{\text {th }}$ Amplitude & 0.0188 \\
\hline $14^{\text {th }}$ Angle & 2.9141 \\
\hline $15^{\text {th }}$ Amplitude & 0.0057 \\
\hline $15^{\text {th }}$ Angle & 1.4044 \\
\hline
\end{tabular}

Table 10: Iron Core Alpha Test Result Summary 


\subsubsection{Iron Core Alpha Simulation}

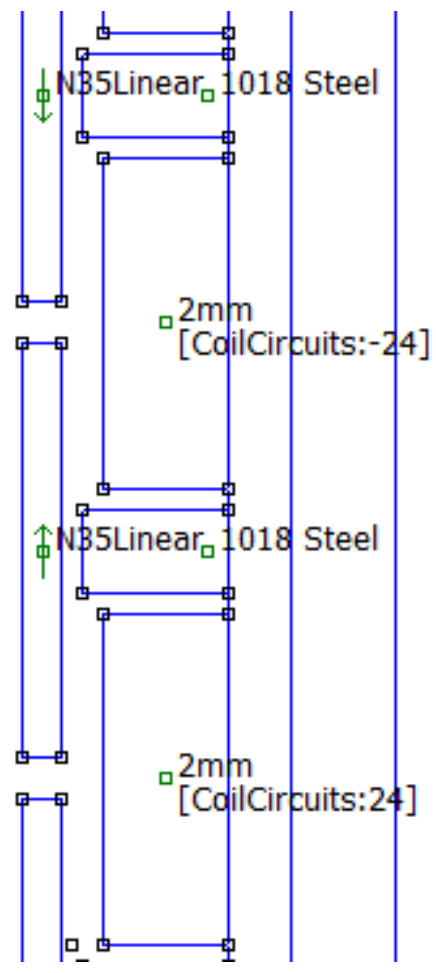

Figure 46: Iron Core Alpha FEMM Model - Iron Pole Detail
For the iron core simulation, the FEMM air core model was modified by adding a $4 \mathrm{~mm}$ wide iron pole between every coil and also to the two outside coils. A $1 \mathrm{~mm}$ gap was left between the magnets and iron poles. The same LUA script was ran as that for the air core machine and magnetic flux was recorded for each turn of copper wire with the translator at $-15 \mathrm{~mm}$ to $15 \mathrm{~mm}$ in $0.5 \mathrm{~mm}$ increments.

The same MATLAB code used above in the air core simulation was also used however the frequency was increased to $83.25 \mathrm{~Hz}$ to match the available test data.

The total flux linkage was recorded for each position and can be seen in Figure 47. The flux linkage over displacement is almost triangular in shape and only within about $3 \mathrm{~mm}$ of the pole positions is there rounding of the waveform. If we consider the equation:

$\varepsilon_{G E N}=\frac{d \lambda}{d t}=\frac{d \lambda}{d x} \cdot \frac{d x}{d t}$

it can be seen that induced voltage is the product of the rate of change of flux linkage with respect to displacement multiplied by velocity. If the translator is oscillating in a sinusoidal motion in the region where $d \lambda / d x$ is linear, the output voltage waveform will be sinusoidal without harmonics. As displacement amplitude increases and approaches the poles, the rate of change of flux linkage will no longer be linear with position and harmonic distortion will become apparent. 


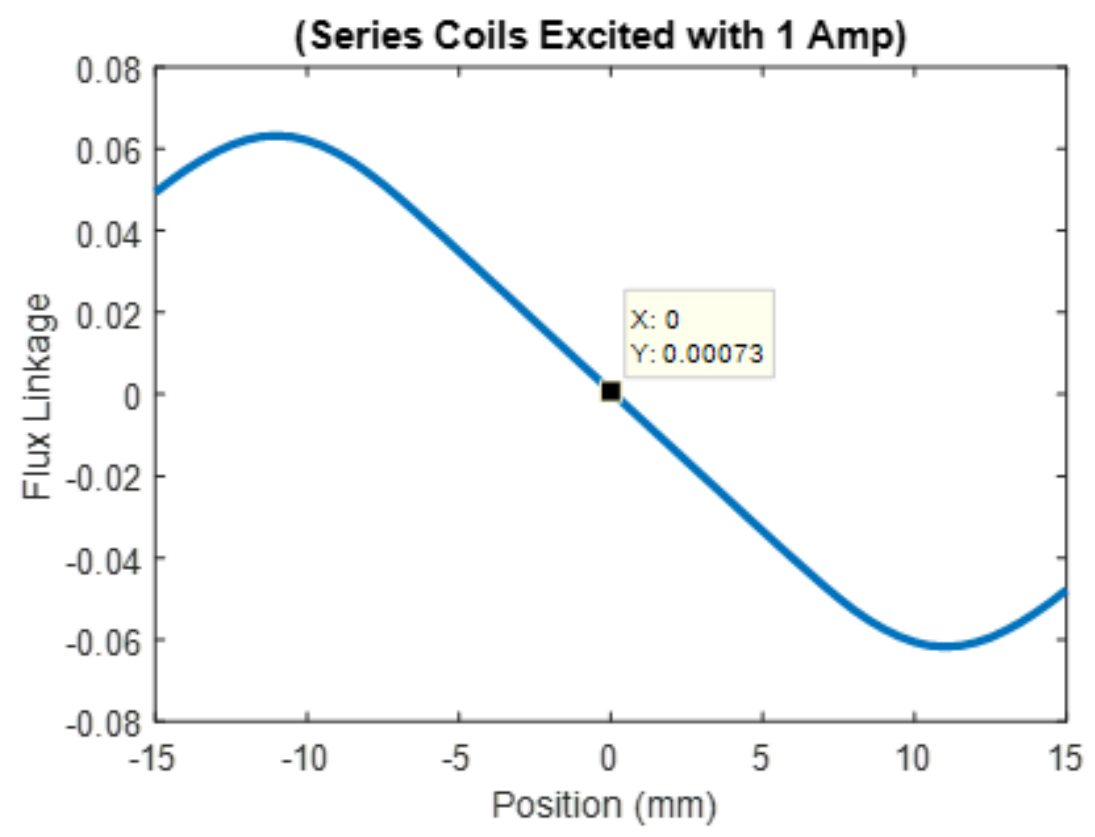

Figure 47: Iron Core Alpha Flux linkage vs Displacement

The output voltage was calculated for a displacement of $22 \mathrm{~mm}$ at various offsets and also at $14 \mathrm{~mm}$ of displacement. Plots of the induced voltages and FFTs of each condition are shown below. 


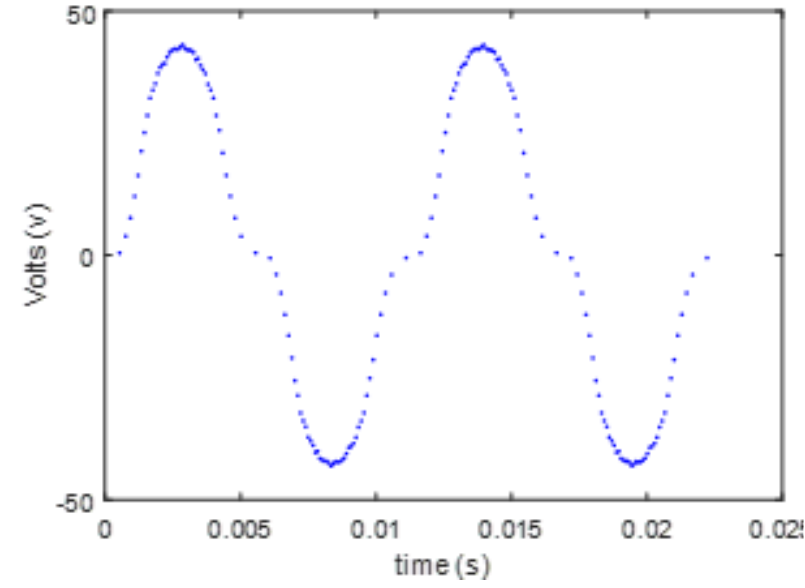

Figure 48: Alpha Iron Core FEMM $\varepsilon_{G E N}$ (22mm Disp., No offset, $90 \mathrm{~Hz}$ )

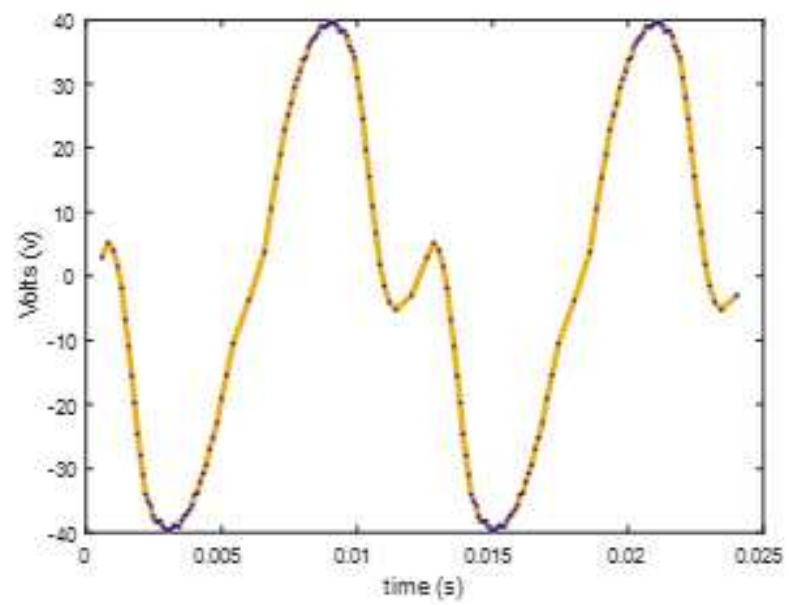

Figure 50: Alpha Iron Core FEMM $\mathcal{E}_{G E N}$ (22mm Disp., $2 \mathrm{~mm}$ offset, $83.25 \mathrm{~Hz}$ )

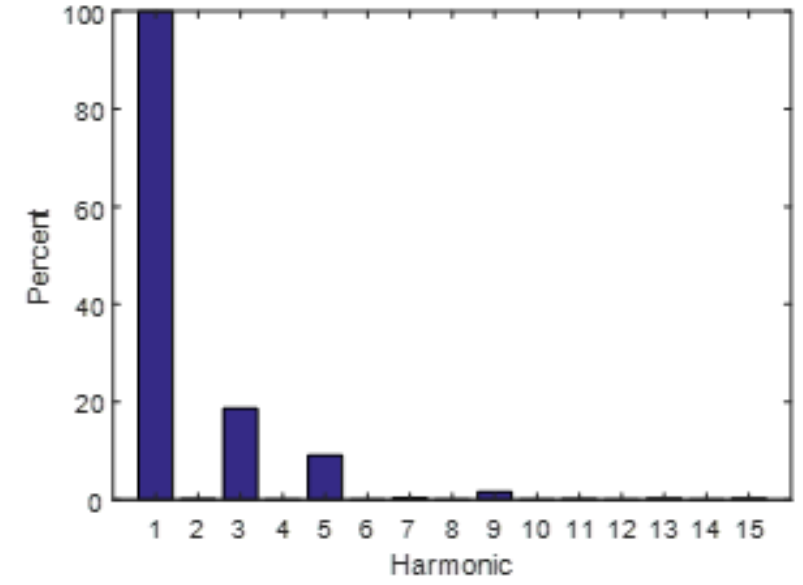

Figure 49: Alpha Iron Core FEMM $\varepsilon_{\text {GEN }}$ FFT (22mm Disp., No offset, $90 \mathrm{~Hz}$ )

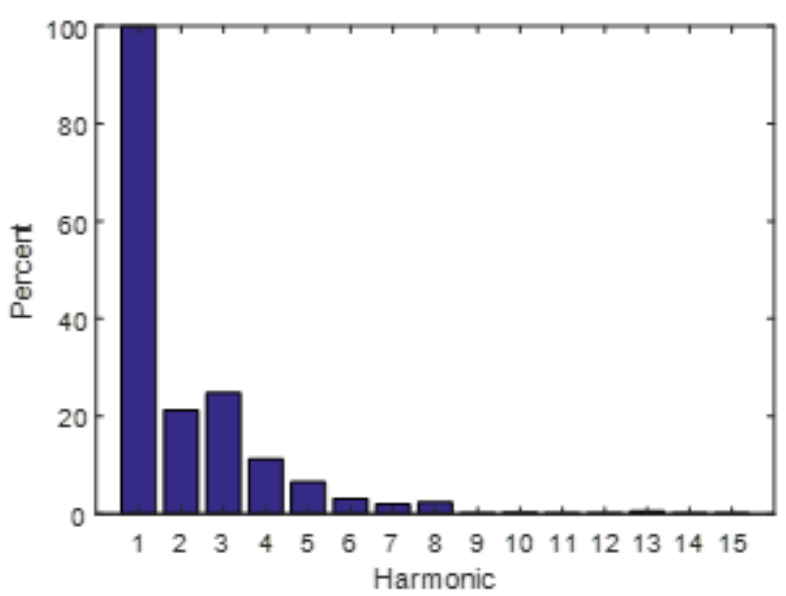

Figure 51: Alpha Iron Core FEMM $\varepsilon_{G E N} F F T$ (22mm Disp., $2 \mathrm{~mm}$ offset, $83.25 \mathrm{~Hz}$ ) 


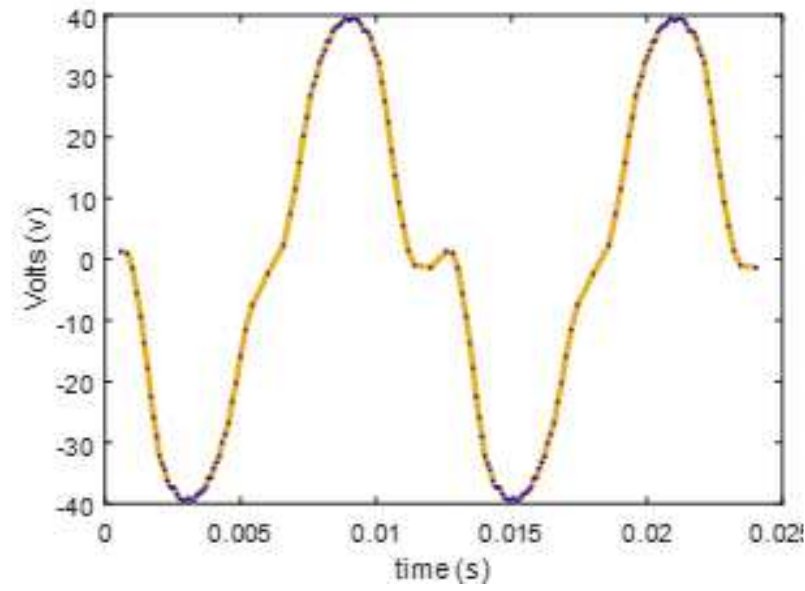

Figure 52: Alpha Iron Core FEMM $\varepsilon_{G E N}$ (22mm Disp., 1mm offset, $83.25 \mathrm{~Hz}$ )

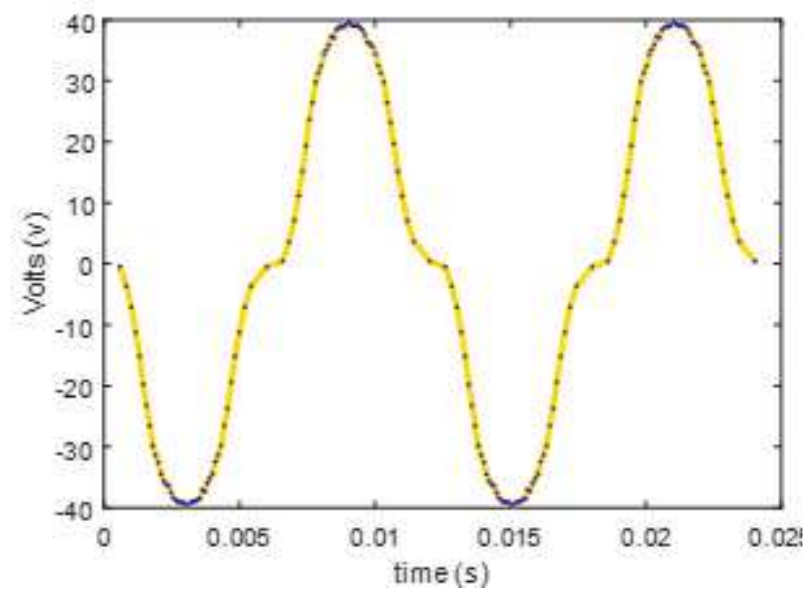

Figure 54: Iron Core Alpha FEMM $\varepsilon_{G E N}$ (83.25Hz, Omm Offset)

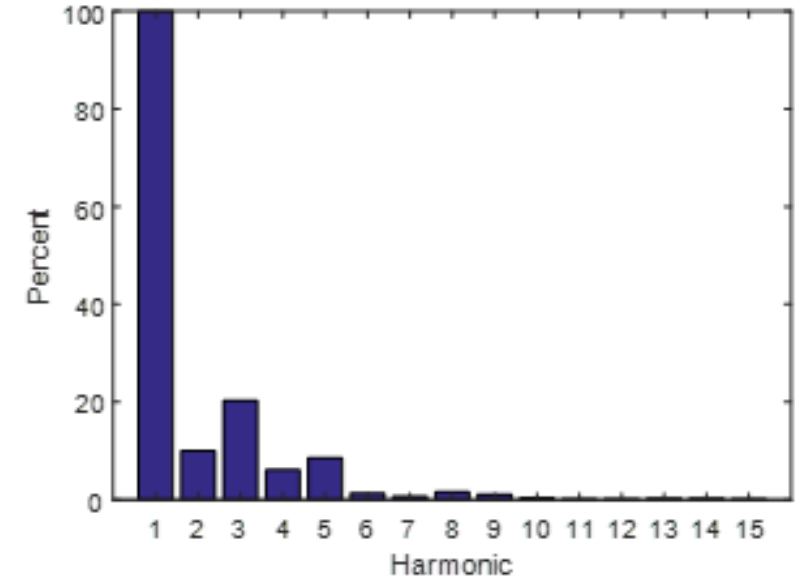

Figure 53: Iron Core Alpha FEMM $\varepsilon_{\text {GEN }}$ FFT (83.25Hz, 1mm Offset)

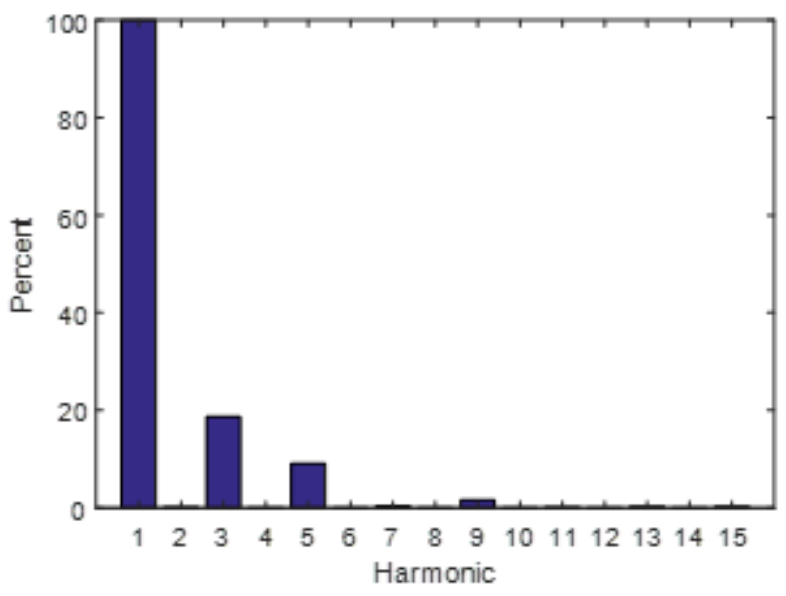

Figure 55: Iron Core Alpha FEMM $\varepsilon_{G E N}$ (83.25Hz, Omm Offset) 


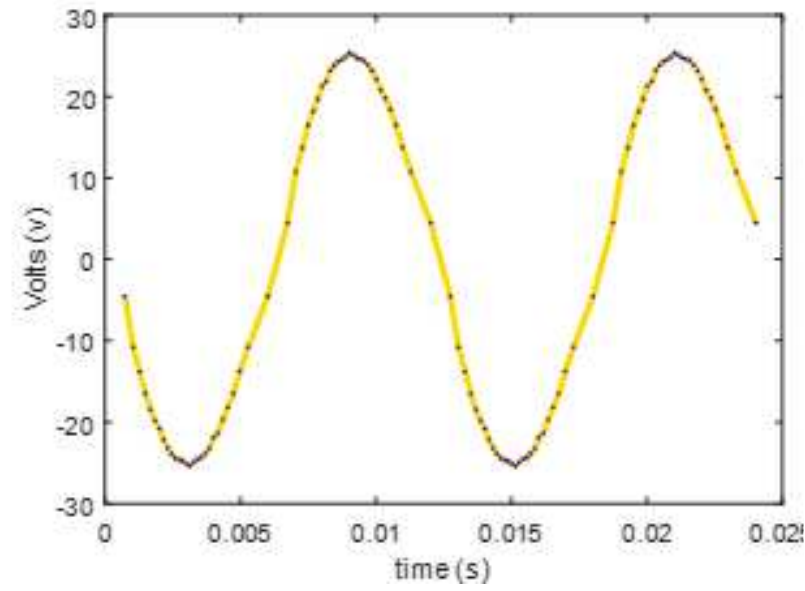

Figure 56: Iron Core Alpha FEMM $\varepsilon_{G E N}$ (14mm Displacement, 83.25Hz, Omm Offset)

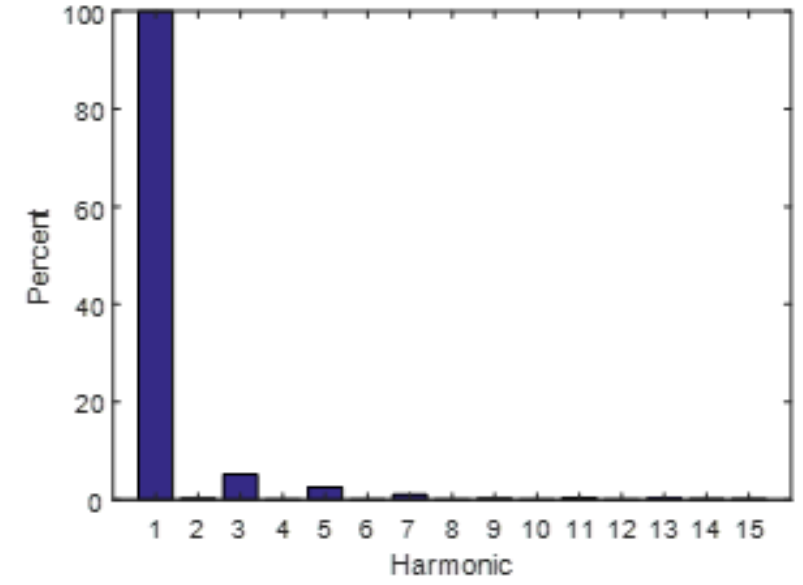

Figure 57: Iron Core Alpha FEMM $\varepsilon_{G E N} F F T$ (14mm Displacement, 83.25Hz, Omm Offset) 


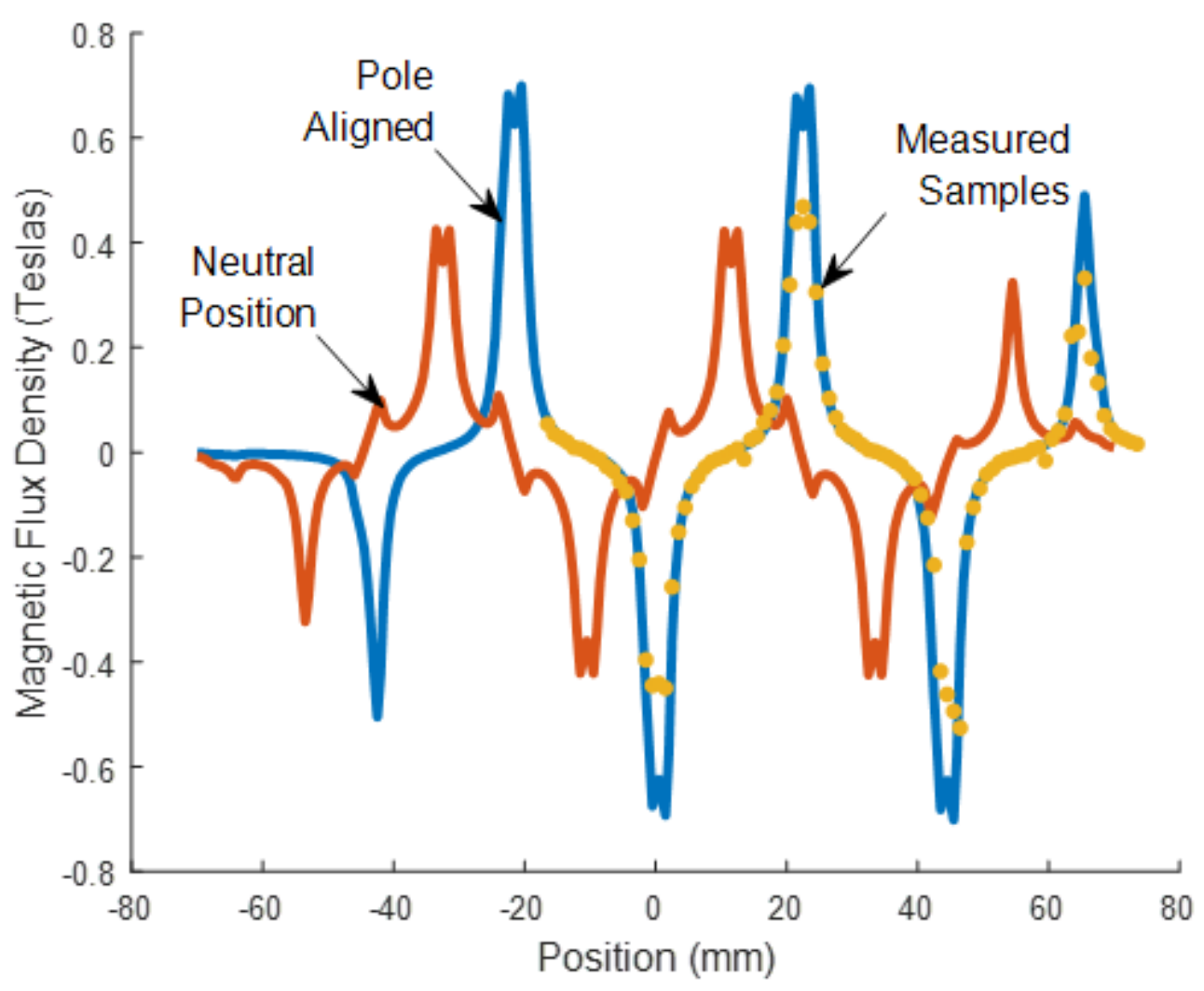

Figure 58: Iron Core Alpha Machine Airgap Normal Flux Density

\subsubsection{Iron Core Alpha Summary}

\begin{tabular}{|l|l|l|l|l|l|}
\hline & FEMM & Measured & & & \\
\hline $\begin{array}{l}\text { Stator } \\
\text { Resistance }(\Omega)\end{array}$ & 0.267895 & 0.273 & & & \\
\hline $\begin{array}{l}\text { Stator } \\
\text { Inductance } \\
(\mathrm{mH})\end{array}$ & 0.730006 & 0.075 & & & \\
\hline & & & & & \\
\hline & Case 1 & Case 2 & Case 3 & Case 4 & Case 5 \\
\hline Displacement & 22 & 22 & 22 & 22 & 14 \\
\hline Offset (mm) & 0 & 1 & 2 & 0 & 0 \\
\hline Frequency & 83.25 & 83.25 & 83.25 & 90 & 83.25 \\
\hline THD \% & 20.85 & 25.13 & 34.46 & 20.85 & 5.97 \\
\hline VRMS & 25.7254 & 25.6130 & 25.3112 & 27.8121 & 17.6076 \\
\hline Vpk & 39.8207 & 39.5728 & 39.5810 & 43.05 & 25.3276 \\
\hline $1^{\text {st } \text { Amplitude }}$ & 35.5961 & 35.1009 & 33.6977 & 38.4823 & 24.8428 \\
\hline $1^{\text {st }}$ Angle & 1.8266 & 1.8278 & 1.8301 & -1.3148 & 1.8404 \\
\hline
\end{tabular}




\begin{tabular}{|l|l|l|l|l|l|}
\hline $2^{\text {nd }}$ Amplitude & 0.0606 & 3.5236 & 7.1737 & 0.0655 & 0.0723 \\
\hline $2^{\text {nd }}$ Angle & 1.9330 & -1.1631 & -1.1530 & -1.2082 & 2.0194 \\
\hline $3^{\text {rd }}$ Amplitude & 6.6484 & 7.1361 & 8.3573 & 7.1875 & 1.2937 \\
\hline $3^{\text {rd }}$ Angle & -0.7002 & -0.7073 & -0.7183 & 2.4418 & 0.6130 \\
\hline $4^{\text {th }}$ Amplitude & 0.0221 & 2.1458 & 3.7849 & 0.0239 & 0.0088 \\
\hline $4^{\text {th }}$ Angle & -0.4229 & -0.6571 & -0.6666 & 2.7193 & 2.1741 \\
\hline $5^{\text {th }}$ Amplitude & 3.2399 & 3.0102 & 2.2055 & 3.5026 & 0.6498 \\
\hline $5^{\text {th }}$ Angle & -0.2340 & -0.2394 & -0.2547 & 2.9083 & 1.0678 \\
\hline $6^{\text {th }}$ Amplitude & 0.0023 & 0.4748 & 1.0622 & 0.0025 & 0.0094 \\
\hline $6^{\text {th }}$ Angle & -1.9940 & -2.5579 & -2.6581 & 1.1514 & 0.5704 \\
\hline $7^{\text {th }}$ Amplitude & 0.1612 & 0.2445 & 0.6680 & 0.1743 & 0.2595 \\
\hline $7^{\text {th }}$ Angle & -1.4983 & -2.1478 & -2.6026 & 1.6443 & 1.4126 \\
\hline $8^{\text {th }}$ Amplitude & 0.0052 & 0.5513 & 0.8055 & 0.0057 & 0.0150 \\
\hline $8^{\text {th }}$ Angle & -1.8811 & -2.3772 & -2.3640 & 1.2616 & 1.1663 \\
\hline $9^{\text {th }}$ Amplitude & 0.5819 & 0.4020 & 0.0582 & 0.6291 & 0.0689 \\
\hline $9^{\text {th }}$ Angle & -2.0952 & -2.0876 & -1.2225 & 1.0476 & 0.9595 \\
\hline $10^{\text {th }}$ Amplitude & 0.0156 & 0.1273 & 0.0977 & 0.0169 & 0.0152 \\
\hline $10^{\text {th }}$ Angle & 1.0023 & 1.1773 & 1.3033 & -2.1380 & -1.3990 \\
\hline $11^{\text {th }}$ Amplitude & 0.0688 & 0.0632 & 0.0432 & 0.0744 & 0.1183 \\
\hline $11^{\text {th }}$ Angle & -0.4729 & -1.1422 & 0.0919 & 2.6702 & -0.1849 \\
\hline $12^{\text {th }}$ Amplitude & 0.0051 & 0.0756 & 0.0417 & 0.0055 & 0.0155 \\
\hline $12^{\text {th }}$ Angle & -0.9047 & 2.0137 & -2.3493 & 2.2386 & -0.5338 \\
\hline $13^{\text {th }}$ Amplitude & 0.1159 & 0.0988 & 0.1706 & 0.1253 & 0.0853 \\
\hline $13^{\text {th }}$ Angle & 1.3206 & -0.6777 & -0.8890 & -1.8192 & 0.4027 \\
\hline $14^{\text {th }}$ Amplitude & 0.0215 & 0.1170 & 0.0557 & 0.0233 & 0.0367 \\
\hline $14^{\text {th }}$ Angle & -0.6454 & -1.1115 & 3.0759 & 2.4981 & -3.1166 \\
\hline $15^{\text {th }}$ Amplitude & 0.1163 & 0.0570 & 0.0355 & 0.1257 & 0.0306 \\
\hline $15^{\text {th }}$ Angle & -0.0417 & 0.3291 & 1.6802 & 3.1019 & 0.0366 \\
\hline
\end{tabular}

Table 11: Iron Core Alpha Simulation Tabulated Summary 


\section{Beta Machine}

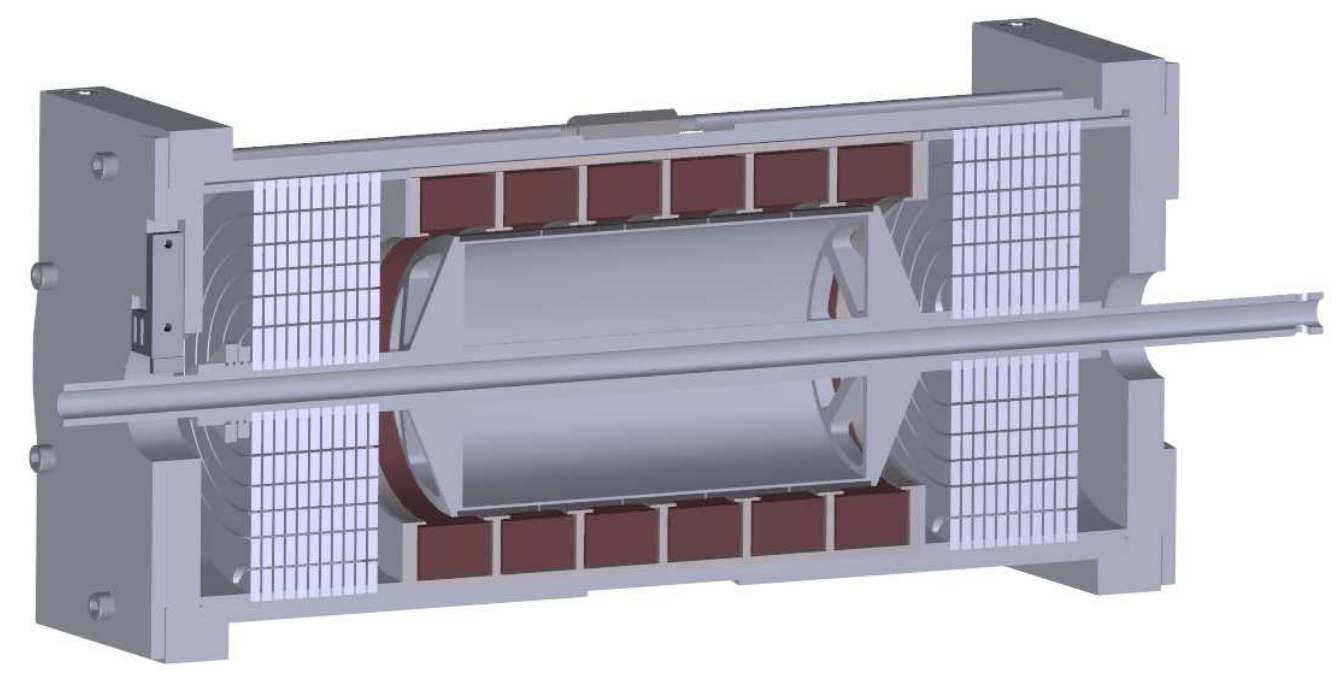

Figure 59: Beta Linear Alternator without Engine CAD model

The air core alternator and engine has been constructed. At the time of writing, it has not been successfully run. Motoring of the machine has been accomplished however the mass spring resonant frequency is too low to successfully combust the 2 stroke engine. Flexure springs were changed to stiffer Sullivan steel design to increase the frequency, however failures of the springs occurred in a very short time (less than one minute). Work on the beta machine is ongoing.

The parameters of the beta machine are given below:

- Pole Pitch

- Magnet Length

- Number of Turns

- Number of Coils

- Number of Magnets

- Coil Inside Diameter

- Ring Magnet Outside Diameter

- Magnet Thickness

- Magnet Type

- Iron Pole Thickness

- Airgap
$33 \mathrm{~mm}$

$32 \mathrm{~mm}$

$14 \times 9=126$ (per coil)

6

5

$106 \mathrm{~mm}$

$100 \mathrm{~mm}$

$2 \mathrm{~mm}$

N35, 1/8 Arc Segments

$3 \mathrm{~mm} \quad$ (Iron Core Only)

$1 \mathrm{~mm} \quad$ (Iron Core Only) 


\subsection{Air Core Beta Machine}

Although not successfully running yet, the air core beta machine was constructed and the airgap flux density had been measured. The flux density was simulated using FEMM in the same way described above for the alpha machine. The measured peak flux density was found to be slightly less than simulation as shown in Figure 60 below.

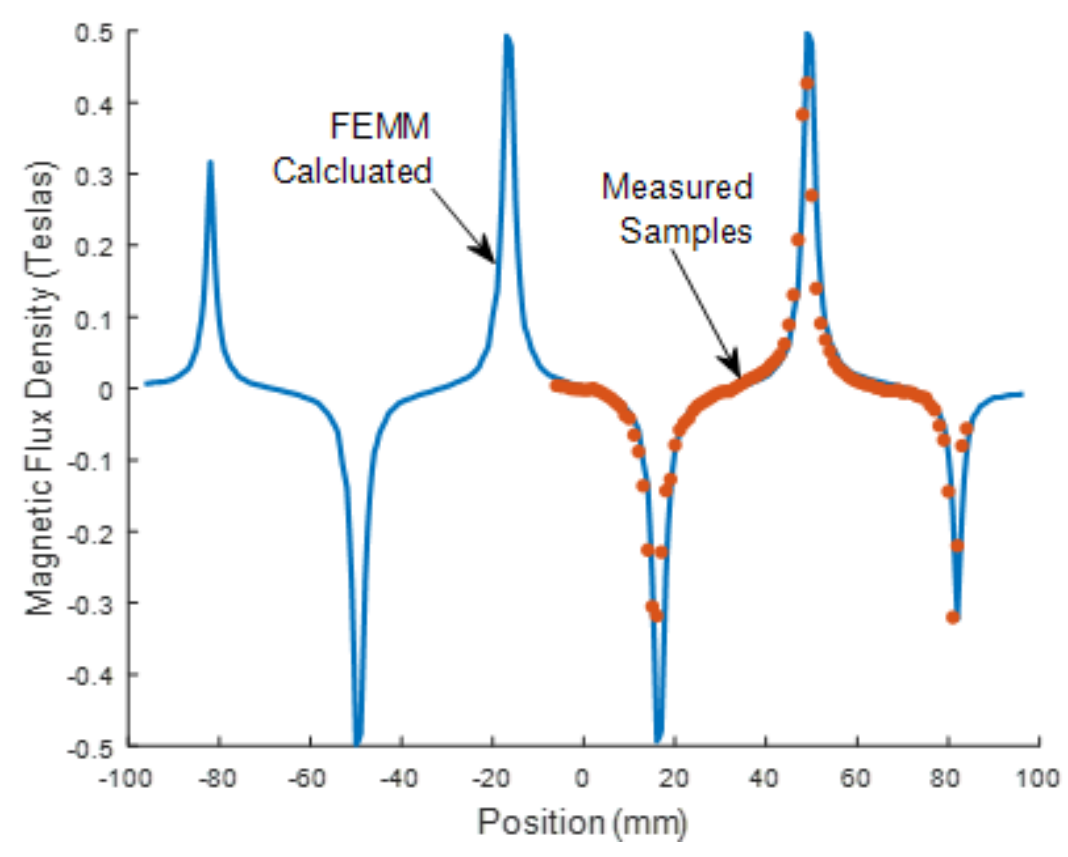

Figure 60: Air Core Beta Machine Airgap Normal Flux Density

\subsubsection{Air Core Beta Machine Simulation}

Simulation of the air core beta machine has been carried out. Results are reminiscent of the air core alpha machine. The flux linkage is sinusoidal over distance and therefore a large third harmonic component appears in the induced voltage. 


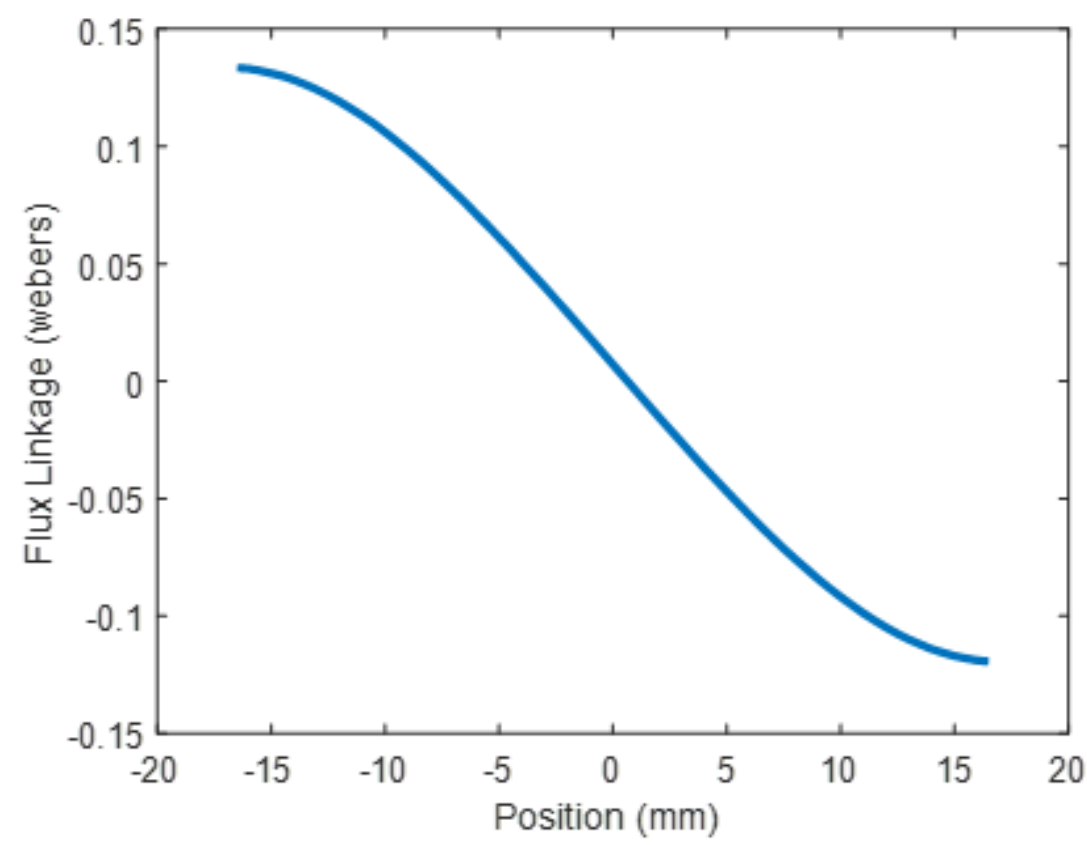

Figure 61: Air Core Beta Flux Linkage vs Displacement
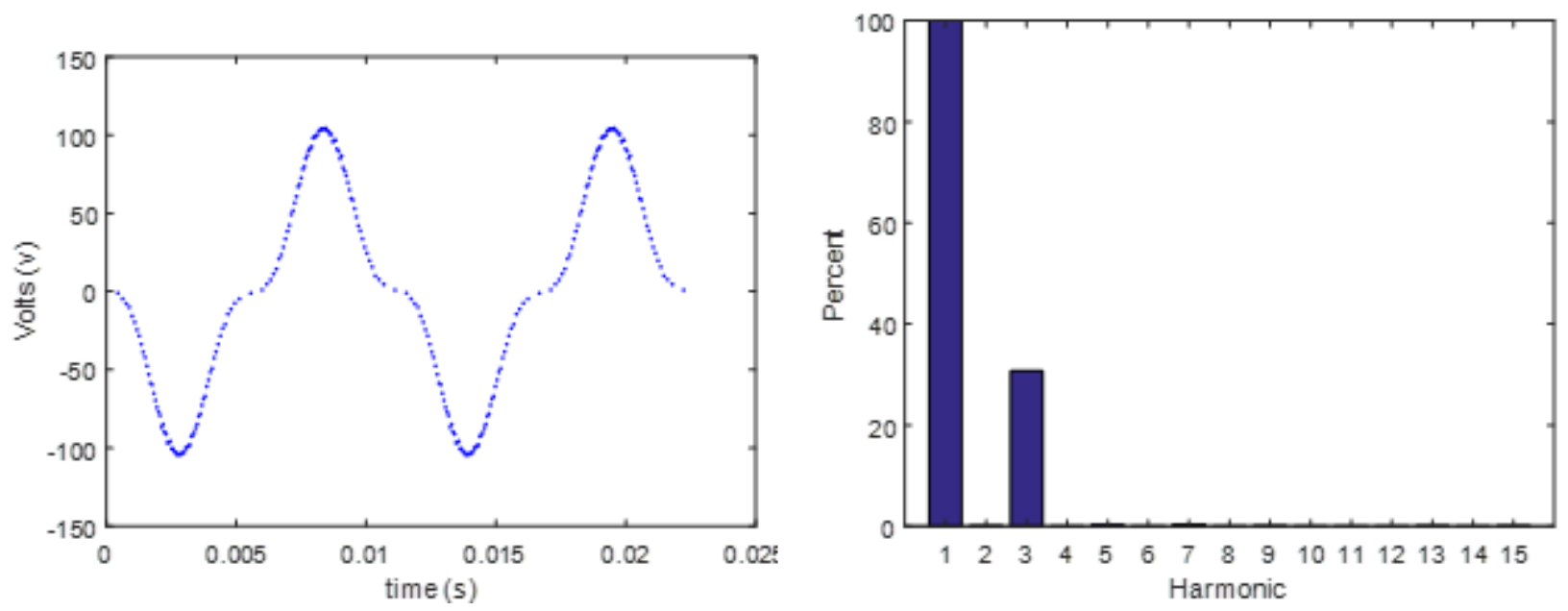

Figure 62: Air Core Beta FEMM $\varepsilon_{G E N} 90 H z, \quad$ Figure 63: Air Core Beta FEMM $\mathcal{E}_{G E N}$ FFT $33 \mathrm{~mm}$ Displacement $90 \mathrm{~Hz}$, 33mm Displacement

\begin{tabular}{|l|l|}
\hline $\begin{array}{l}\text { Stator } \\
\text { Resistance }(\Omega)\end{array}$ & $\begin{array}{l}1.58545 \\
(1.59 \\
\text { measured })\end{array}$ \\
\hline $\begin{array}{l}\text { Stator } \\
\text { Inductance }\end{array}$ & $\begin{array}{l}7.0908 \\
(7.5\end{array}$ \\
\hline
\end{tabular}




\begin{tabular}{|l|l|}
\hline (mH) & measured) \\
\hline & Case 1 \\
\hline & 33 \\
\hline Displacement & 0 \\
\hline Offset (mm) & 90 \\
\hline Frequency & 30.72 \\
\hline THD $\%$ & 58.975 \\
\hline VRMS & 104.34 \\
\hline Vpk & 79.6782 \\
\hline $1^{\text {st }}$ Amplitude & 1.8451 \\
\hline $1^{\text {st }}$ Angle & 0.0865 \\
\hline $2^{\text {nd }}$ Amplitude & 1.8879 \\
\hline $2^{\text {nd }}$ Angle & 24.4703 \\
\hline $3^{\text {rd }}$ Amplitude & -0.6979 \\
\hline $3^{\text {td }}$ Angle & 0.0408 \\
\hline $4^{\text {th }}$ Amplitude & -0.6423 \\
\hline $4^{\text {th }}$ Angle & 0.2569 \\
\hline $5^{\text {th }}$ Amplitude & -0.5615 \\
\hline $5^{\text {th }}$ Angle & 0.0482 \\
\hline $6^{\text {th }}$ Amplitude & 0.0113 \\
\hline $6^{\text {th }}$ Angle & 0.3254 \\
\hline $7^{\text {th }}$ Amplitude & -2.6767 \\
\hline $7^{\text {th }}$ Angle & 0.0163 \\
\hline $8^{\text {th }}$ Amplitude & -2.0955 \\
\hline $8^{\text {th }}$ Angle & 0.1345 \\
\hline $9^{\text {th }}$ Amplitude & -2.1116 \\
\hline $9^{\text {th }}$ Angle & 0.0043 \\
\hline $10^{\text {th }}$ Amplitude & 0.2974 \\
\hline $10^{\text {th }}$ Angle & 0.1084 \\
\hline $11^{\text {th }}$ Amplitude & 0.0644 \\
\hline $11^{\text {th }}$ Angle & -1.0982 \\
\hline $12^{\text {th }}$ Amplitude & 0.0162 \\
\hline $12^{\text {th }}$ Angle & -1.0173 \\
\hline $13^{\text {th }}$ Amplitude & 0.1118 \\
\hline $13^{\text {th }}$ Angle & -0.4104 \\
\hline $14^{\text {th }}$ Amplitude & 0.0134 \\
\hline $14^{\text {th }}$ Angle & -0.1261 \\
\hline $15^{\text {th }}$ Amplitude & 0.1087 \\
\hline $15^{\text {th }}$ Angle & 1.889 \\
\hline ir Core Beta Simultabuted \\
\hline
\end{tabular}

Table 12: Air Core Beta Simulation Tabulated Summary 


\subsection{Iron Core Beta Machine}

At the time of writing, the beta machine has not been successfully ran as an alternator. Below are the results of the simulation of the iron core beta machine.

\subsubsection{Iron Core Beta Machine Simulation}

A FEMM simulation and MATLAB analysis of the beta machine was ran in a manner similar to the alpha machine described above. A displacement of $33 \mathrm{~mm}$ and frequency of $90 \mathrm{~Hz}$ was used for the analysis as this was the design target. The flux linkage vs displacement as seen in Figure 64 is linear for most of the displacement. At approximately $2 \mathrm{~mm}$ from each pole there is a rounding of the flux linkage. A displacement of $29 \mathrm{~mm}$ of translator movement is possible while staying within the region with a nearly constant rate of change of flux linkage.

A displacement of $29 \mathrm{~mm}$ at $90 \mathrm{~Hz}$ frequency was also analyzed to investigate the improvement in voltage distortion and its impact on induced voltage, power, and efficiency. As can be seen in Figure 65 through Figure 68, there is an improvement in voltage distortion but also a reduction in output voltage when operating at $29 \mathrm{~mm}$ displacement. The beta iron core design can provide a 130 Vrms output voltage with less than 5\% THD when operating at $29 \mathrm{~mm}$ of displacement.

Next, a graph of power verses load resistance was produced for each case. A "for" loop was used in MATLAB to add all the solutions of the individual harmonic components up to the 15th using the property of superposition. All the following figures of power and efficiency include the effects of harmonics. As can be seen in Figure 69and Figure 70, a 1kW load is not achievable. A maximum load of $736 \mathrm{~W}$ is possible with an efficiency of $88.7 \%$ when operating at $33 \mathrm{~mm}$.

To transfer more power to the load and to improve efficiency, the stator reactance of $\mathrm{j} 12.3 \Omega$ (at 90) $\mathrm{Hz}$ can be cancelled with a capacitor If a capacitor of $143 \mathrm{uF}$ is connected in series with the load resistance, all imaginary reactances cancel. A load of $1 \mathrm{~kW}$ can be supplied to a $17.3 \Omega$ resistor while operating at 33mm displacement with $91.6 \%$ efficiency (Figure 71). If the displacement decreased to $29 \mathrm{~mm}, 1 \mathrm{~kW}$ can still be supplied however the efficiency of the machine will drop to $88.6 \%$ (Figure 72 ).

It is worth noting that when all imaginary reactances cancel, the machine and the load are in resonance. The equation for the resonant frequency of a series RLC circuit is $f=\frac{1}{2 \pi \sqrt{L C}}$. When this is solved using load capacitance of $143 \mathrm{uF}$ and stator inductance of $21.76 \mathrm{mH}$, the resonant frequency is found to be $90 \mathrm{~Hz}$, the operating frequency of the machine.

In practice a series connected capacitor may not be practical, an equivalent parallel combination of load resistance and capacitance can be found to achieve the same results.

MATLAB code for generating the plots at $33 \mathrm{~mm}$ are included in the appendix. 


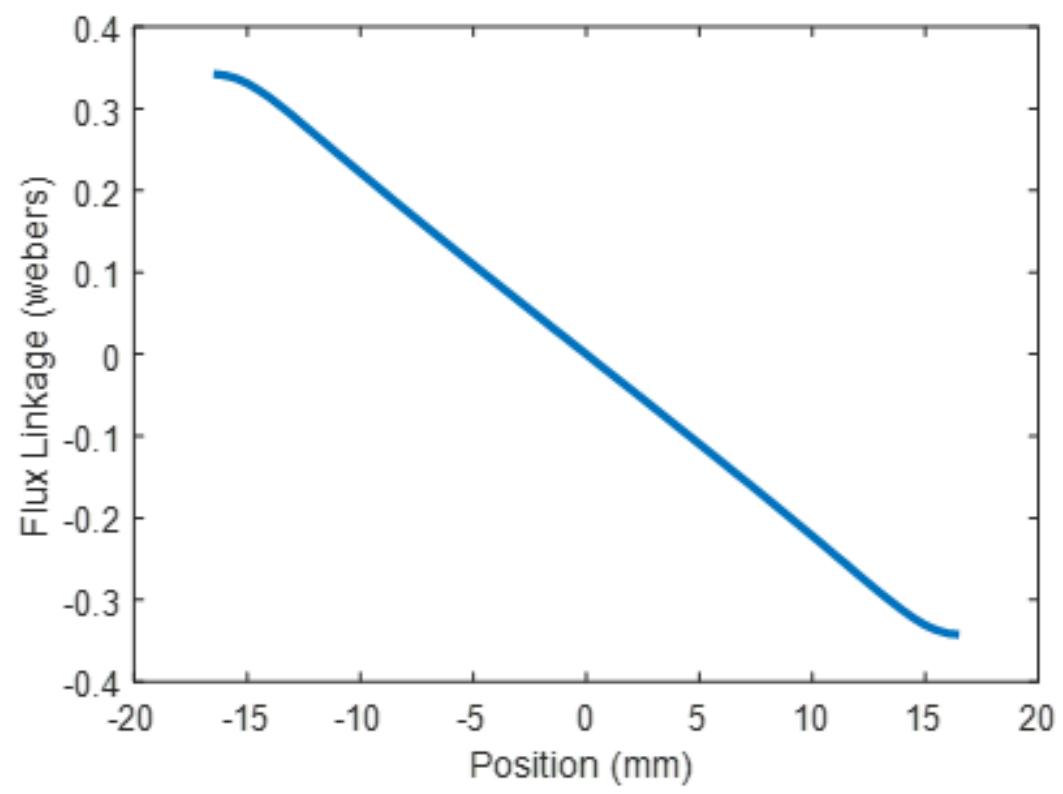

Figure 64: Iron Core Beta Flux Linkage vs Displacement
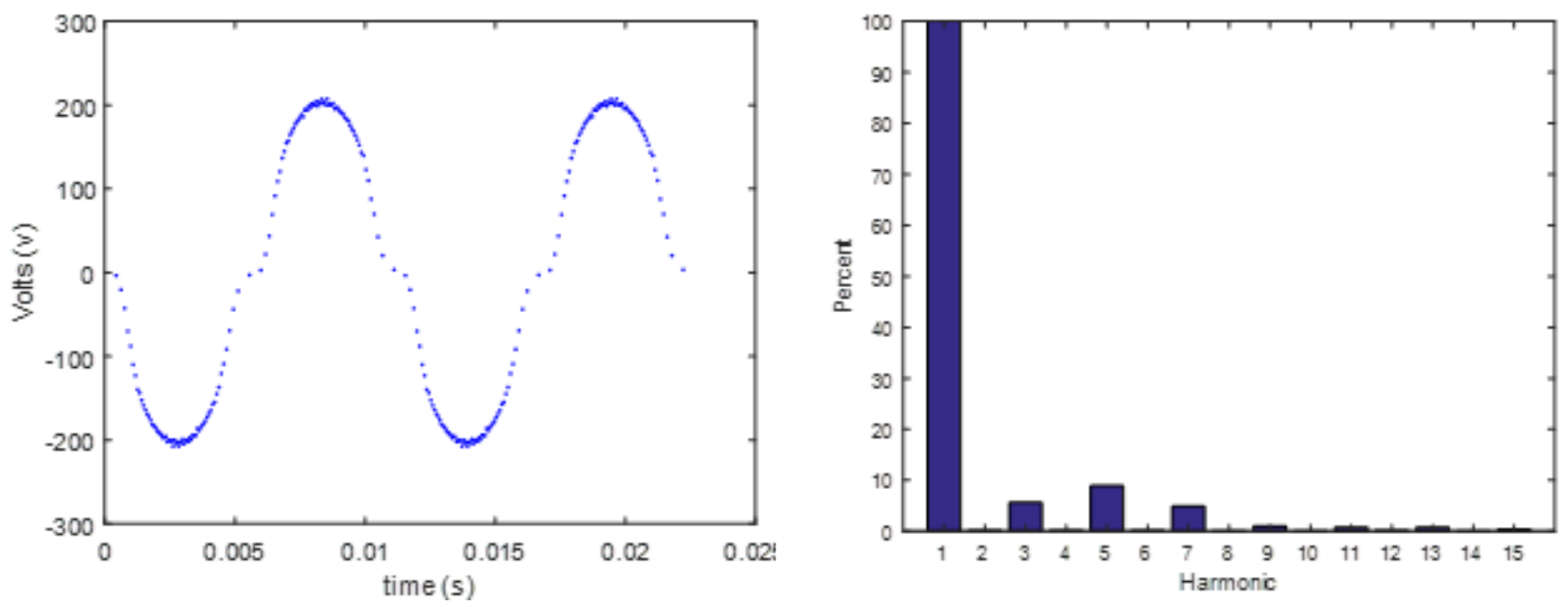

Figure 65: Iron Core Beta FEMM $\varepsilon_{G E N} 90 H z, \quad$ Figure 66: Iron Core Beta FEMM $\varepsilon_{G E N}$ FFT $33 \mathrm{~mm}$ Displacement $90 \mathrm{~Hz}$, 33mm Displacement 


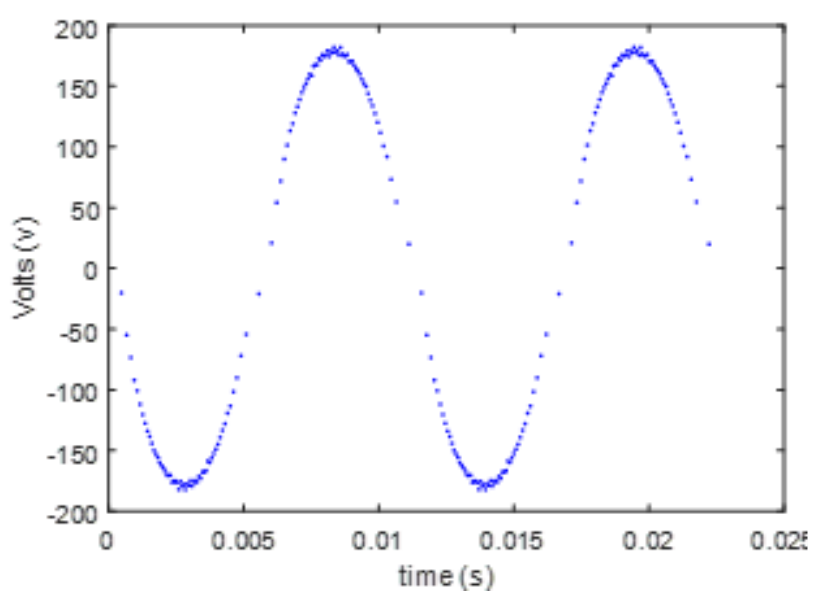

Figure 67: Iron Core Beta FEMM $\varepsilon_{G E N} 90 H z$, $29 \mathrm{~mm}$ Displacement

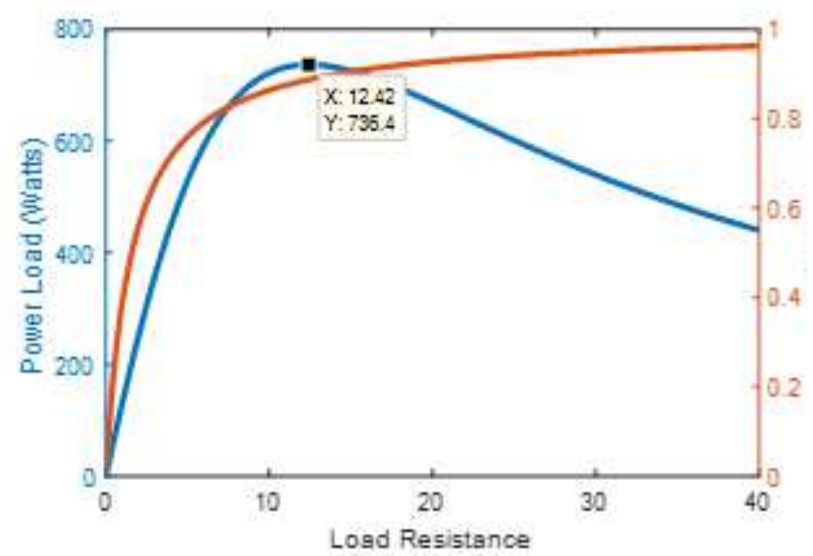

Figure 69: Iron Core Beta 33mm Resistive Loading

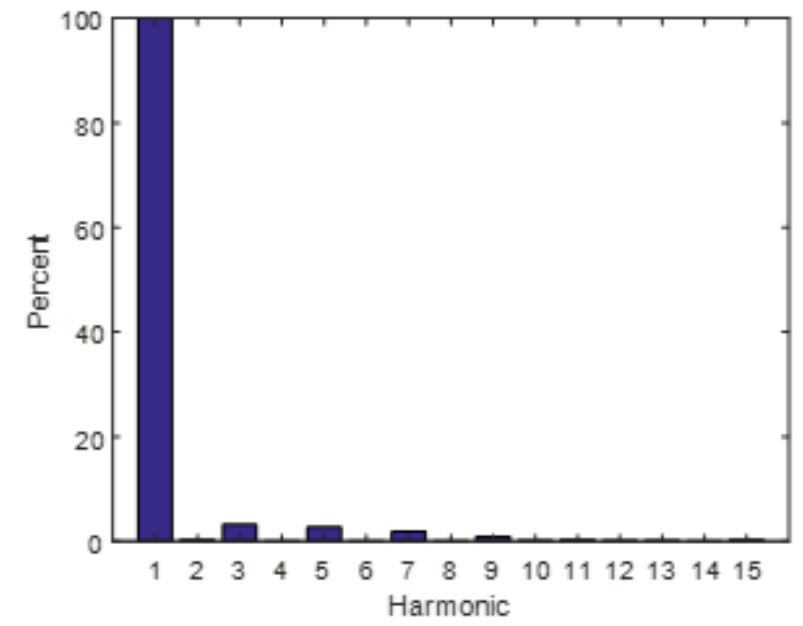

Figure 68: Iron Core Beta FEMM $\varepsilon_{G E N}$ FFT $90 \mathrm{~Hz}, 29 \mathrm{~mm}$ Displacement

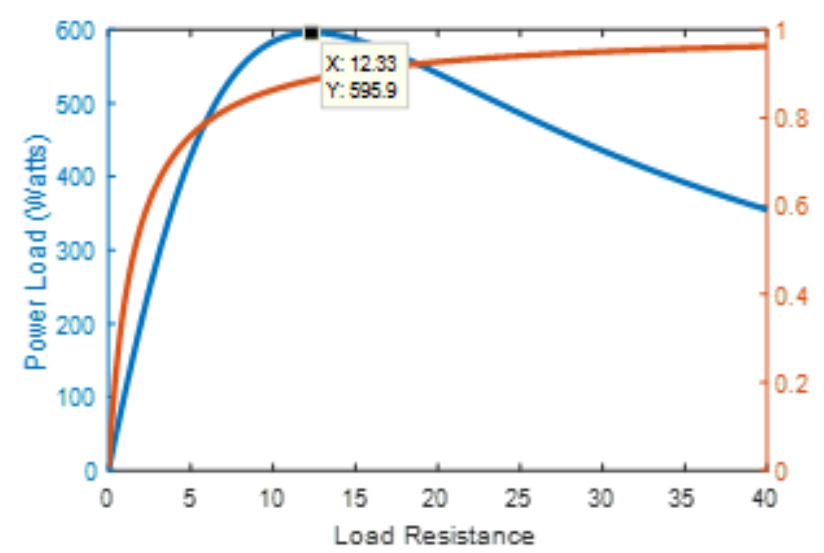

Figure 70: Iron Core Beta 29mm Resistive Loading 


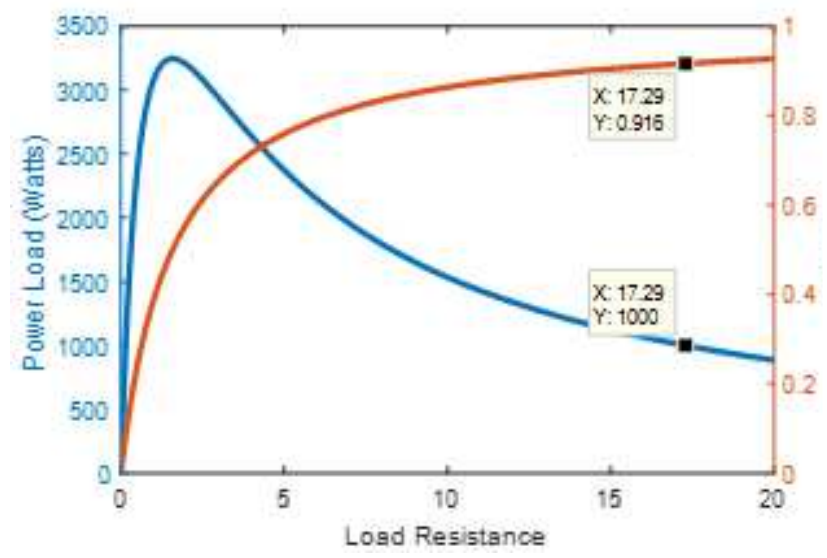

Figure 71: Iron Core Beta 33mm Resistive Loading $w / 143 \mu F$ Series Capacitor

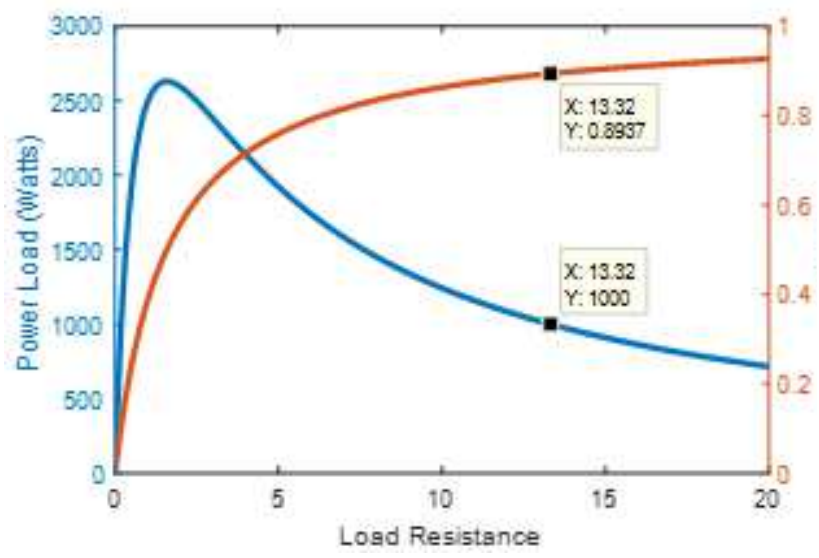

Figure 72: Iron Core Beta 29mm Resistive

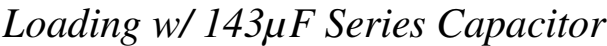

\begin{tabular}{|l|l|l|}
\hline $\begin{array}{l}\text { Stator } \\
\text { Resistance }(\Omega)\end{array}$ & 1.58545 & $\begin{array}{l}1.59 \\
\text { (measured) }\end{array}$ \\
\hline $\begin{array}{l}\text { Stator } \\
\text { Inductance } \\
\text { (mH) }\end{array}$ & 21.7664 & $\begin{array}{l}20.5 \\
\text { (measured) }\end{array}$ \\
\hline & & \\
\hline & Case 1 & Case 2 \\
\hline Displacement & 33 & 29 \\
\hline Offset (mm) & 0 & 0 \\
\hline Frequency & 90 & 90 \\
\hline THD $\%$ & 11.66 & 4.70 \\
\hline VRMS & 144.495 & 129.3246 \\
\hline Vpk & 207.3468 & 182.0510 \\
\hline $1^{\text {st }}$ Amplitude & 202.8776 & 182.6129 \\
\hline $1^{\text {st }}$ Angle & 1.8355 & 1.8129 \\
\hline $2^{\text {nd }}$ Amplitude & 0.3277 & 0.4581 \\
\hline $2^{\text {nd }}$ Angle & 2.0536 & 1.9865 \\
\hline $3^{\text {rd }}$ Amplitude & 11.3037 & 5.8536 \\
\hline $3^{\text {rd }}$ Angle & -0.522 & 1.1610 \\
\hline $4^{\text {th }}$ Amplitude & 0.2075 & 0.1019 \\
\hline $4^{\text {th }}$ Angle & -0.4887 & 2.4772 \\
\hline $5^{\text {th }}$ Amplitude & 18.0159 & 4.9293 \\
\hline $5^{\text {th }}$ Angle & -0.1534 & 0.5210 \\
\hline $6^{\text {th }}$ Amplitude & 0.2219 & 0.0677 \\
\hline $6^{\text {th }}$ Angle & 0.0722 & -2.8515 \\
\hline $7^{\text {th }}$ Amplitude & 9.8706 & 3.3525 \\
\hline $7^{\text {th }}$ Angle & 0.3187 & 0.8576 \\
\hline & & \\
\hline
\end{tabular}




\begin{tabular}{|l|l|l|}
\hline $8^{\text {th }}$ Amplitude & 0.1044 & 0.0503 \\
\hline $8^{\text {th }}$ Angle & 0.7971 & -0.9451 \\
\hline $9^{\text {th }}$ Amplitude & 2.0490 & 1.6527 \\
\hline $9^{\text {th }}$ Angle & 0.5315 & 1.2598 \\
\hline $10^{\text {th }}$ Amplitude & 0.0646 & 0.1977 \\
\hline $10^{\text {th }}$ Angle & -2.7156 & 0.8257 \\
\hline $11^{\text {th }}$ Amplitude & 1.5539 & 0.5574 \\
\hline $11^{\text {th }}$ Angle & -1.2708 & 1.4150 \\
\hline $12^{\text {th }}$ Amplitude & 0.2343 & 0.2285 \\
\hline $12^{\text {th }}$ Angle & -1.6111 & 1.4353 \\
\hline $13^{\text {th }}$ Amplitude & 1.5167 & 0.3239 \\
\hline $13^{\text {th }}$ Angle & -0.8880 & 0.2300 \\
\hline $14^{\text {th }}$ Amplitude & 0.1420 & 0.0743 \\
\hline $14^{\text {th }}$ Angle & -1.1897 & 0.3476 \\
\hline $15^{\text {th }}$ Amplitude & 0.6941 & 0.5347 \\
\hline $15^{\text {th }}$ Angle & -0.2706 & 0.2858 \\
\hline
\end{tabular}

Table 13: Iron Core Beta Simulation Tabulated Summary 


\section{Conclusions}

A resonant system OLEA was constructed, ran under load, and instantaneous voltage, current, and translator position was captured. It was demonstrated by testing that position versus time remained sinusoidal and therefore demonstrated that the mass spring oscillation is the dominant force for the system. Subsequently, the non-linear compression of gases, the non-linear combustion forces, and cogging forces of the iron core stators can be ignored. By assuming that motion is purely sinusoidal, modeling of the alternator is simplified and was performed using FEMM and MATLAB. It was demonstrated that the FEMM/MATLAB simulation model for the alpha machine was a close match. The actual voltage produced was about $12 \%$ lower than the simulation model. The difference can be accounted for by the lower peak airgap flux density measured than simulated.

It was found that operating at a displacement equal to the pole pitch caused distortion of the voltage waveform. A misalignment of the stator and translator as small as $1 \mathrm{~mm}$ can also cause considerably more distortion. An iron core machine operating at a displacement less than the pole pitch can have a nearly sinusoidal output. However, to achieve a higher operating efficiency, a displacement equal to the pole pitch is desired. Of course, this is neglecting core losses and skin effect of the windings. In the larger beta machine, the large stator self-inductance limits the high order harmonic currents when operating at a high frequency of $90 \mathrm{~Hz}$. The high self-inductance also limits the machines ability to source current to the load. A leading power factor load is necessary to deliver higher power and to increase efficiency. The highest

efficiency will occur when the load capacitance reactance cancels the stator reactance completely and the machine and load are in resonance. This demonstrates that along with engine resonance and mechanical mass-spring resonance, electrical resonance is also needed for high efficiency. 


\section{References}

[1] I. Boldea and S. A. Nasar, "Permanent-magnet linear alternators part 1: Fundamental equations," IEEE Transactions on Aerospace and Electronic Systems, vol. 23, no. 1, pp. 73 78, 1987.

[2] A. H. Memon, T. B. Ibrahim and P. Nallagowden, "Design analysis, optimization and identification of optimum single-phase linear PM generator using different magnet shape for wave energy conversion," in Intelligent and Advanced Systems (ICIAS), Kuala Lumpur, Malaysia, 2016.

[3] W. Cawthorne, P. Famouri and N. Clark, "Integrated design of linear alternator/engine system for HEV auxiliary power unit," in IEEE International Electric Machines and Drives Conference, Cambridge, MA, USA, 2001.

[4] P. Famouri et al., "Design and testing of a novel linear alternator and engine system for remote electrical power generation," in IEEE Power Engineering Society, New York, NY, USA, 1999.

[5] F. Kock, J. Haag and H. E. Friedrich, "The Free Piston Linear Generator - Development of an Innovative, Compact, Highly Efficient Range-Extender Module," in SAE Technical Paper 2013-01-1727, 2013.

[6] "ARPA-E About," Advanced Research Projects Agency - Energy, [Online]. Available: https://arpa-e.energy.gov/?q=arpa-e-site-page/about. [Accessed $25 \mathrm{Jul} 2018$ ].

[7] F. Mahmudzadeh, "Development of Resonating Oscillating Linear Engine Alternator; Instrumentation and Control," West Virginia University, Morgantown, WV, 2018.

[8] I. Boldea and S. A. Nasar, "Permanent-Magnet Linear Alternators Part II: Design Guidelines," IEEE Transactions on Aerospace and Electronic Systems, vol. 23, no. 1, pp. 79 - 82, 1987.

[9] Q. Li, J. Xiao and Z. Huang, "Flat-type permanent magnet linear alternator: A suitable device for a free piston linear alternator," Journal of Zhejiang University-SCIENCE A, vol. 10, no. 3, p. 345-352, 2009.

[10] I. Boldea and S. Nasar, "Linear electric actuators and generators," in IEEE International Electric Machines and Drives Conference Record, Milwaukee, WI, USA, 1997.

[11] R. Krishnan and K. Sitapati, "Performance Comparisons of Radial and Axial Field, Permanent-Magnet, Brushless Machines," IEEE Transactions on Industry Applications, vol. 37, no. 5, pp. 1219-1226, 2001. 
[12] P. R. Upadhyay and K. R. Rajagopal, "Comparison of performance of the axial-field and radial-field permanent magnet brushless direct current motors using computer aided design and finite element methods," Journal of Applied Physics, vol. 97, no. 10, 2005.

[13] Velington de Aquino Neumann and Roberto Petry Homrich, "Comparison between radial and axial permanent magnet generators for low speed application.," in Instrumentation and Measurement Technology Conference (I2MTC) Proceedings, Montevideo, Uruguay, 2014.

[14] J. Subramanian, G. Heiskell, F. Mahmudzadeh and P. Famouri, "Study of radial and axial magnets for linear alternator - Free piston engine system," in North American Power Symposium (NAPS), Morgantown, WV, USA, 2017.

[15] R. Mikalsen and A. Roskilly, "A review of free-piston engine history and applications," Applied Thermal Engineering, vol. 27, no. 14-15, pp. 2339-2352, 2007.

[16] M. R. Hanipah, R. Mikalsen and A. P. Roskilly, "Recent commercial free-piston engine developments for automotive applications," Sir Joseph Swan Centre for Energy Research, Newcastle University, Newcastle upon Tyne, NE1 7RU, United Kingdom, 2015.

[17] H. Feng, C. Guo, C. Yuan, Y. Guo, Z. Zuo, A. P. Roskilly and B. Jia, "Research on combustion process of a free piston diesel linear generator," Applied Energy, vol. 161, pp. 395-403, 2016.

[18] E. Cheever, "Analogous Electrical and Mechanical Systems," Swarthmore College, 2015. [Online]. Available: http://lpsa.swarthmore.edu/Analogs/ElectricalMechanicalAnalogs.html. [Accessed 26 June 2018].

[19] D. Dorran, "Using Matlab's fft function," Youtube.com, 14 June 2012. [Online]. Available: https://www.youtube.com/watch?v=dM1y6ZfQkDU.

[20] D. Dorran, "Using matlabs fft function 2 - zero padding and windowing," Youtube.com, 3 April 2013. [Online]. Available: https://www.youtube.com/watch?v=V_dxWuWw8yM\&t=1233s.

[21] P. Krause, O. Wasynczuk, S. Sudhoff and S. Pekarek, Analysis of Electric Machinery and Drive Systems, Hoboken, NJ: John Wiley \& Sons, 2013. 


\section{$8 \quad$ Appendix}

\subsection{MATLAB Air Core Alpha Data Analysis Code}

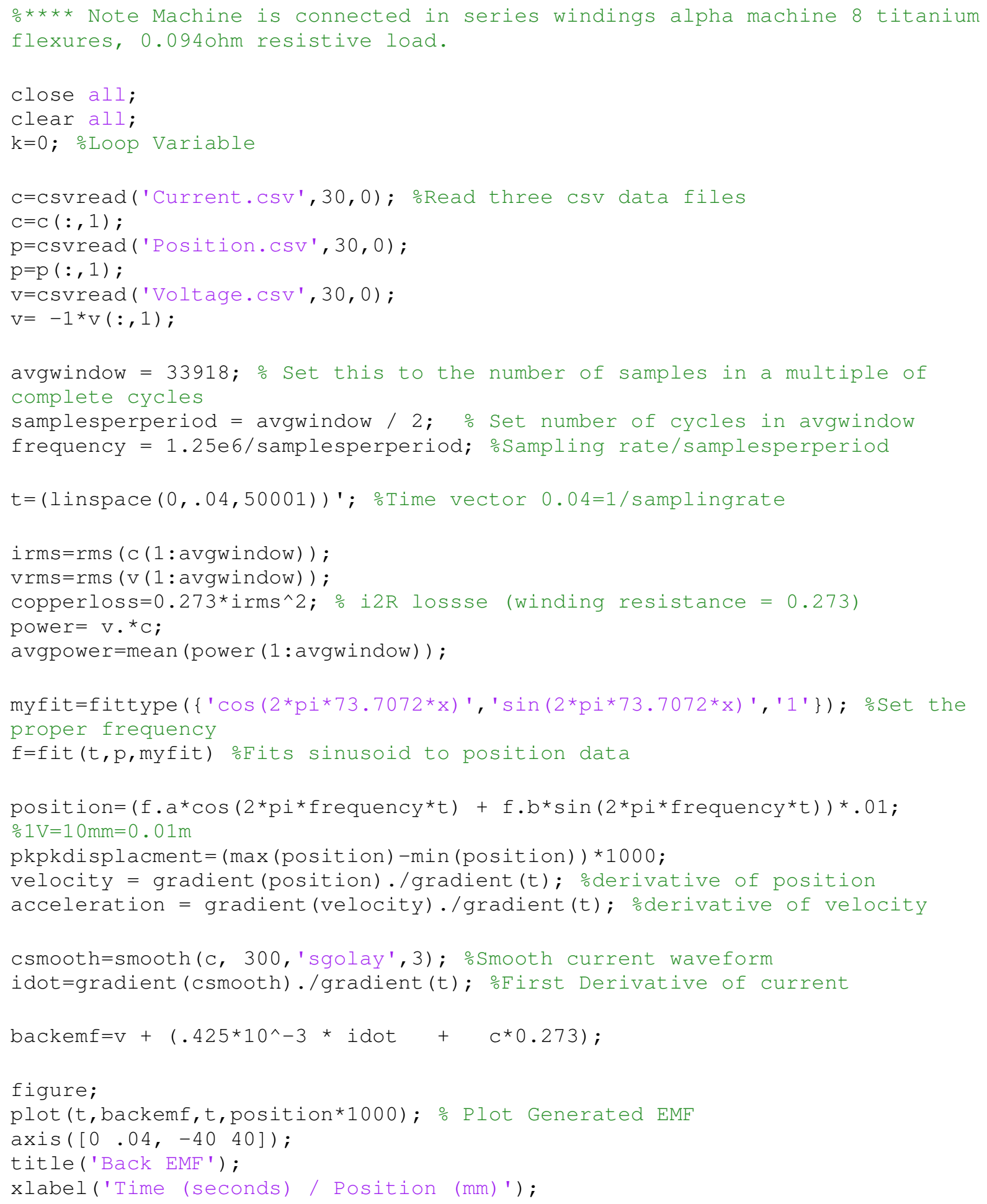




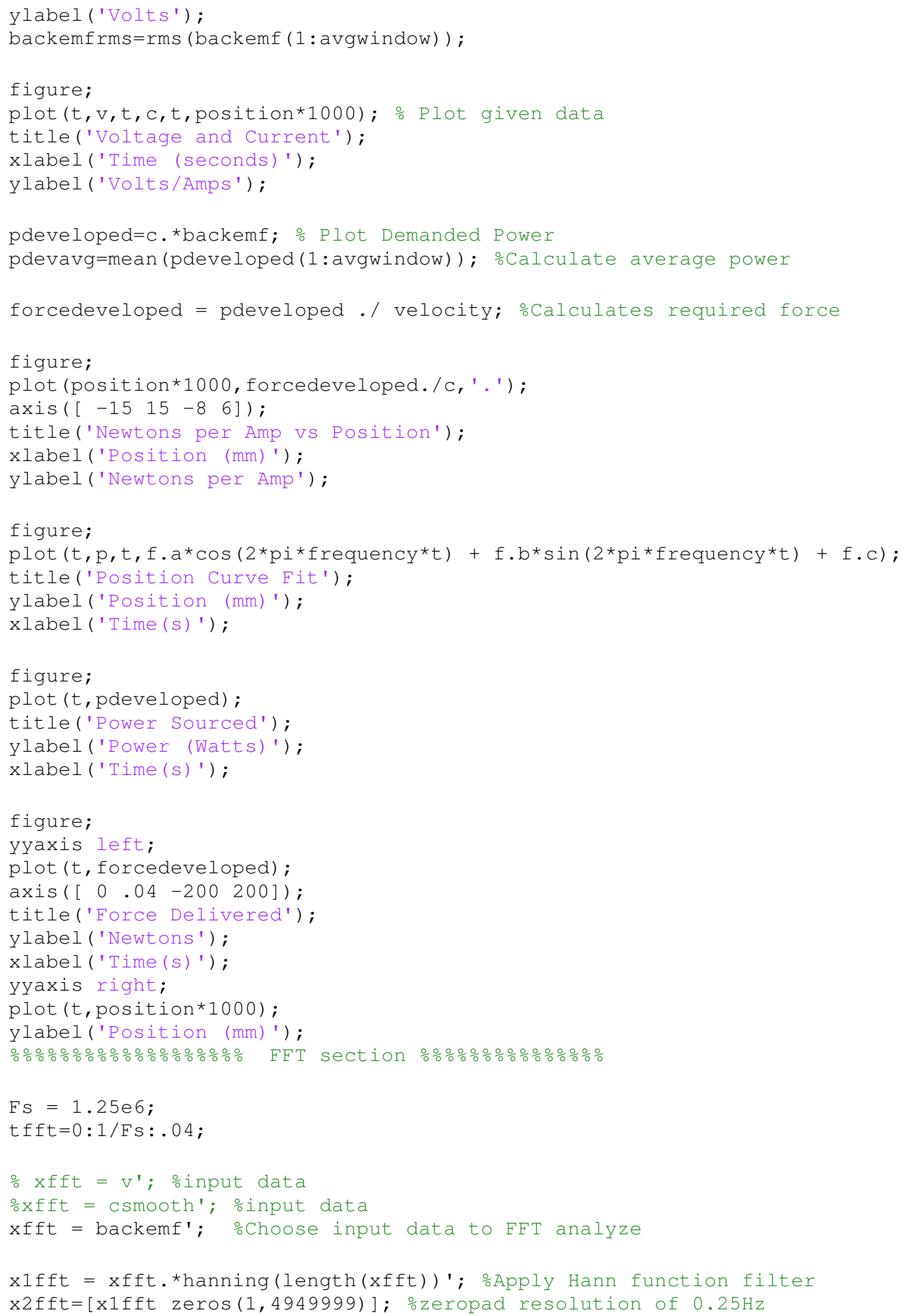




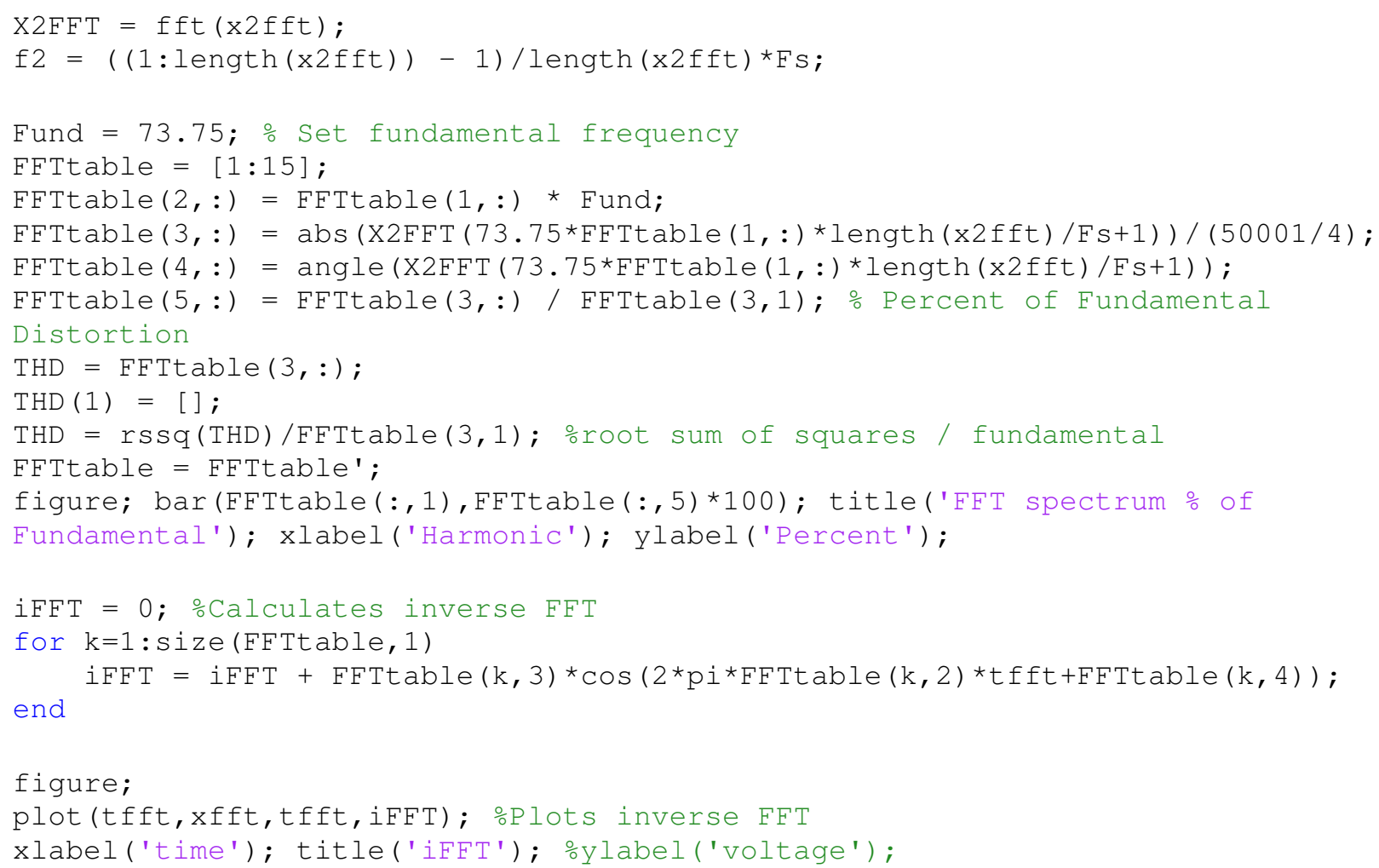




\subsection{LUA Script for FEMM (Alpha Air Core $\pm 15 \mathrm{~mm}$ movement)}

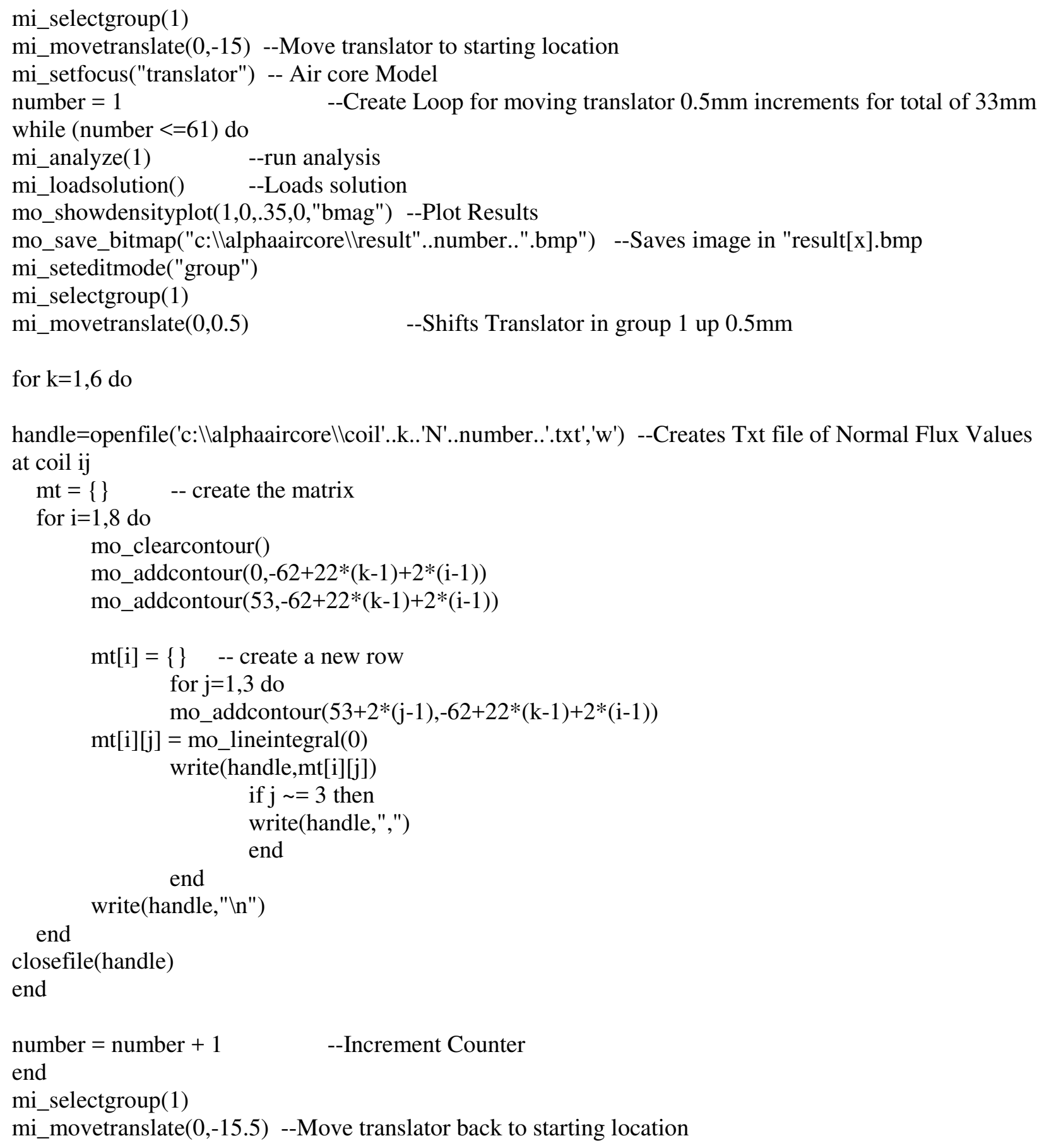




\subsection{MATLAB analysis of FEMM Data code}

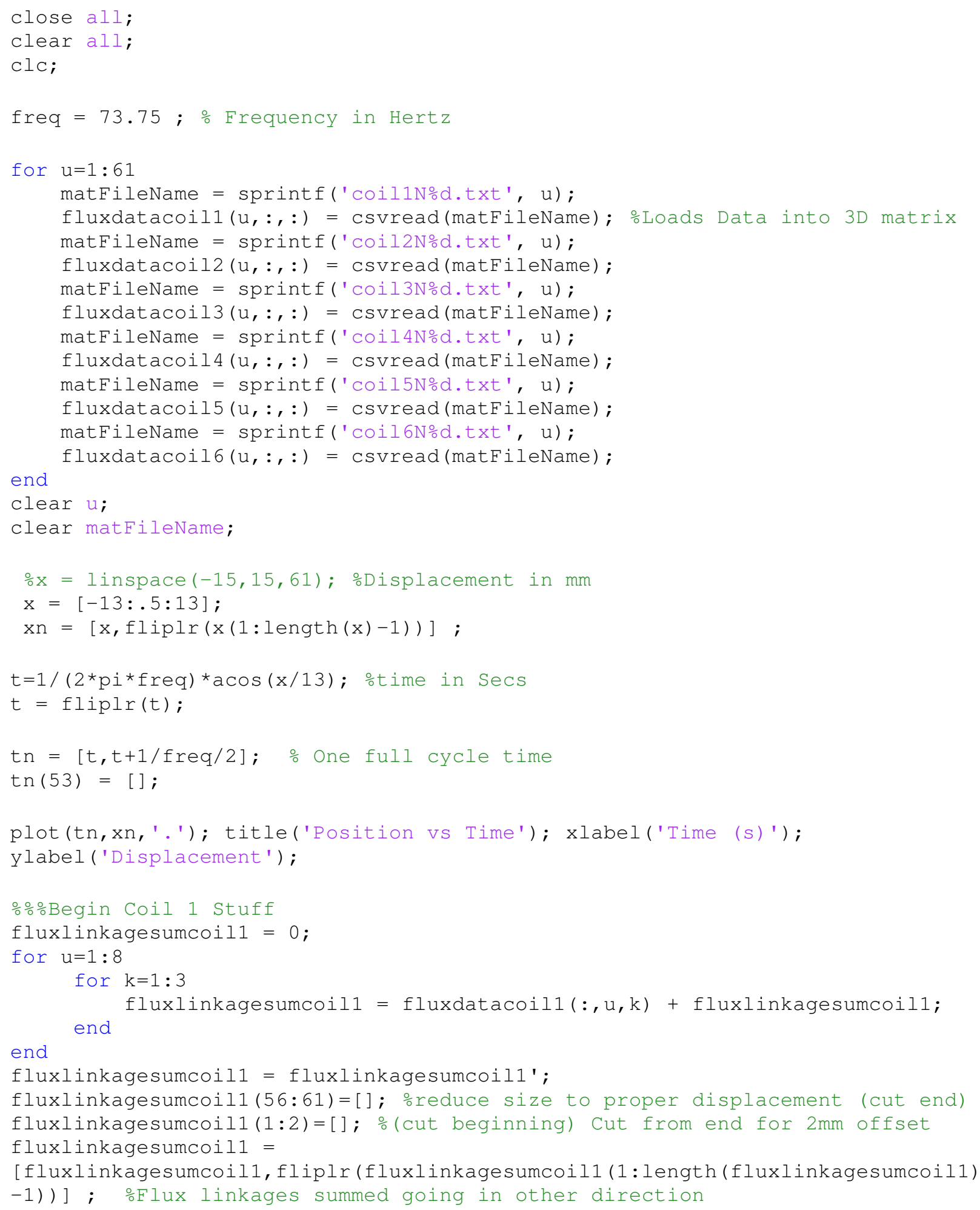




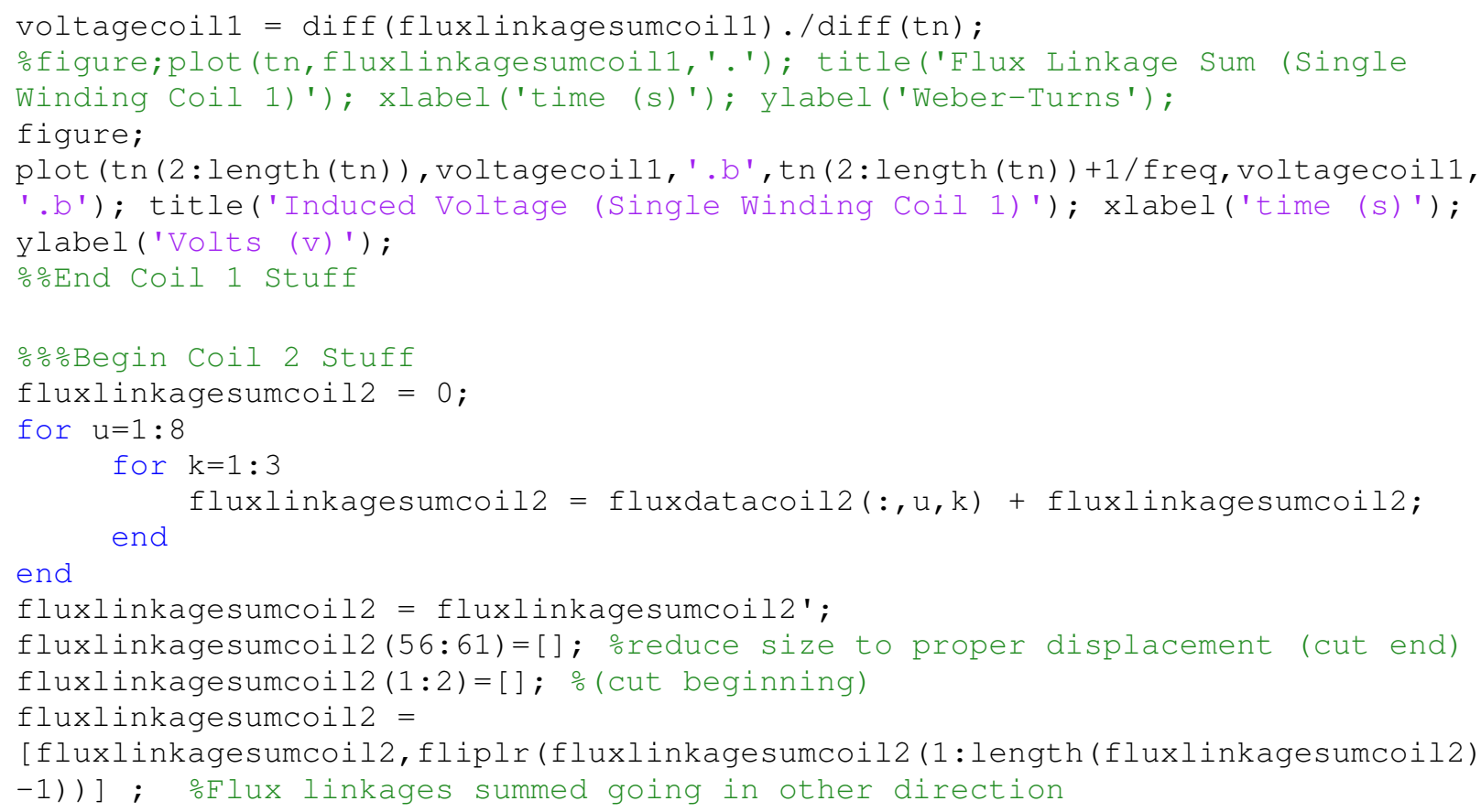




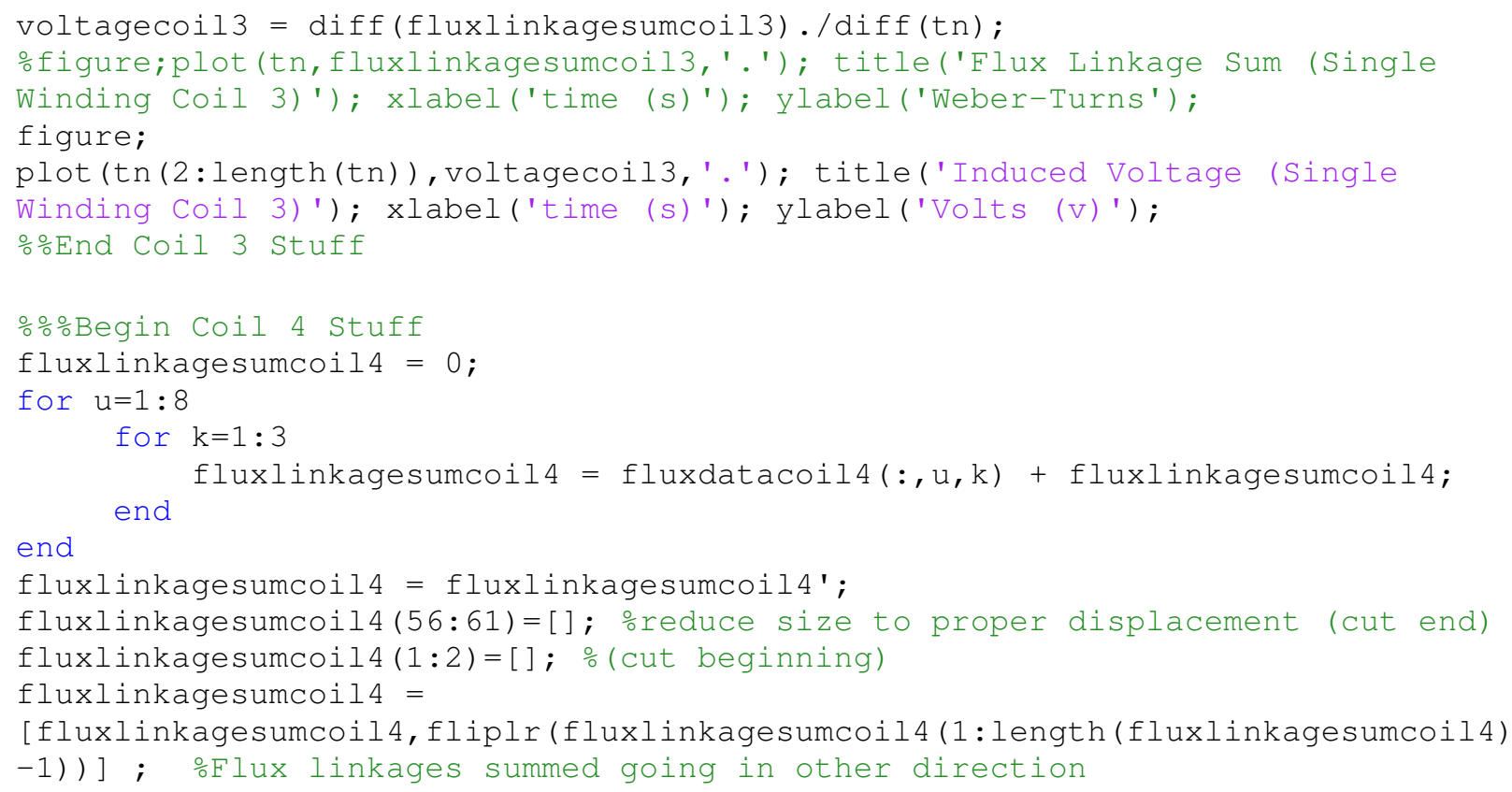

voltagecoil5 = diff(fluxlinkagesumcoil5)./diff(tn); ofigure;plot(tn, fluxlinkagesumcoil5,'.'); title('Flux Linkage Sum (Single Winding Coil 5)'); xlabel ('time (s)'); ylabel('Weber-Turns'); figure; 
plot (tn (2:length(tn)), voltagecoil5,'.'); title('Induced Voltage (Single Winding Coil 5)'); xlabel('time (s)'); ylabel('Volts (v)');

응nd Coil 5 Stuff

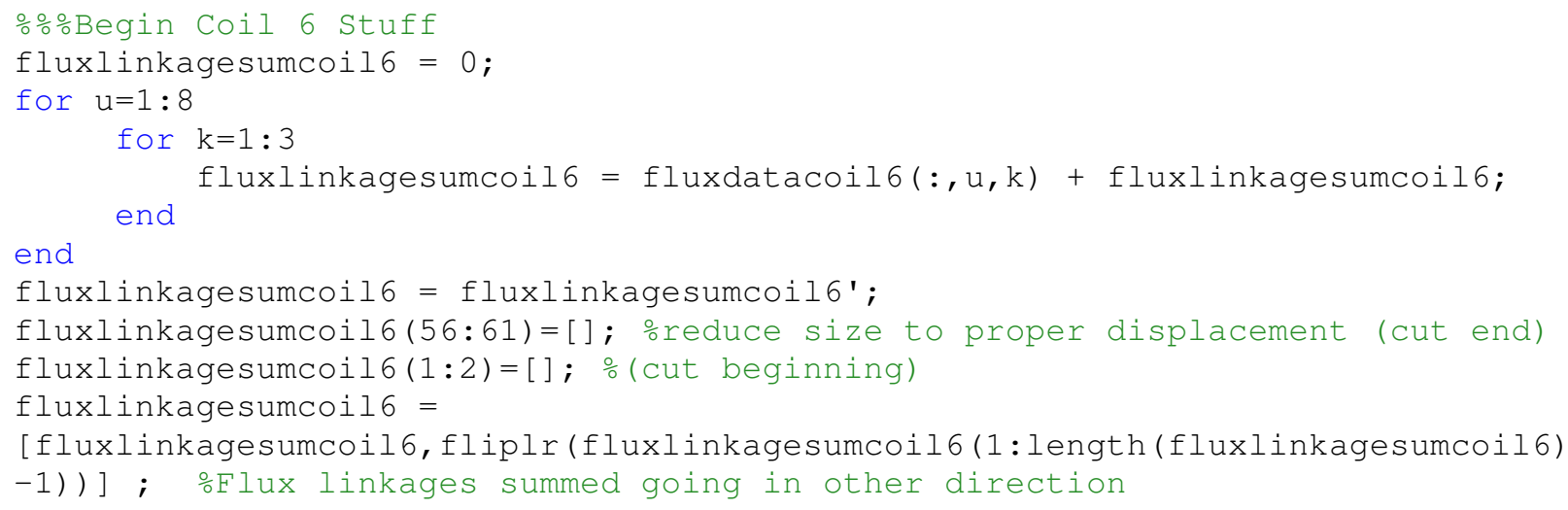




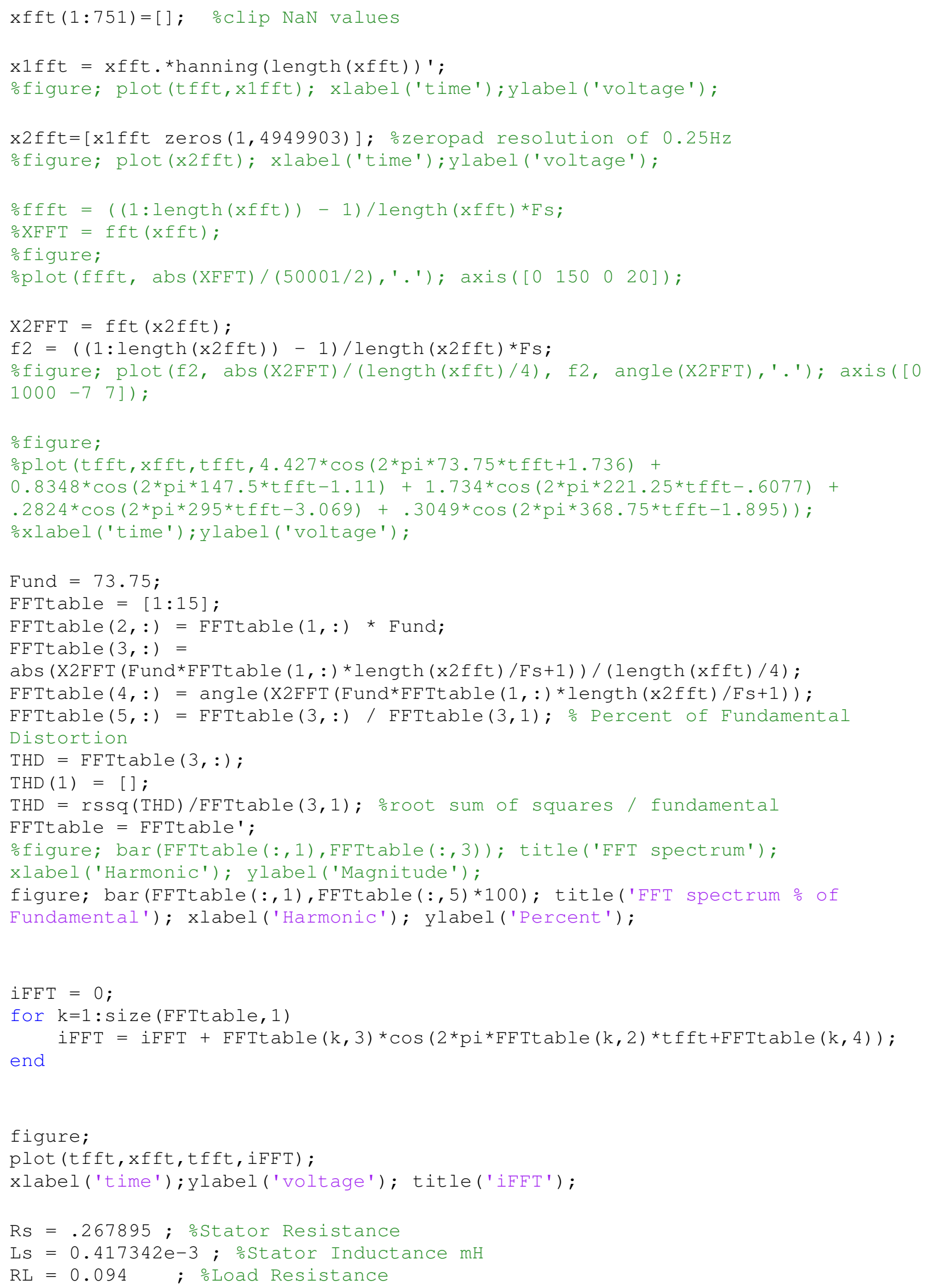




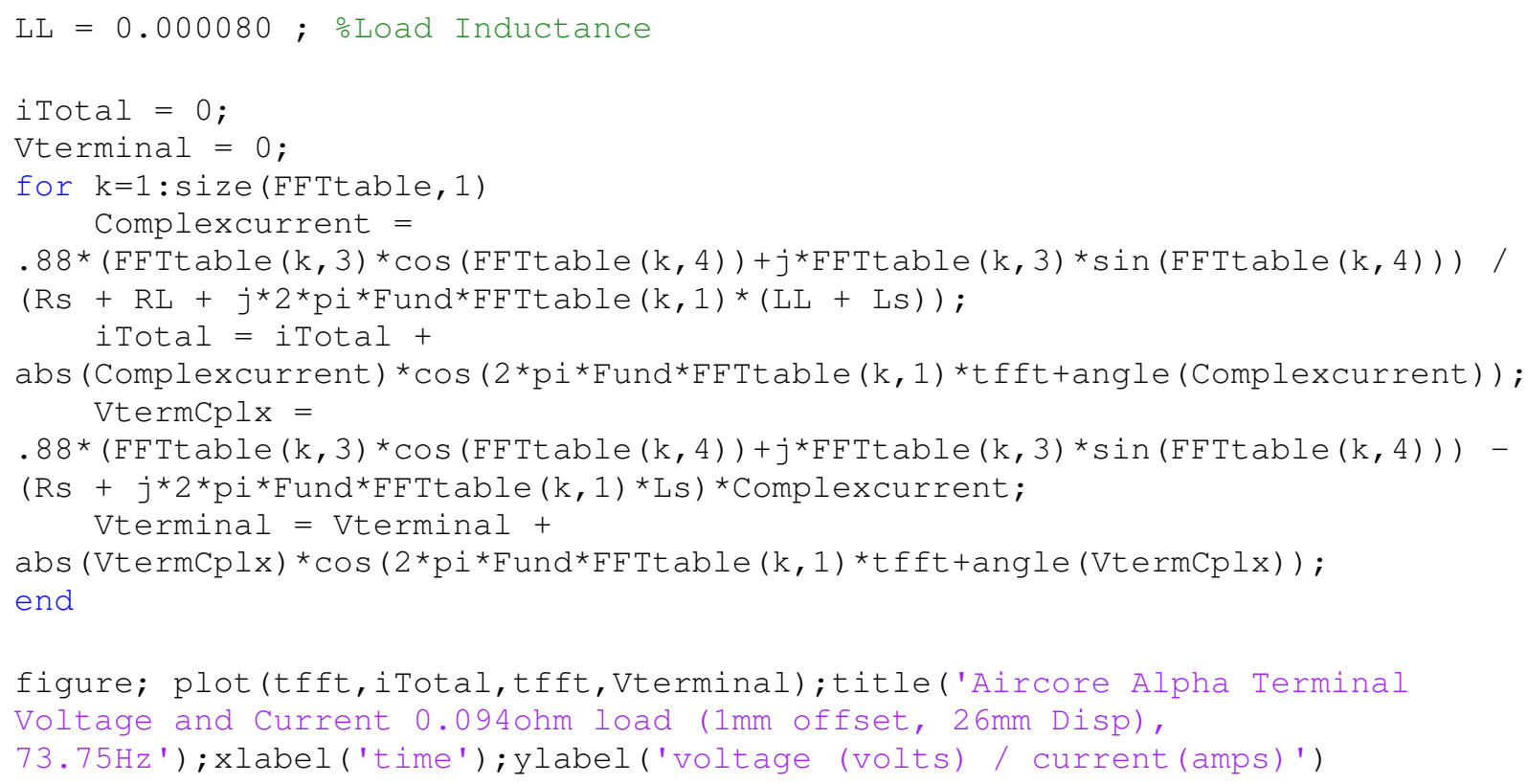

\subsection{MATLAB Code for Iron Core Beta Analysis}

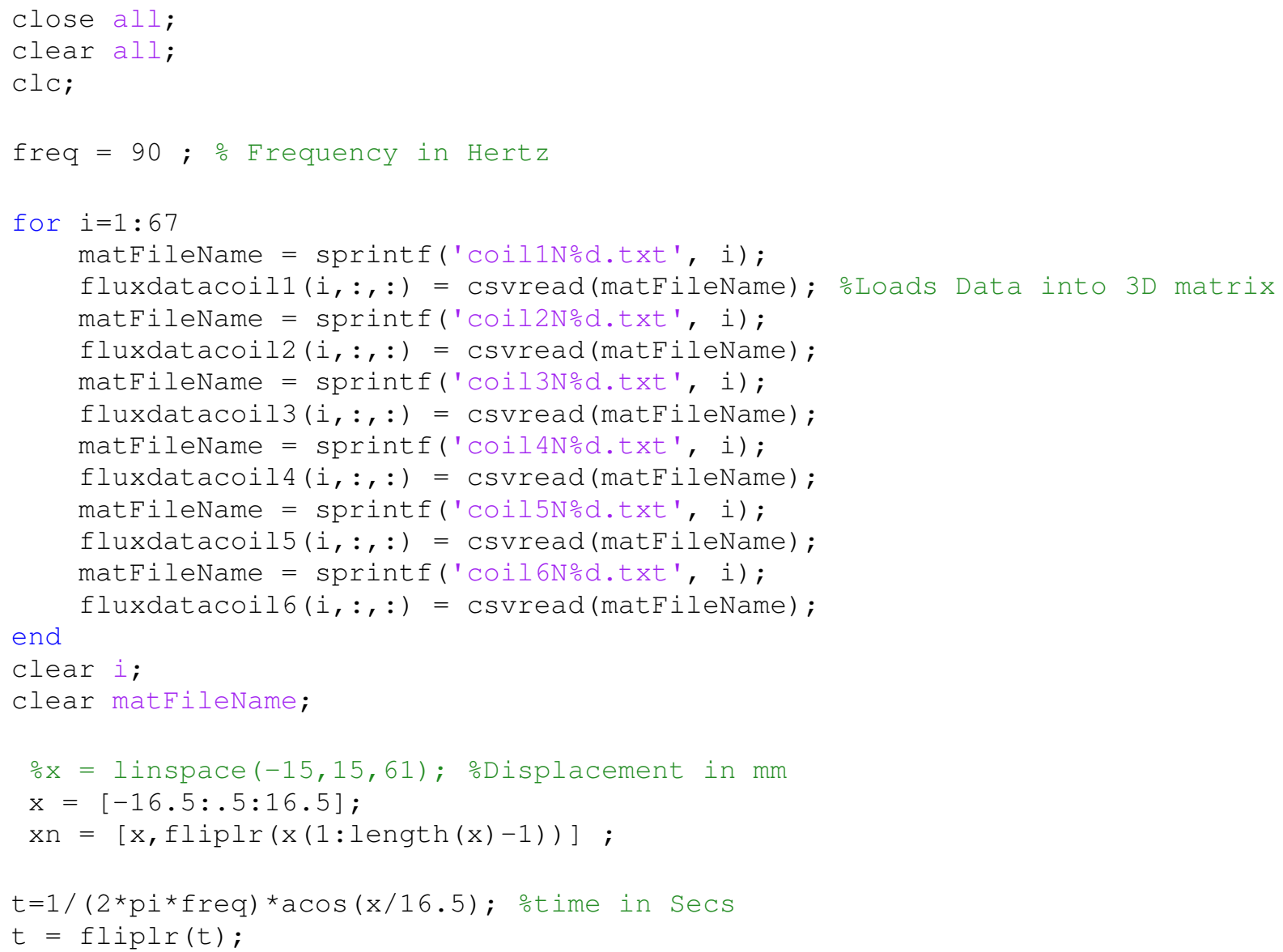




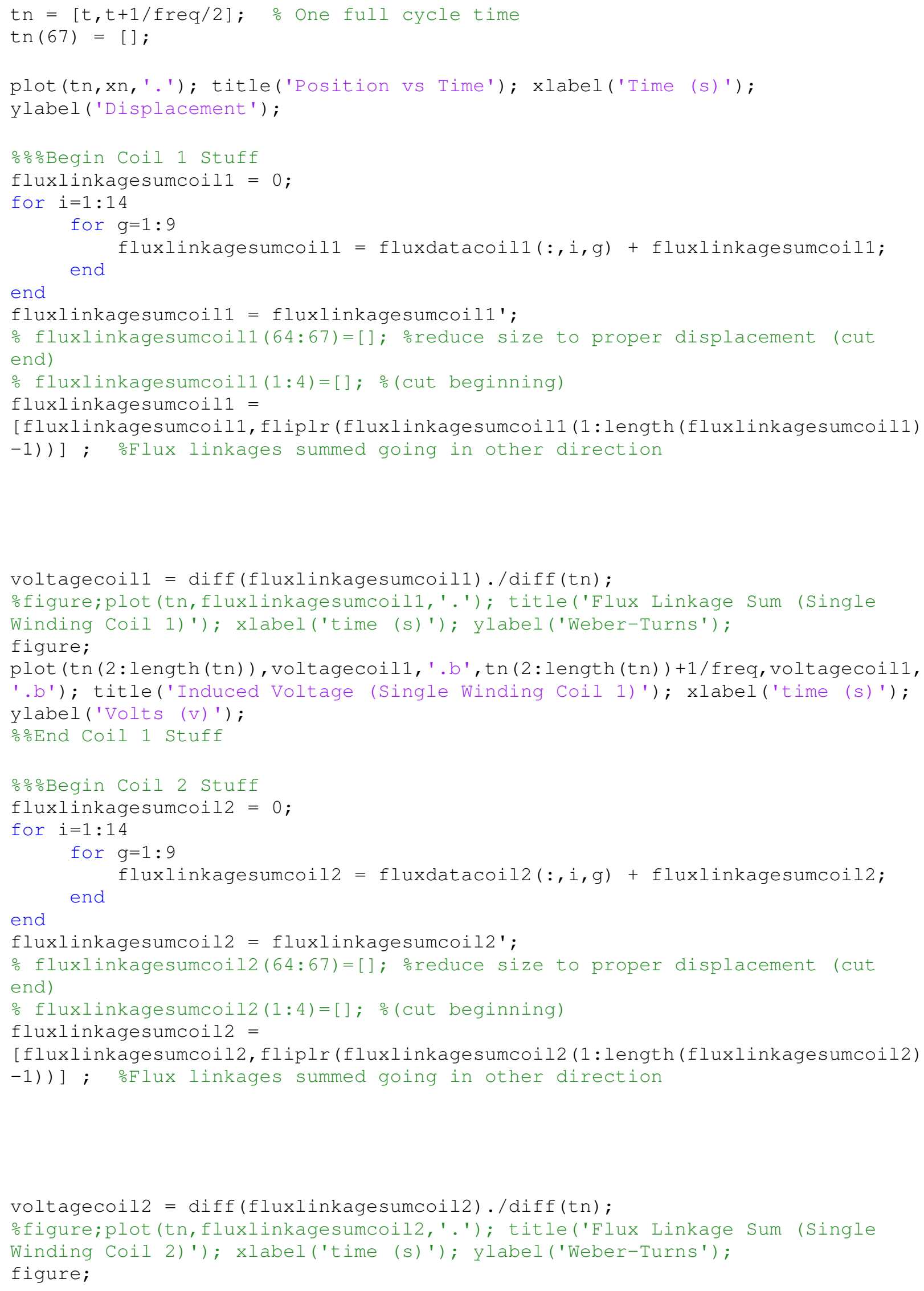


plot (tn (2: length (tn)), voltagecoil2, '.b', tn (2: length (tn)) +1/freq, voltagecoil2, '.b'); title('Induced Voltage (Single Winding Coil 2)'); xlabel('time (s)'); ylabel ('Volts (v)');

으을 Coil 2 Stuff

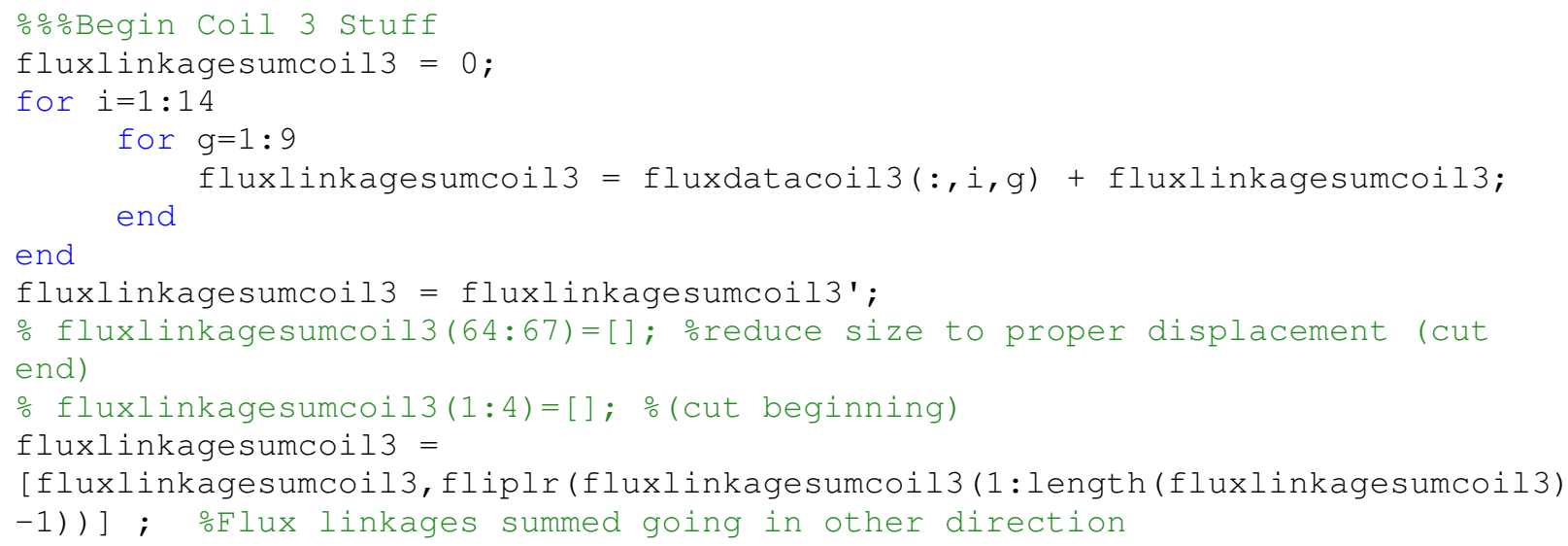


plot (tn (2:length(tn)), voltagecoil4,'.'); title('Induced Voltage (Single Winding Coil 4)'); xlabel('time (s)'); ylabel('Volts (v)');

응nd Coil 4 Stuff

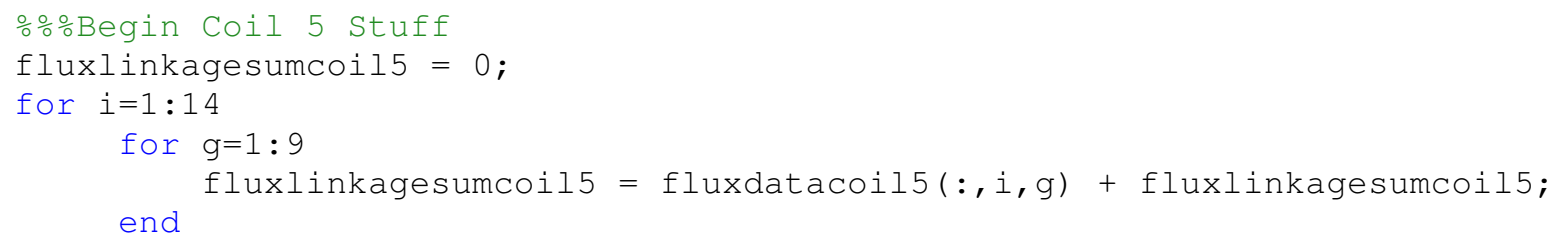




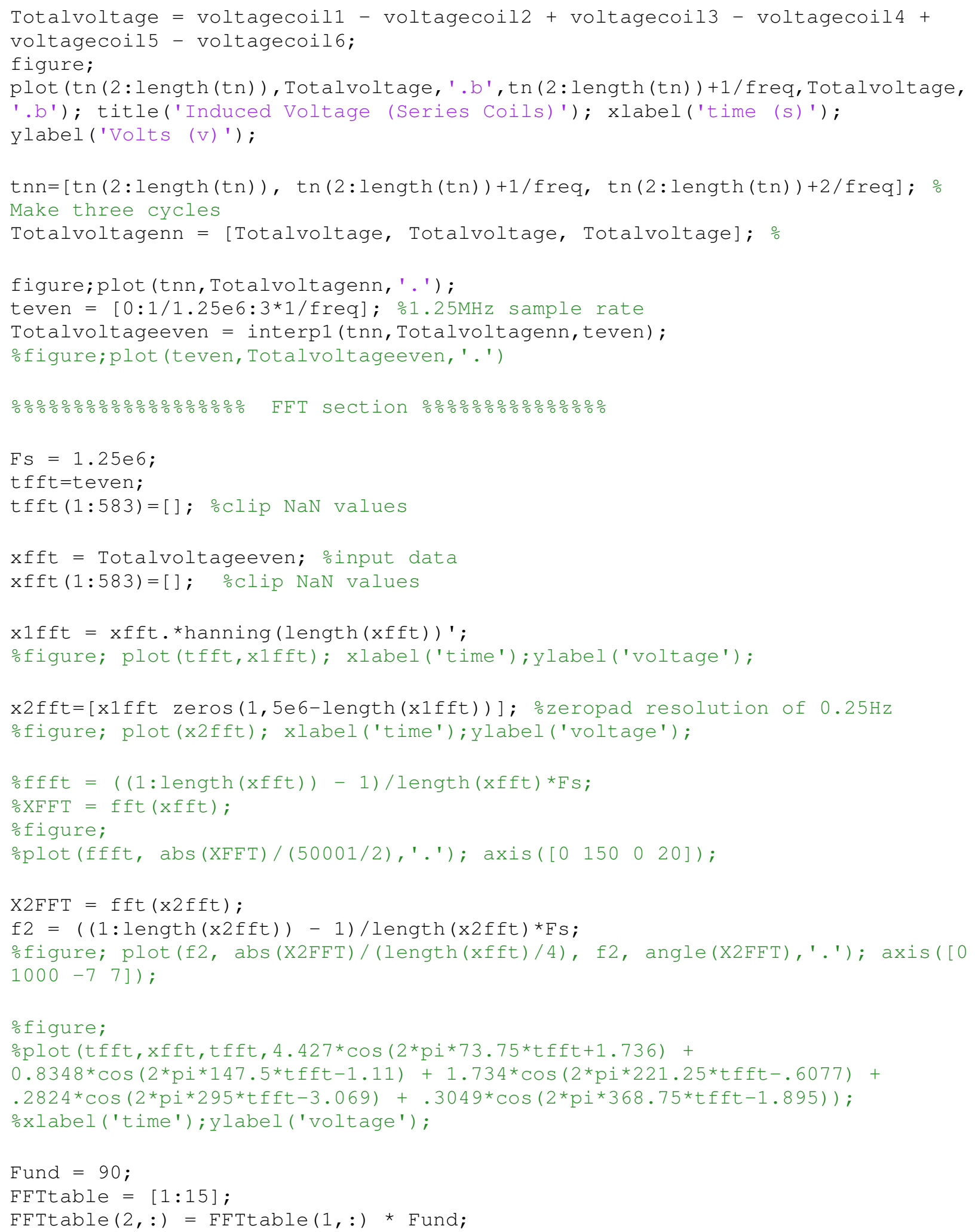




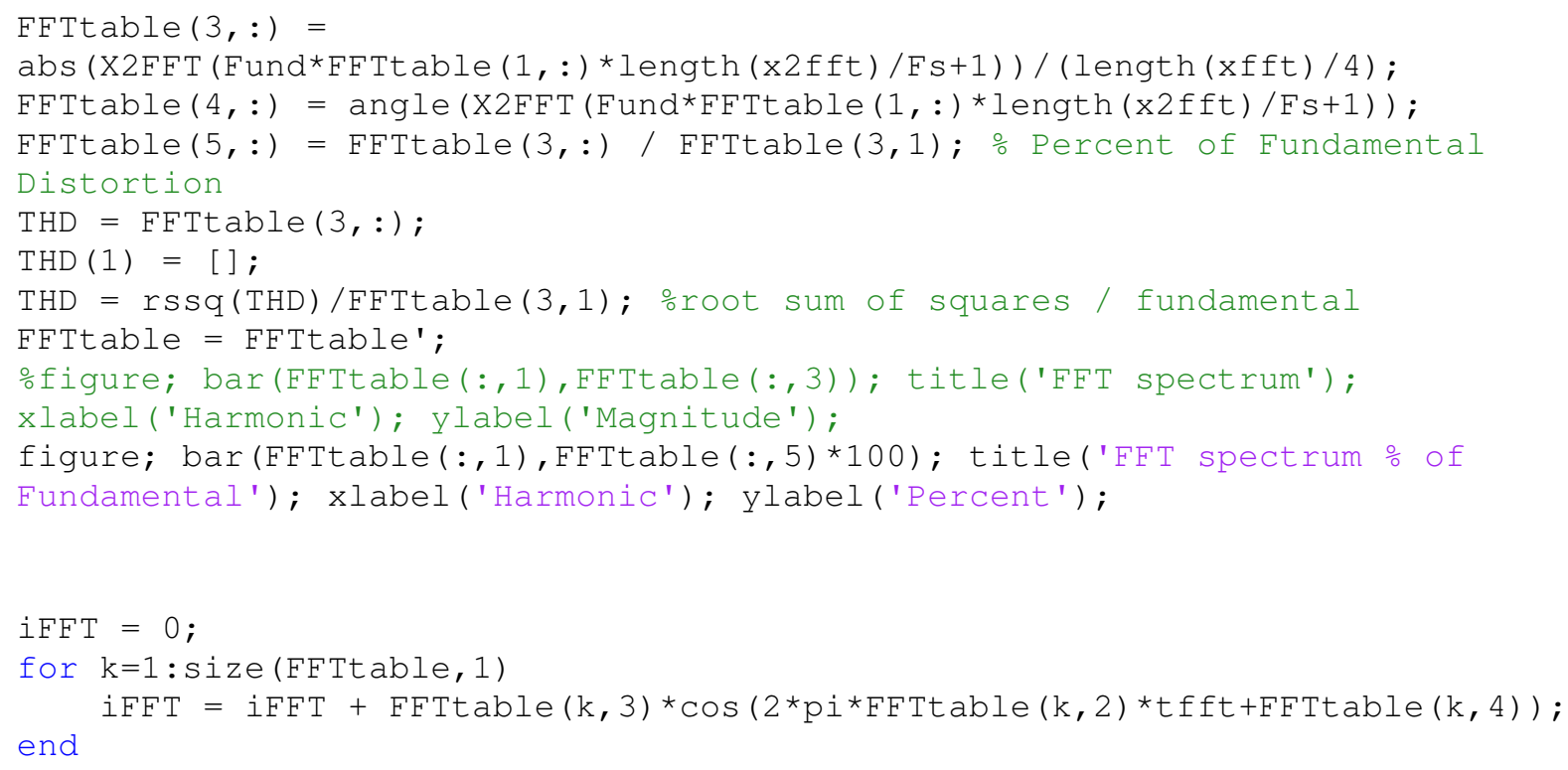


ofigure; plot(tfft,iTotal,tfft,Vterminal); title('Ironcore Alpha Terminal

Voltage and Current $13.30 \mathrm{hm}$ load (Omm offset, $29 \mathrm{~mm}$ Disp,

$90 \mathrm{~Hz}$ )') ; xlabel('time') iylabel('voltage (volts) / current(amps)')

Pload $(g)=\operatorname{mean}\left(\operatorname{Vterminal}(1: \operatorname{round}(\mathrm{Fs} / 90)) \cdot{ }^{*}\right.$ iTotal $\left.(1: \operatorname{round}(\mathrm{Fs} / 90))\right) ;$ oPower to Load

\%rms (iTotal (1:round (Fs/90)) )^2*Rs \% Power Loss

efficiency $(g)=\operatorname{mean}($ Vterminal $(1: \operatorname{round}(\mathrm{Fs} / 90)) \cdot * i \operatorname{Total}(1: \operatorname{round}(\mathrm{Fs} / 90)))$ /

(mean (Vterminal (1:round (Fs/90)).*iTotal (1:round (Fs/90))) +

rms (iTotal (1:round (Fs/90)))^2*Rs);

end

figure; yyaxis left;plot([1:4000]/100,Pload, 'LineWidth',3);ylabel ('Power Load (Watts)','Fontsize', 12) ; yyaxis right;

plot ([1:4000]/100, efficiency, 'LineWidth',3);ylabel ('Efficiency', 'FontSize', 12

) ; xlabel ('Load Resistance', 'FontSize',12); title('Load Power and

Efficiency', 'FontSize', 14);

\subsection{MATLAB Code for Vibration Analysis}

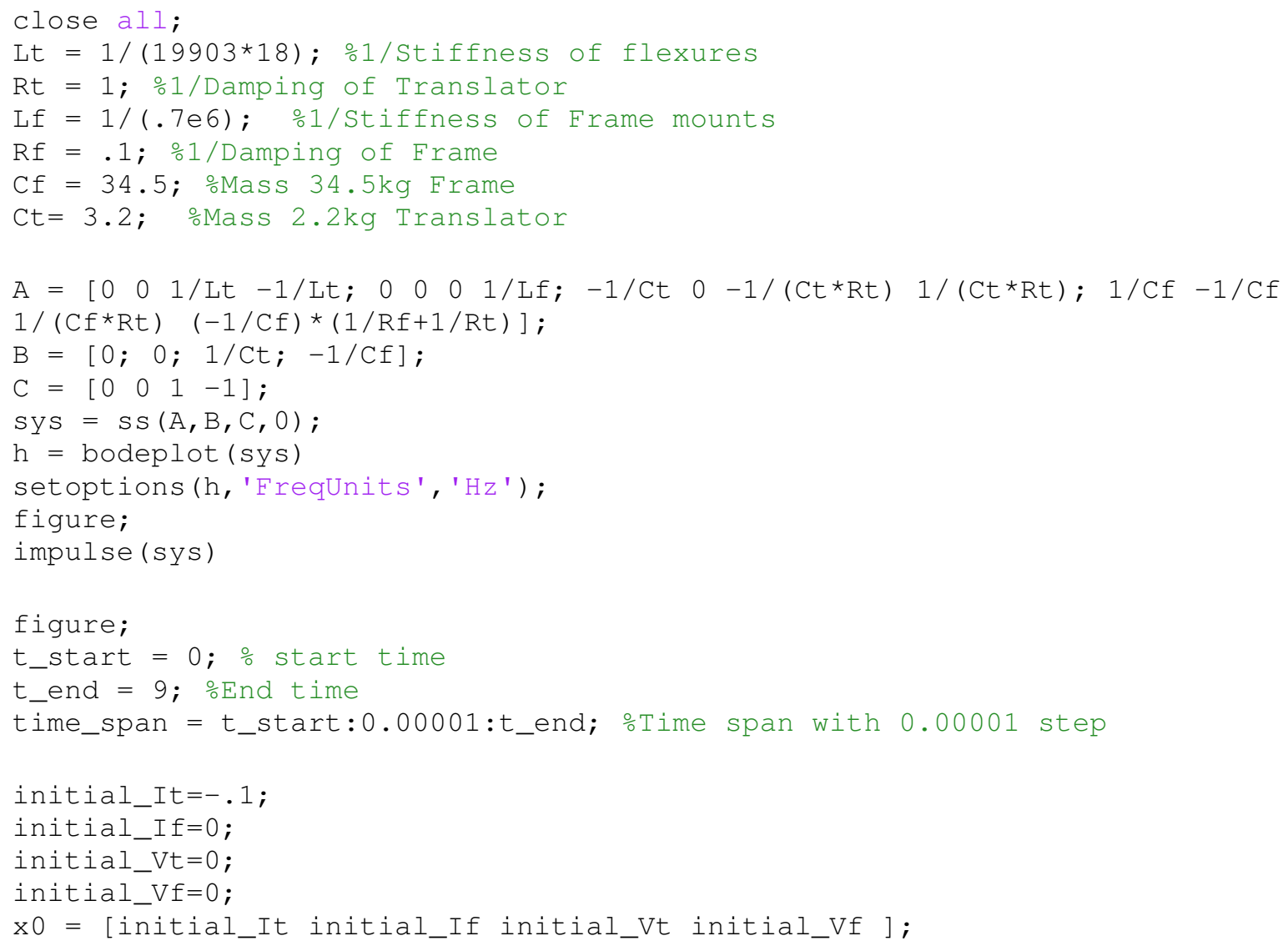




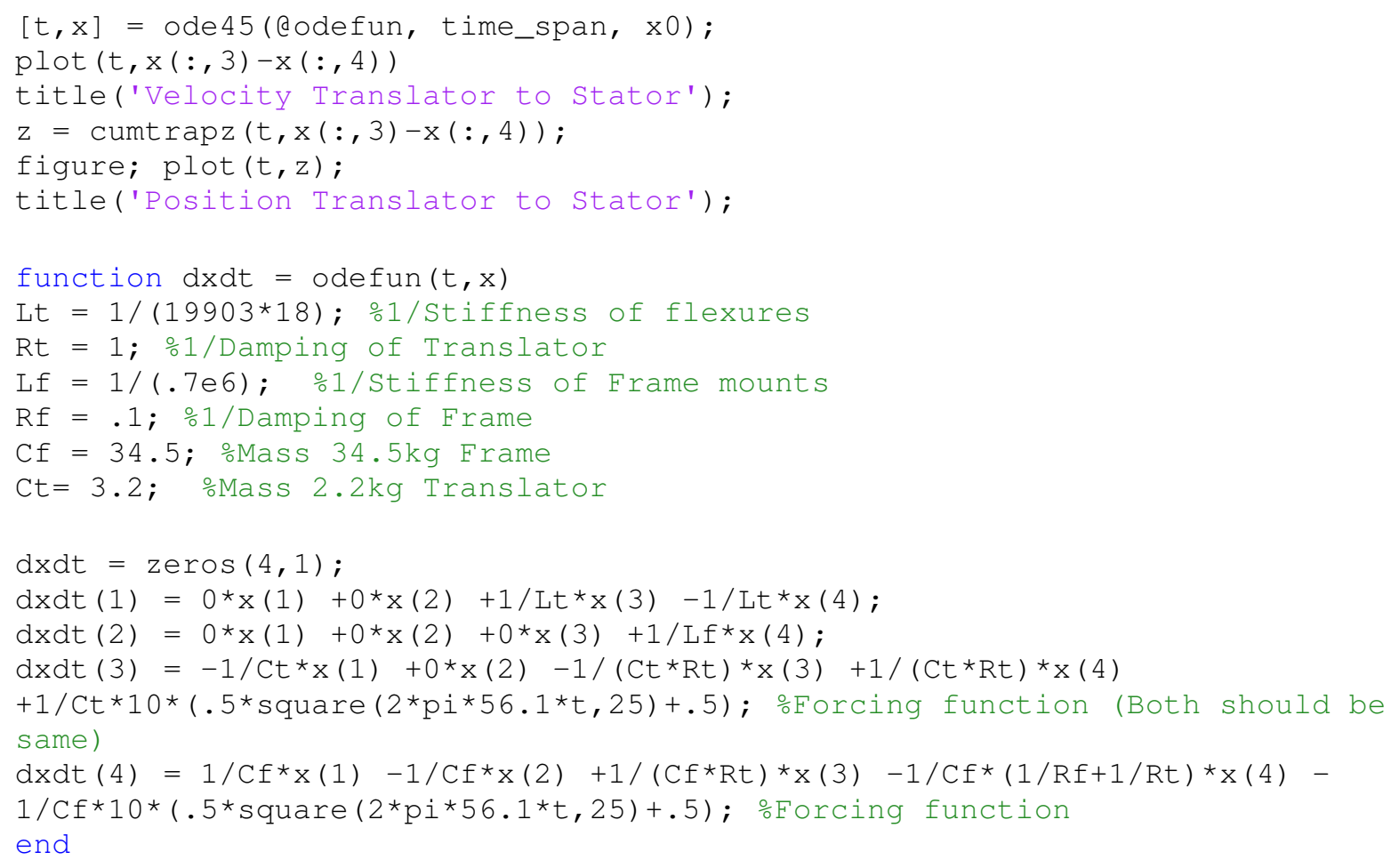

